\title{
Pattern of Nitrergic Neuronal System Organization in the Brain of Two Holostean Fishes (Actinopterygii: Ginglymodi)
}

\author{
Jesús M. López Daniel Lozano Lorena Morales Agustín González \\ Departamento de Biología Celular, Facultad de Biología, Universidad Complutense, Madrid, Spain
}

\section{Keywords}

Neuronal nitric oxide synthase - NADPH diaphorase .

Immunohistochemistry · Spotted gar · Florida gar .

Lepisosteidae $\cdot$ Brain evolution

\begin{abstract}
The study of the nitrergic system, formed by the networks of neurons containing the enzyme nitric oxide synthase (NOS), has been extremely useful in unraveling neuroanatomical features of the organization of the central nervous system of vertebrates. Thus, data are available for representatives of most vertebrate classes and, in particular, several studies have detailed the organization of this system in teleosts. In contrast, no information is available regarding this neurotransmission system in the brains of holosteans, an early diverged and poorly understood group of actinopterygian fishes, currently considered a sister group of teleosts that contains only 8 species. The present study provides the first detailed information on the distribution of nitrergic cell bodies and fibers in 2 holostean species of the genus Lepisosteus, the spotted gar L. oculatus and the Florida gar L. platyrhincus. NOS immunohistochemistry and the NADPH diaphorase (NADPH-d) histochemical reaction were used, and both
\end{abstract}

techniques yielded identical results, with the exception of the primary olfactory and terminal nerve fibers, which only labeled for NADPH-d exclusively in L. oculatus. Double immunohistochemistry was conducted for the simultaneous detection of NOS with tyrosine hydroxylase, choline acetyltransferase, calbindin, calretinin, and serotonin to accurately establish the localization of the nitrergic neurons and fibers in the brain of holosteans, the neuroanatomy of which has been mostly neglected, and to assess possible interactions between these neuroactive substances. Distinct groups of nitrergic cells were located in subpallial areas, the basal hypothalamus, posterior tubercle, optic tectum and mesencephalic tegmentum, reticular formation, solitary tract nucleus, spinal cord, and amacrine cells in the retina. In addition, low numbers of nitrergic cells were observed in the pallium, suprachiasmatic nucleus, prethalamic and thalamic areas, torus lateralis and torus semicircularis, cerebellar and laterodorsal tegmental nuclei, and the ventral octavolateral area. Comparison of these results with those from other classes of vertebrates, and including a segmental analysis to correlate cell populations, reveals that the pattern of the nitrergic system in holosteans is very close to that in ancestral actinopterygian fishes and highlights conserved and derived traits.

\section{KARGER}

(c) 2017 S. Karger AG, Basel

E-Mail karger@karger.com

www.karger.com/bbe
Dr. Agustín González

Departamento de Biología Celular

Facultad de Biología, Universidad Complutense

ES-28040 Madrid (Spain)

E-Mail agustin@bio.ucm.es 


\begin{tabular}{|c|c|c|c|}
\hline \multicolumn{4}{|c|}{ List of abbreviations } \\
\hline ac & anterior commissure & $\mathrm{p} 1-\mathrm{p} 3$ & prosomeres $1-3$ \\
\hline $\mathrm{aCb}$ & cerebellar auricle & POA & preoptic area \\
\hline $\mathrm{Cb}$ & cerebellum & PT & pretectum \\
\hline $\mathrm{cc}$ & central canal & PTh & prethalamus \\
\hline $\mathrm{cCb}$ & crista cerebellaris & $\mathrm{r}$ & rostral \\
\hline $\mathrm{Cg}$ & rhombencephalic central gray & $\mathrm{r} 0-\mathrm{r} 8$ & rhombomeres $0-8$ \\
\hline $\mathrm{Cn}$ & central nucleus of the inferior hypothalamic lobes & Rai & inferior raphe nucleus \\
\hline d & dorsal & Ram & median raphe nucleus \\
\hline Dd & dorsal zone of the dorsal telencephalic area & Ras & superior raphe nucleus \\
\hline DF & dorsal funiculus & $\mathrm{rHb}$ & right habenula \\
\hline $\mathrm{dh}$ & dorsal horn of the spinal cord & Rhom & rhombencephalon \\
\hline $\mathrm{Dl}$ & lateral zone of the dorsal telencephalic area & $\mathrm{Ri}$ & inferior reticular nucleus \\
\hline Dld & dorsolateral zone of the dorsal telencephalic area & RM & retromammillary hypothalamic area \\
\hline Dlv & ventrolateral zone of the dorsal telencephalic area & $\mathrm{Rm}$ & middle reticular nucleus \\
\hline $\mathrm{Dm}$ & medial zone of the dorsal telencephalic area & Rs & superior reticular nucleus \\
\hline Dn & diffuse nucleus of the inferior hypothalamic lobes & $\mathrm{sac}$ & stratum album centrale of the mesencephalic tectum \\
\hline $\mathrm{Dp}$ & posterior zone of the dorsal telencephalic area & SC & suprachiasmatic nucleus \\
\hline $\mathrm{fb}$ & forebrain bundle & sco & subcommissural organ \\
\hline flm & fasciculus longitudinalis medialis & sfgs & stratum fibrosum et griseum superficiale of the mesencephalic \\
\hline fr & fasciculus retroflexus & & tectum \\
\hline GCL & ganglion cell layer of the retina & $\operatorname{sg}$ & granular layer of the cerebellum \\
\hline gl & glomerular layer of the olfactory bulb & $\mathrm{sm}$ & molecular layer of the cerebellum \\
\hline $\mathrm{Hb}$ & habenula & smn & somatomotor neurons of the spinal cord \\
\hline Hyp & hypophysis & so & stratum opticum of the mesencephalic tectum \\
\hline $\mathrm{ICL}$ & internal cellular layer of the olfactory bulb & sol & solitary tract \\
\hline INL & inner nuclear layer of the retina & son & spino-occipital motor nucleus \\
\hline Ip & interpeduncular nucleus & son-smn & spino-occipital motor nucleus-somatomotor neurons of the \\
\hline IPL & inner plexiform layer of the retina & & spinal cord \\
\hline Ipn & interpeduncular neuropil & $\mathrm{spc}$ & spinal cord \\
\hline Is & nucleus isthmi & spv & periventricular layer of the mesencephalic tectum \\
\hline $\mathrm{Lc}$ & locus coeruleus & Tegm & tegmentum \\
\hline LDT & laterodorsal tegmental nucleus & Tel & telencephalon \\
\hline LF & lateral funiculus & Th & thalamus \\
\hline $\mathrm{lHb}$ & left habenula & $\mathrm{Tl}$ & torus longitudinalis \\
\hline lih & inferior hypothalamic lobe & Tor & torus semicircularis \\
\hline Ln & nucleus of the lateral hypothalamic recess & Torl & torus lateralis \\
\hline L.o & Lepisosteus oculatus & $\mathrm{TP}$ & nucleus of the posterior tubercle \\
\hline L.p & Lepisosteus platyrhincus & $\mathrm{Tu}$ & tuberal hypothalamus \\
\hline $\operatorname{lr}$ & lateral hypothalamic recess & $\mathrm{v}$ & ventricle \\
\hline $\mathrm{MC}$ & Mauthner cell & $\mathrm{Vd}$ & dorsal part of the ventral telencephalic area \\
\hline $\mathrm{MCa}$ & Mauthner cell axon & $\mathrm{Vdc}$ & caudodorsal part of the ventral telencephalic area \\
\hline MTP & nucleus medianus of the posterior tubercle & $\mathrm{VF}$ & ventral funiculus \\
\hline $\mathrm{nCb}$ & cerebellar nucleus & vh & ventral horn of the spinal cord \\
\hline nso & spino-occipital nerve & $\mathrm{VL}$ & lateral part of the ventral telencephalic area \\
\hline Nsol & nucleus of the solitary tract & $\mathrm{Vm}$ & trigeminal motor nucleus \\
\hline nt & terminal nerve & $\mathrm{Vn}$ & 'nother nucleus of the ventral telencephalic area \\
\hline $\mathrm{nI}$ & olfactory nerve & $\mathrm{Vp}$ & posterior nucleus of the ventral telencephalic area \\
\hline nII & optic nerve & Vs & supracommissural part of the ventral telencephalic area \\
\hline nIII & oculomotor nerve & VTA & ventral tegmental area \\
\hline $\mathrm{nV}$ & trigeminal nerve & Vv & ventral part of the ventral telencephalic area \\
\hline nVIII & octaval nerve & III & oculomotor nucleus \\
\hline $\mathrm{nX}$ & vagal nerve & IV & trochlear nucleus \\
\hline $\mathrm{ob}$ & olfactory bulb & VI & abducens nucleus \\
\hline oc & optic chiasm & VIIm & facial motor nucleus \\
\hline ONL & outer nuclear layer of the retina & VIII-lla & anterior octavolateral area \\
\hline OPL & outer plexiform layer of the retina & VIII-lli & intermediate octavolateral area \\
\hline $\mathrm{OT}$ & optic tectum & VIIIv & ventral octavolateral area \\
\hline ot & optic tract & IXm & glossopharyngeal motor nucleus \\
\hline $\mathrm{Pa}$ & paraventricular hypothalamic area & $\mathrm{Xm}$ & vagal motor nucleus \\
\hline pc & posterior commissure & & \\
\hline
\end{tabular}




\section{Introduction}

Nitric oxide (NO) is a gaseous neurotransmitter and neuromodulator produced in the central nervous system (CNS) by the neuronal NO synthase (nNOS) after the oxidation of arginine into citrulline. Its main target is the soluble guanylate cyclase, which increases the intracellular levels of cyclic guanosine monophosphate. A second action of NO is the production of a posttranslational modification of proteins by S-nitrosylation of cysteine residues [Bredt and Snyder, 1992; Dawson et al., 1998; Jaffrey et al., 2001; Bartus et al., 2013; Dzoljic et al., 2015; Raju et al., 2015; Bradley and Steinert, 2016]. In addition to nNOS, 2 other isoforms of this enzyme have been identified (endothelial and inducible) [Alderton et al., 2001], and the molecular structure of these isoforms is highly conserved throughout evolution [González-Domenech and Muñoz-Chapuli, 2010; Andreakis et al., 2011]. The importance of the nitrergic system, formed by the networks of neurons containing nNOS, in the control of other "classical" neurotransmitter systems has been established. Thus, the NO-mediated signal can modulate glutamatergic [Garthwaite, 1991; Lawrence and Jarrott, 1993; Rudkouskaya et al., 2010; Neitz et al., 2011; Raju et al., 2015] and dopaminergic [Zhu and Luo, 1992; Bugnon et al., 1994; Chaparro-Huerta et al., 1997; Kiss et al., 2004] neurotransmission, via presynaptic regulation of neurotransmitter release and/or postsynaptic regulation of signal action. In addition, $\mathrm{NO}$ also acts on GABAergic synaptic transmission [Yang et al., 2007; Maggesissi et al., 2009; Tarasenko et al., 2014; Gasulla and Calvo, 2015; Yamamoto et al., 2015] by reducing the strength of inhibition, which allows the fine tuning of information processing [Yassin et al., 2014]. Therefore, NO plays a key role in synaptic plasticity, being involved in long-term potentiation and long-term depression, and in the regulation of the sleep-wake cycle. It is also related to processes of neuroprotection and neurodegeneration [Shibuki and Okada, 1991; Haley et al., 1992; Mizutani et al., 1993; McCann, 1997; Calabresi et al., 1999; Hars, 1999; Bon and Garthwaite, 2003; Stanton et al., 2003; Wang et al., 2005; Sultana et al., 2006; Mancuso et al., 2007; Sergeeva et al., 2007; Rudkouskaya et al., 2010; Hardingham et al., 2013; Rafalovich et al. 2015], as an excessive release of NO produces nitrosative stress and has a neurotoxic effect [Brown, 2010; Steinert et al., 2010; Nakamura et al., 2013; Bradley and Steinert, 2016].

The neuroanatomical organization of the nitrergic systems was first investigated by the NADPH diaphorase (NADPH-d) histochemical reaction, a quick and easy technique that generally labels the nitrergic structures [Bredt et al., 1991; Hope et al., 1991], although a more consistent labeling of this system is achieved by the immunodetection of nNOS with specific antibodies. Thus, the anatomy of the nitrergic system has been extensively studied by histochemical and immunohistochemical methods in the CNS of most groups of vertebrates [for references see Alonso et al., 2000; López et al., 2016]. In particular, several studies have described the organization of the nitrergic system in teleosts [Holmqvist et al., 1994, 2000; Arévalo et al., 1995; Brüning et al., 1995; Villani and Guarnieri, 1995; Anken and Rahmann, 1996; Bell et al., 1997; Virgili et al., 2001; Singru et al., 2003; Giráldez-Pérez et al., 2008, 2013] but little information is available for other actinopterygian groups [López et al., 2016].

Actinopterygians (ray-finned fishes) are among the most successful radiations in the long evolutionary history of vertebrates that contains more than 30,000 species, of which only 50 are not teleosts [Nelson et al., 2016]. The group commonly known as "gars" is formed by 7 extant species of nonteleost actinopterygian fishes belonging to the superorder Ginglymodi, which includes a single family (Lepisosteidae) and 2 genera: Atractosteus (with 3 living species) and Lepisosteus (with 4 living species). Gars and bowfins (superorder Halecomorphi with the single species Amia calva) are included in the "Holostei" (holosteans), which are restricted to the fresh waters of eastern North America [Nelson, 2006]. Although the phylogenetic relationships among actinopterygian fishes have been controversial, recent studies, in which multiple nuclear DNA-encoded genes and whole genome duplication events have been analyzed, showed that holosteans form a monophyletic group (Fig. 1a). This lineage diverged from the lineage leading to teleosts before the teleost-specific round of whole genome duplication occurred more than 320-350 million years ago [Hoegg et al., 2004; Kikugawa et al., 2004; Amores et al., 2011; Near et al., 2012; Pasquier et al., 2016]. Thus, holosteans and teleosts are currently grouped in the "Neopterygii" (neopterygians). These data are consistent with traditional morphologically based inferences [Stiassny et al., 2004] and previous neuroanatomical studies that observed peculiar features present only in the telencephalon and cerebellum of holosteans [Nieuwenhuys, 1967; Nieuwenhuys and Meek, 1990], and absent in other actinopterygian fishes [Nieuwenhuys, 2011]. In contrast to the extensive experimental data about the organization of the CNS of teleosts, there is little information concerning the brain of holosteans. In particular, there are limited hodological data related to the visual and the lateral line 

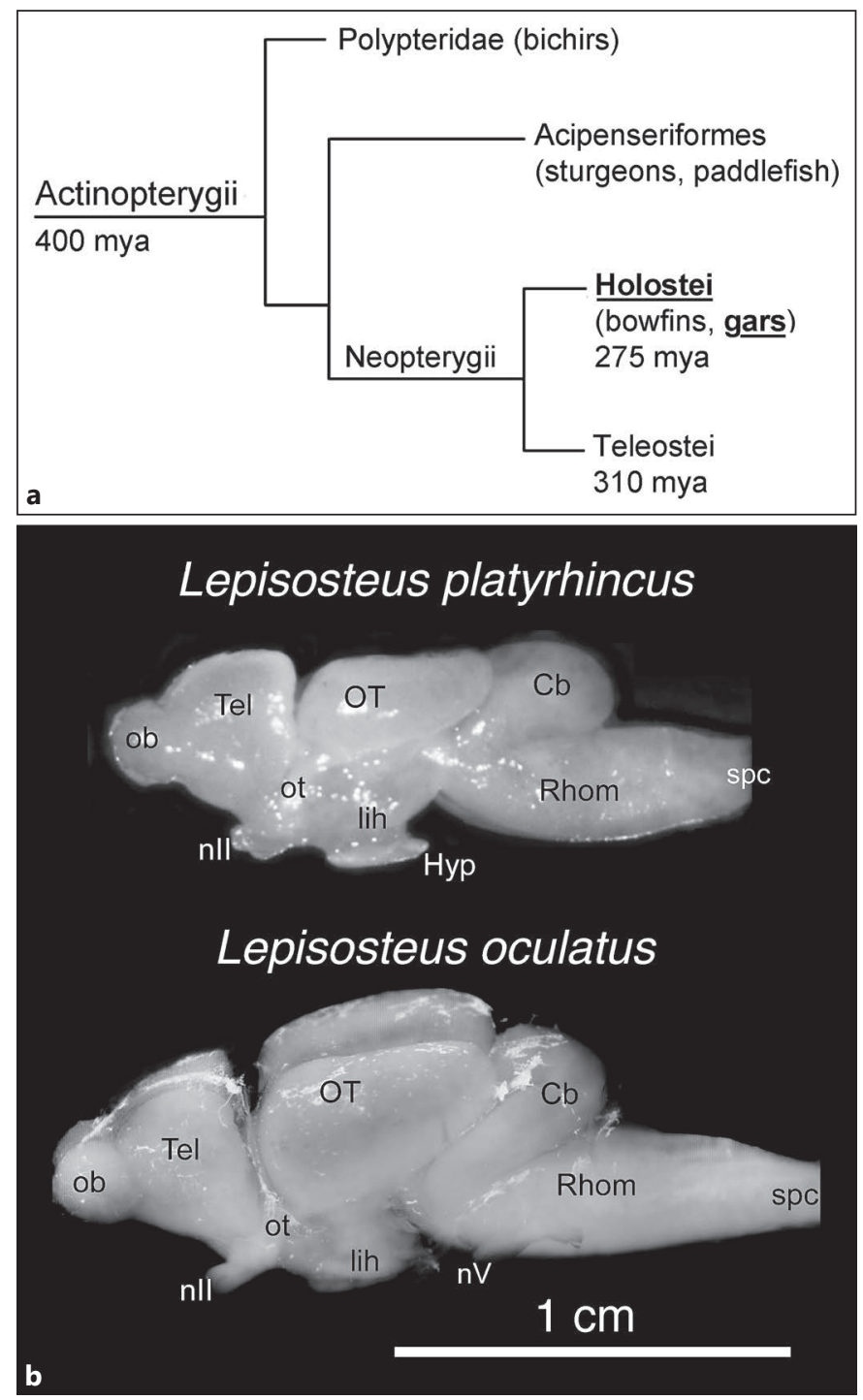

Fig. 1. a Cladogram illustrating Holostei as the sister group of Teleostei and the relationship to other actinopterygian fishes; approximate dates are from Near et al. [2012]. b Lateral view of the brains of the Florida gar (L. platyrhincus) and the spotted gar (L. oculatus) dissected after fixation so that the major divisions of its CNS can be observed. See list of abbreviations.

systems [Northcutt and Butler, 1976, 1980; Song and Northcutt, 1991; Collin and Northcutt, 1995], and several mapping studies of the distribution of monoamines [Parent and Northcutt, 1982; Chiba and Oka, 1999] and diverse neuropeptides [Malz et al., 1999; Baker and Bird, 2002; Chiba, 2005]. In addition, in a previous study we described in detail the organization of the brain cholinergic system [Morona et al., 2013].
Given the phylogenetic importance of holosteans as the sister group of teleosts, the aim of the present study was to provide a comprehensive description of the organization of the nitrergic system in 2 holostean species of the genus Lepisosteus, the spotted gar L. oculatus and the Florida gar L. platyrhincus. In a previous review article, some information based on the NADPH-d method was provided for the telencephalon [Braford, 2009]. We used nNOS immunolocalization and NADPH-d histochemistry to confirm the consistency of both approaches in the detection of this gaseous neurotransmission system, as in previous studies conducted by our group in different vertebrates [González et al., 1996,2002b; López and González, 2002; López et al., 2016]. This neuroanatomical information is a useful tool for distinguishing and defining classes of neurons and cell groups within the poorly investigated brain of gars. In addition, double-labeling experiments for NOS or NADPH-d and choline acetyltransferase (ChAT; the synthesis enzyme of acetylcholine), tyrosine hydroxylase ( $\mathrm{TH}$; the first and rate-limiting enzyme for catecholamine synthesis), serotonin (5-HT), and the calcium binding proteins calbindin $(\mathrm{CB})$ and calretinin $(\mathrm{CR})$, were conducted to locate more precisely the nitrergic cell populations and to evaluate some neurochemical features of the NOS immunoreactive (NOS-ir) neurons, given the previous descriptions of the localization of these neuroactive molecules in the brain of gars [Chiba and Oka, 1999; Morona et al., 2013; González et al., 2014]. The results are compared with those reported in other groups of fishes and tetrapods to establish conserved and specific features along their evolution, and therefore to increase the current knowledge of this neurotransmitter system. To facilitate these comparisons, the study was framed within the neuromeric model of the vertebrate brain, which serves to compare structures that are topologically homologous although their topography in the adult vertebrate brain may appear different [ $\mathrm{Pu}$ elles, 1995; Puelles and Rubenstein, 2003, 2015].

\section{Materials and Methods}

For the present study, a total of 9 spotted gars, L. oculatus, and 5 Florida gars, L. platyrhincus, were used. The animals, young adults $10-16 \mathrm{~cm}$ in length, were obtained from licensed suppliers (PezyCia, Madrid, Spain) and were maintained in aquaria with a controlled temperature $\left(24-28^{\circ} \mathrm{C}\right)$ and natural light conditions. The original research reported herein was performed according to the regulations and laws established by the European Union (2010/63/EU) and Spain (royal decree 53/2013) for the care and handling of animals in research and after approval from Complutense University to conduct the experiments described. 
The animals were deeply anesthetized by immersion in $0.1 \%$ tricaine methanesulfonate solution (MS222, Sandoz, Basel, Switzerland; $\mathrm{pH}$ 7.3) and perfused transcardially with physiological saline followed by $100-150 \mathrm{~mL}$ of cold $4 \%$ paraformaldehyde in a $0.1 \mathrm{M}$ phosphate buffer ( $\mathrm{PB} ; \mathrm{pH}$ 7.4). The brain, olfactory sacs, eyes, and spinal cord were removed and kept in the same fixative for $2-3 \mathrm{~h}$. Subsequently, they were immersed in a solution of $30 \%$ sucrose in PB for $4-6 \mathrm{~h}$ at $4{ }^{\circ} \mathrm{C}$ until they sank. They were then embedded in a solution of $20 \%$ gelatin with $30 \%$ sucrose in $\mathrm{PB}$, and stored for $6 \mathrm{~h}$ in a $10 \%$ formaldehyde solution at $4^{\circ} \mathrm{C}$. The brains and the rest of the biological material were cut on a freezing microtome at a thickness of $30-40 \mu \mathrm{m}$ in the transverse or sagittal plane, and sections were collected and rinsed in cold PB.

\section{NADPH-d Histochemistry}

Free-floating sections were rinsed in fresh $\mathrm{PB}$ and incubated in a medium made up of $1 \mathrm{mM} \beta-\mathrm{NADPH}$ (Sigma), $0.8 \mathrm{mM}$ nitro blue tetrazolium (Sigma), and $0.06 \%$ Triton $\mathrm{X}-100$ in $\mathrm{PB}$, at $37^{\circ} \mathrm{C}$ in darkness for 1-2 h. The reaction was stopped by successive rinses in cold PB. Some sections were incubated in a medium without $\beta$-NADPH. A second group of control sections was heated in PB to $70^{\circ} \mathrm{C}$ for $10 \mathrm{~min}$. In both cases, no reaction was observed. Transverse and sagittal series were mounted on glass slides (mounting medium: $0.25 \%$ gelatin in $0.1 \mathrm{M}$ Tris- $\mathrm{HCl}$ buffer, $\mathrm{pH} 7.6$ ) and, after dehydration, coverslipped with Entellan (Merck, Darmstadt, Germany). Some sections were counterstained with cresyl violet to facilitate the analysis of the results.

\section{NOS Immunohistochemistry}

In another series of experiments, the free-floating sections were rinsed twice in $\mathrm{PB}$, treated with $1 \% \mathrm{H}_{2} \mathrm{O}_{2}$ in $\mathrm{PB}$ for 15 min to eliminate endogenous peroxidase activity, and rinsed again 3 times in $\mathrm{PB}$. The sections were then incubated in a sheep antiserum against neuronal NOS (K205 antibody, kindly donated by Dr. Piers Emson), diluted $1: 15,000$ in $\mathrm{PB}$ containing $0.5 \%$ Triton X-100 (PB-T), for $48-60 \mathrm{~h}$ at $4^{\circ} \mathrm{C}$. Subsequently, the sections were rinsed 3 times in $\mathrm{PB}$ for $10 \mathrm{~min}$ and incubated for $60 \mathrm{~min}$ at room temperature in rabbit anti-sheep biotinylated IgG (Vector Laboratories, Burlingame, CA, USA) diluted 1:100. After rinsing a further 3 times for $10 \mathrm{~min}$, the sections were incubated for $90 \mathrm{~min}$ in Vectastain ABCperoxidase system (Vector). Secondary antiserum and $\mathrm{ABC}$ complex were diluted in PB containing $0.5 \%$ Triton X-100 and $2 \%$ BSA. Finally, the sections were rinsed 3 times for $10 \mathrm{~min}$ in $\mathrm{PB}$ and subsequently stained in $0.5 \mathrm{mg} / \mathrm{mL}$ of $3,3^{\prime}$-diaminobenzidine (DAB; Vector; catalog No. SK4100) intensified with nickel [Adams, 1981], with $0.01 \% \mathrm{H}_{2} \mathrm{O}_{2}$ in $\mathrm{PB}$ for 5-10 min.

In addition, after incubation in the sheep antiserum against neuronal NOS (in the same conditions mentioned above), another set of free-floating sections were processed for immunohistofluorescence using Alexa 594-conjugated donkey anti-sheep (Molecular Probes, Eugene, OR, USA; catalog No. A11058) diluted 1:300 in PB-T or FITC-conjugated donkey anti-sheep (Vector Laboratories, Burlingame, CA, USA; catalog No. FI-6000) diluted 1:100 in $\mathrm{PB}-\mathrm{T}$, applied for $2 \mathrm{~h}$ at room temperature. These sections were mounted on glass slides with $0.25 \%$ gelatine in $0.1 \mathrm{M}$ Tris- $\mathrm{HCl}$ buffer and coverslipped with Vectashield (Vector).

\section{Double Labeling for NOS or ChAT and NADPH-d}

NOS immunofluorescence was conducted in sections as described above. Similarly, ChAT-immunofluorescence detection was accomplished with a first incubation of the sections in a primary goat anti-ChAT (diluted 1:100; Millipore; catalog No. AB144P) in PB-T for $48-60 \mathrm{~h}$ at $4^{\circ} \mathrm{C}$, and revealed by using Alexa 594-conjugated donkey anti-goat (Molecular Probes) diluted 1:300 or FITC-conjugated donkey anti-goat (Vector) diluted $1: 100$, both in $\mathrm{PB}-\mathrm{T}$, applied for $2-4 \mathrm{~h}$ at room temperature. The sections were mounted on glass slides and studied, plotted, and photographed without drying. They were then recovered from the slides and rinsed thoroughly in PB for $1 \mathrm{~h}$. The histochemical technique for NADPH-d was subsequently performed. The results of both labels were compared throughout the brain after plotting and photographing the NADPH-d reactive elements.

\section{Double NOS and TH, 5-HT, CB or CR Immunofluorescence}

To analyze the possible codistribution/colocalization of NOS and $\mathrm{TH}, 5-\mathrm{HT}, \mathrm{CB}$ or $\mathrm{CR}$, combinations of antibodies were used in a procedure based on immunohistofluorescence as follows: (1) first incubation for $72 \mathrm{~h}$ at $4{ }^{\circ} \mathrm{C}$ in a mixture of sheep anti-NOS (diluted 1:15,000) and mouse anti-TH (diluted 1:1,000; ImmunoStar; catalog No. 22941), rabbit anti-5-HT (diluted 1:1,000; ImmunoStar; catalog No. 20080), mouse anti-CB (diluted 1:1,000; Swant; catalog No. 300) or rabbit anti-CR (diluted 1:1,000; Swant; catalog No. $7699 / 3 \mathrm{H}$ ); (2) second incubation for $90 \mathrm{~min}$ at room temperature in a mixture of secondary antisera: donkey antisheep Alexa 594 (red fluorescence; diluted 1:300; Molecular Probes) and Alexa 488-conjugated chicken anti-mouse (green fluorescence; diluted 1:300; Molecular Probes; catalog No. A21200) or Alexa 488-conjugated chicken anti-rabbit (green fluorescence; diluted 1:300; Molecular Probes; catalog No. A21441). After rinsing 3 times in $\mathrm{PB}$, the sections were mounted on glass slides and coverslipped with UltraCruz ${ }^{\mathrm{TM}}$ mounting medium containing DAPI for fluorescent labeling of DNA (sc-24941; Santa Cruz Biotechnology).

\section{Double Brightfield Labeling for NADPH-d and ChAT or TH}

These series of experiments were conducted to correlate in brightfield microscopy the nitrergic structures with the cholinergic and catecholaminergic cell groups. Following the histochemical reaction for NADPH-d which produced a blue reaction product, the free-floating sections were rinsed twice in $\mathrm{PB}$, treated with $1 \% \mathrm{H}_{2} \mathrm{O}_{2}$ in $\mathrm{PB}$ for $15 \mathrm{~min}$ to reduce endogenous peroxidase activity, rinsed again 3 times in $\mathrm{PB}$ and processed by the peroxidase antiperoxidase (PAP) method [Sternberger, 1979]. This included a first incubation of the sections in a primary goat anti-ChAT (diluted 1:100; Millipore) or mouse anti-TH (diluted 1:1,000; ImmunoStar) antisera, for $48-60 \mathrm{~h}$ at $4^{\circ} \mathrm{C}$. The sections were then processed immunohistochemically according to the PAP technique using rabbit anti-goat (Chemicon; diluted 1:50) or goat antimouse (Dakopatts, diluted 1:50) in PB for $1 \mathrm{~h}$ at room temperature. After further rinsing 3 times in $\mathrm{PB}$ for $10 \mathrm{~min}$, the sections were incubated for $90 \mathrm{~min}$ in goat PAP complex (Chemicon) or mouse PAP complex (Chemicon) diluted 1:500 for $90 \mathrm{~min}$. Secondary antiserum and PAP complex were diluted in PB containing $0.5 \%$ Triton X-100 and $2 \%$ BSA. Finally, the sections were rinsed 3 times for $10 \mathrm{~min}$ in $\mathrm{PB}$ and subsequently stained in 0.5 $\mathrm{mg} / \mathrm{mL}$ of DAB (SK4100; Vector), with $0.01 \% \mathrm{H}_{2} \mathrm{O}_{2}$ in $\mathrm{PB}$ for 3-5 $\mathrm{min}$, giving rise to a brown reaction product. The sections were then mounted, dehydrated, and coverslipped as for NADPH-d histochemistry. 
Controls and Specificity of the Antibodies

There were 2 general controls for the immunohistochemical reaction: (1) staining some selected sections with preimmune normal serum, and (2) controls in which either the primary and/or the secondary antibody or the ABC/PAP complex was omitted. The immunostaining was eliminated in all these negative controls. The antibodies used have been tested under identical conditions in tissues devoid of antigen, as a negative control, and in tissues positive for the antibodies. The controls were shown to be satisfactory in all cases.

The polyclonal NOS antiserum was raised in sheep against recombinant rat NOS, and its specificity has been previously described [Herbison et al., 1996; Smeets et al., 1997]. Antibody specificity against neuronal NOS was assessed by liquid-phase adsorption experiments [Simonian and Herbison, 1996]. In addition, the specificity of the antiserum for the detection of NOS was warranted by the observation of a staining pattern that was identical to that in previous reports in which it matched the NADPH-d histochemical reaction [González et al., 1996; Smeets et al., 1997; Muñoz et al., 2000; Brüning and Mayer, 2001; López and González, 2002; Moreno et al., 2002; Moreno and González, 2004, 2005a, 2005b; López et al., 2016]. The immunoreactivity is abolished by absorption of the K205 antiserum with recombinant neuronal NOS protein $\left(1 \mathrm{mM}\right.$ overnight at $\left.4^{\circ} \mathrm{C}\right)$.

The specificity of the ChAT, TH, CB, and CR antisera has been previously described in L. platyrhincus [Morona et al., 2013], and a similar pattern of labeling for these markers has been detected in L. oculatus (present results).

\section{Evaluation and Presentation of the Results}

The distribution of nitrergic cell bodies and fibers in the brain was carefully analyzed in both the single- and double-labeled sections. The correspondence between the NADPH-d method and NOS immunohistochemistry was first assessed in the double-labeled sections (Fig. 2). The pattern of labeling was charted in representative transverse sections of L. platyrhincus, from rostral to caudal levels (Fig. 3). Drawings were made by means of a camera lucida in which the sections counterstained with cresyl violet facilitated the interpretation of the localization of the labeled structures. The sections were analyzed with an Olympus BX51 microscope equipped with a digital camera (Olympus DP70). Contrast and brightness were adjusted in Adobe PhotoShop CS4 (Adobe System, San Jose, CA, USA) and figures were mounted in Canvas 11 (ACS System International). Selected single-labeled sections were photographed and the pattern of nitrergic structures is presented from rostral to caudal levels (Fig. 4-6). Double-labeled sections for NADPH-d and TH or CHAT analyzed with brightfield microscopy are shown in Figure 7, whereas images of double immunoflurescence are illustrated in Figures 8 and 9. Finally, the main groups of nitrergic neurons detected in the present study are summarized for the case of L. platyrhincus in a sagittal schematic drawing, with special reference to the neuromeric regionalization of the brain (Fig. 10).

The nomenclature used is essentially the same as in previous studies of the brain in the genus Lepisosteus [Northcutt, 1982; Parent and Northcutt, 1982; Song and Northcutt, 1991; Northcutt and Butler, 1993; Collin and Northcutt, 1995; Meek and Nieuwenhuys, 1998; Chiba and Oka, 1999; Baker and Bird, 2002; Chiba, 2005; Morona et al., 2013], including the terminology of the prosomeric model for the forebrain [Puelles and Rubenstein, 2003, 2015].

\section{Results}

The antibody against neuronal NOS used in the present study revealed patterns of immunoreactivity that, for each of the 2 species examined, were constant from animal to animal. This pattern of labeling was widely coincident with the staining of the NADPH-d technique (Fig. 2), with the exceptions found in the olfactory system and terminal nerve of $L$. oculatus detailed below. In both transverse and sagittal sections, labeling of neuronal cell bodies and fibers was observed in distinct groups of the forebrain, brainstem, and spinal cord (charted for L. platyrhincus in Fig. 3). In addition, the regional localization of nitrergic cell groups was summarized in a schematic sagittal drawing in Figure 10, according to a segmental interpretation of the brain. In the following sections, we describe the rostrocaudal regional distribution of the nitrergic system (neuronal bodies and fibers) taking $L$. platyrhincus as the core species for which the complete pattern is detailed, but commenting on the small differences obtained in particular brain regions of L. oculatus (Table 1). The widespread nitrergic structures are presented in selected photomicrographs in Figures 4-6 and will be described in the following sections. The doubly labeled sections for NOS/NADPH-d and TH, ChAT, $5-\mathrm{HT}, \mathrm{CB}$ or CR were mainly used to corroborate the actual position of certain cell groups in the brain and to establish some neurochemical features of nitrergic populations, and the selected images are shown in Figures 7-9.

\section{Forebrain}

The brain of gars shows a discretely everted telencephalon, which differs from the greatly developed optic tectum, the inferior hypothalamic lobes, and the cerebellum (Fig. 1b). In the most rostral part of the telencephalon, the large olfactory bulbs of L. platyrhincus lacked NOS immunoreactivity and NADPH-d activity (Fig. $4 \mathrm{~g}$ ), whereas the olfactory receptor cells in the olfactory mucosa of $L$. oculatus, the axons of which form the olfactory nerve ending in the glomerular layer of the olfactory bulbs, showed intense NADPH-d reactivity, as well as the coarse fibers that

Fig. 2. Photomicrographs of transverse sections through the telencephalon (a), mesencephalon (c), and rhombencephalon $(\mathbf{e}, \mathbf{g})$ of L. platyrhincus $(\mathbf{a}, \mathbf{c})$ and L. oculatus $(\mathbf{e}, \mathbf{g})$ illustrating the perfect match of cell bodies and processes immunolabeled with NOS antiserum and NADPH-d histochemistry in the $\operatorname{Vdc}\left(\mathbf{b}, \mathbf{b}^{\prime}\right)$, the mesencephalic tegmentum (Tegm; d, $\left.\mathbf{d}^{\prime}\right)$, the Rm (f, $\left.\mathbf{f}^{\prime}\right)$, and the Nsol $\left(\mathbf{h}, \mathbf{h}^{\prime}\right)$. See list of abbreviations. Scale bars, $50 \mu \mathrm{m}\left(\mathbf{b}, \mathbf{b}^{\prime}, \mathbf{d}, \mathbf{d}^{\prime}, \mathbf{f}, \mathbf{f}^{\prime}\right.$, $\left.\mathbf{h}, \mathbf{h}^{\prime}\right), 200 \mu \mathrm{m}(\mathbf{a}, \mathbf{c}, \mathbf{e}, \mathbf{g})$. See online version for colors.

(For figure see next page.) 


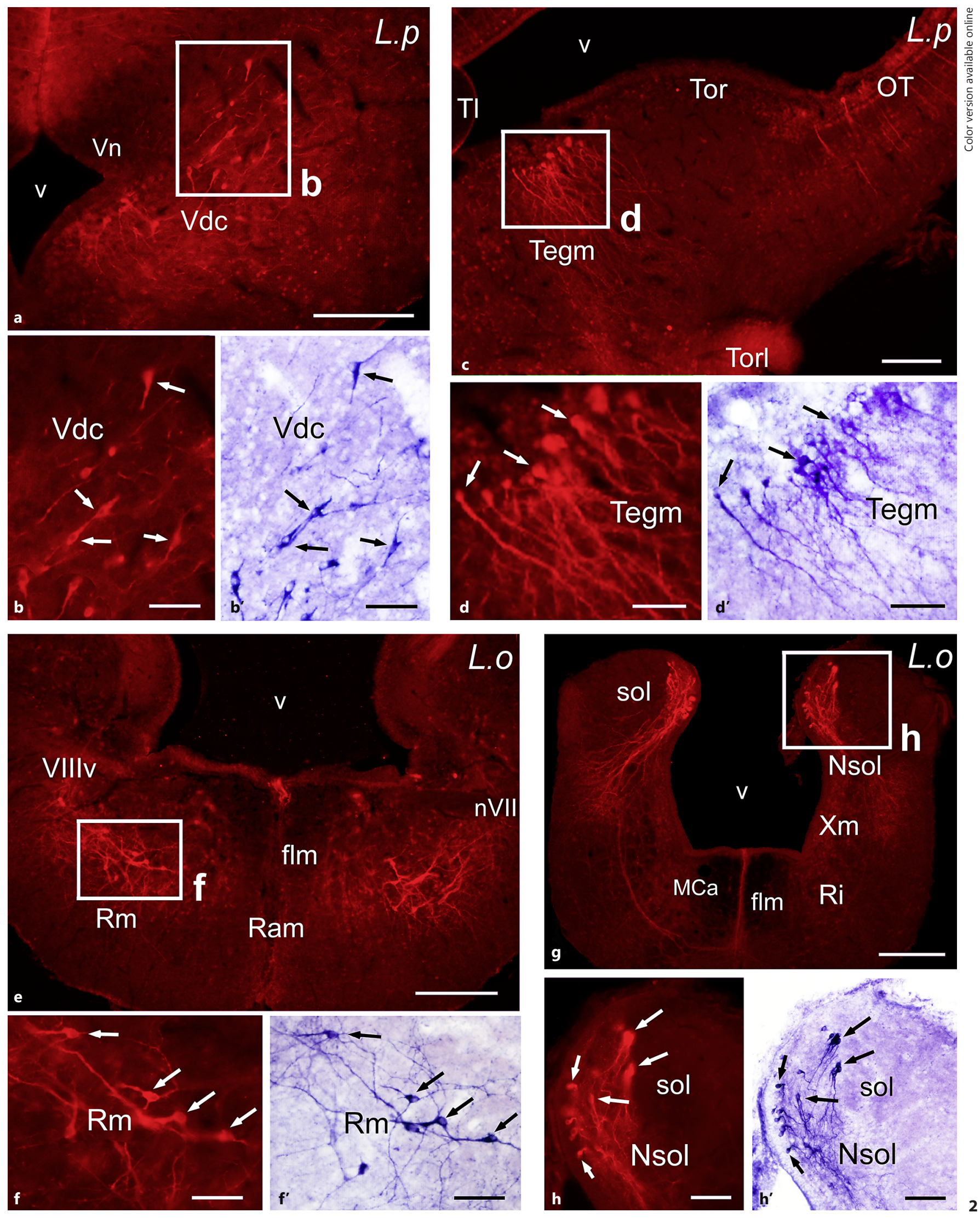




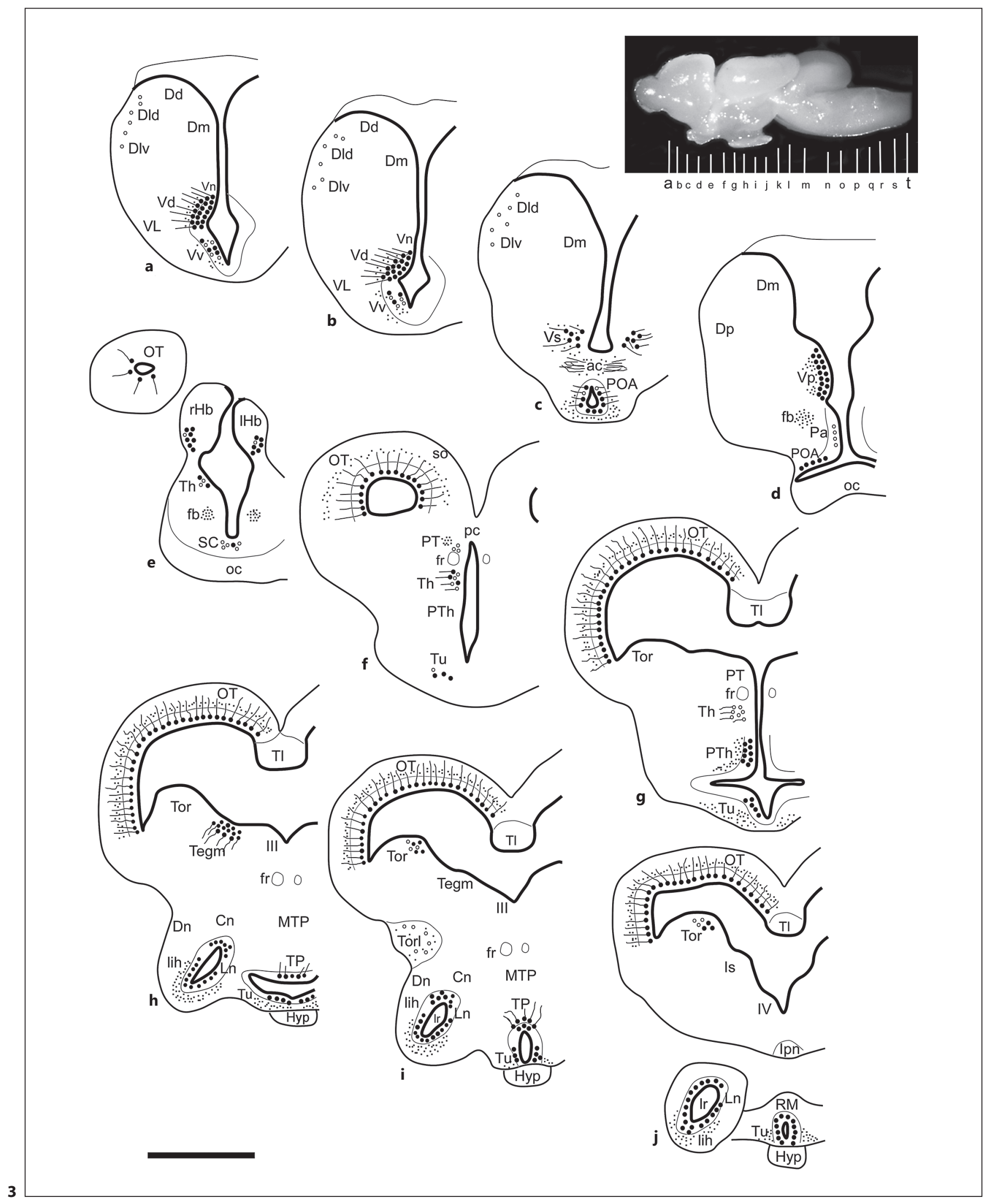

(For rest of figure and legend see next page.) 


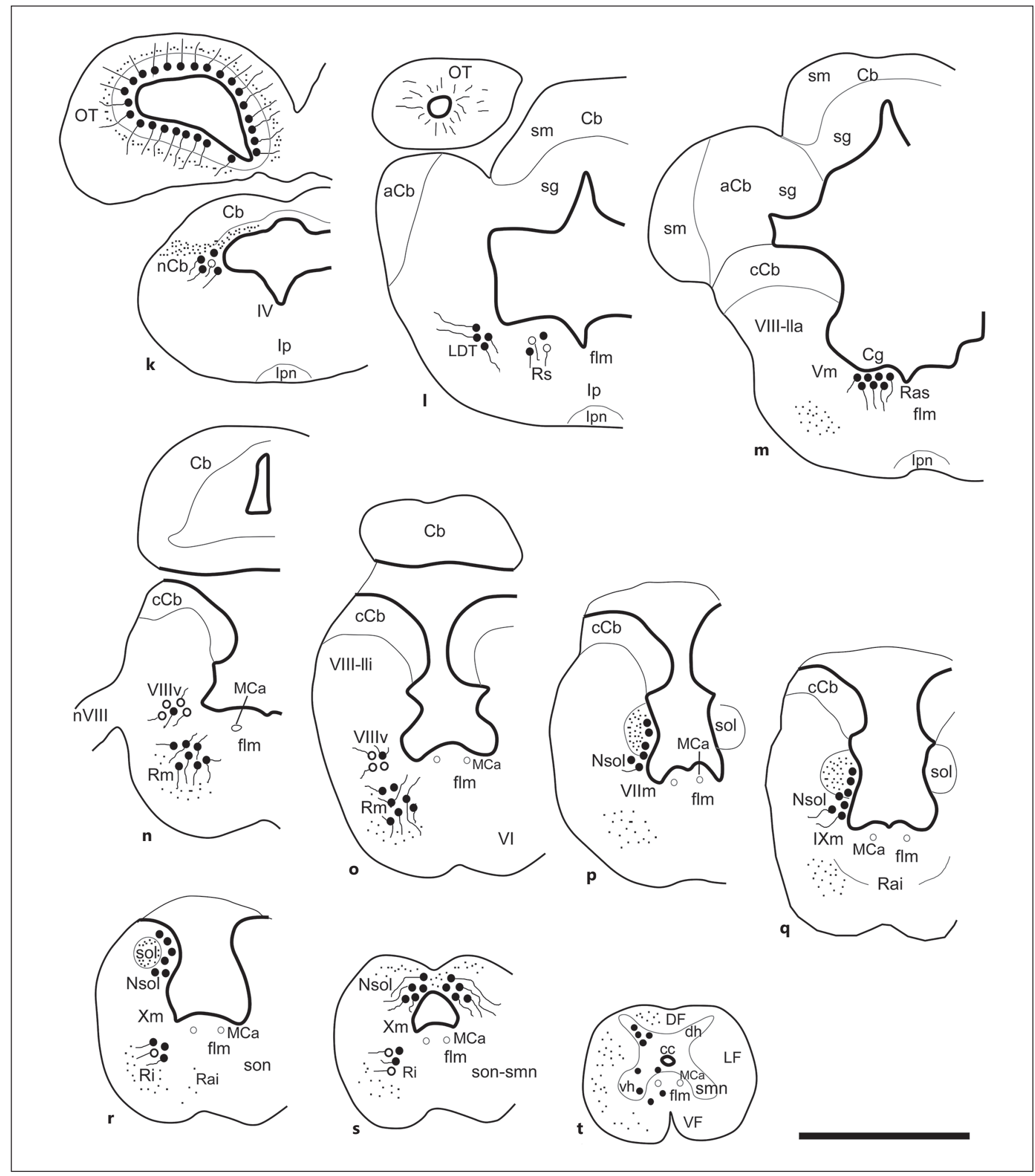

Fig. 3. a-t Diagrams of transverse sections through the brain of $L$. platyrhincus at the rostrocaudal levels indicated in the photograph of the lateral view of the brain. NOS-ir cell bodies (large dots) and fibers (small dots, wavy lines) are represented in the left half of each section. Faintly labeled cells are drawn empty. The thick line in each diagram demarcates the ventricular surface. See list of abbreviations. Scale bar, 1,000 $\mu \mathrm{m}$. 
Table 1. Localization and relative abundance of NOS-immunoreactive cells and fibers in the CNS of the gars L. platyrhincus and L. oculatus

\begin{tabular}{lllll} 
L. platyrhincus & & & L. oculatus & \\
\cline { 1 - 1 } & $\mathrm{F}$ & $\mathrm{C}$ & $\mathrm{F}$
\end{tabular}

\section{Forebrain}

Olfactory bulb

Pallium (Dl)

Subpallial area Vd

Subpallial area Vv

Subpallial areas Vn and VL

Subpallial areas Vs

Subpallial area Vp

Preoptic area

Paraventricular area

Suprachiasmatic nucleus

Tuberal hypothalamus

Inferior hypothalamic lobe

Retromammillary hypothalamic region

Hypophysis

Prethalamus

Posterior tubercle

Habenula

Thalamus

Pretectum

-
+
++++
+++
-
++
+++
+++
+
+
+++
+++
++
-
++
+++
++
++
+

$\begin{array}{lll}- & - & - \\ - & + & - \\ +++ & ++++ & +++ \\ ++ & ++ & ++ \\ - & - & - \\ ++ & ++ & ++ \\ ++ & +++ & ++ \\ ++ & +++ & ++ \\ + & + & + \\ + & ++ & + \\ ++ & +++ & ++ \\ ++ & +++ & ++ \\ ++ & ++ & ++ \\ - & - & - \\ + & ++ & + \\ ++ & +++ & ++ \\ + & ++ & + \\ + & ++ & + \\ ++ & + & +\end{array}$

Midbrain

Optic tectum

Torus semicircularis

Torus lateralis

Torus longitudinalis

Mesencephalic tegmentum

Oculomotor nucleus

$\begin{array}{ll}++++ & ++ \\ ++ & + \\ ++ & +++ \\ - & - \\ +++ & ++ \\ - & -\end{array}$

$++++$

$++$

$+$

$+$

$-$

$+++$

$++$

$+$

$++$

$-$

$-$

$++$

Hindbrain

Trochlear nucleus

Interpeduncular nucleus

Cerebellum

Cerebellar nucleus

Central gray

Laterodorsal tegmental nucleus

Superior reticular nucleus

Trigeminal motor nucleus

Mauthner cells

Abducens nucleus

Median reticular nucleus

Ventral octavolateral area

VIIm-IXm-Xm

Nucleus of the solitary tract

Raphe nuclei

Inferior reticular nucleus

Spino-occipital motor nucleus

\begin{tabular}{|c|c|c|c|c|}
\hline Spinal cord & +++ & ++ & ++ & ++ \\
\hline Retina & ++ & ++ & ++ & + \\
\hline Sensory ganglia of cranial nerves & ++ & + & ++ & + \\
\hline
\end{tabular}

C, immunoreactive cell bodies; F, immunoreactive fibers; +, low density; ++, moderate density; +++ , high density; ++++, very high density; -, no immunoreactive cell bodies or fibers. 
might represent the terminal nerve (Fig. 4b, d). However, all these structures were NOS immunonegative and, therefore, were not consiered nitrergic structures. The intense NADPH-d labeling throughout the glomerular layer served to delimitate the caudal extent of the olfactory bulb, and also to trace the projections of the putative terminal nerve, only in L. oculatus. Thus, these thick fibers were observed in ventromedial locations of the olfactory bulbs, coursing caudally through the ventral part of the ventral telencephalic area (Vv; Fig. 4b, d) and reaching the rostral preoptic area in the caudal telencephalon.

The pallial part of the slightly everted telencephalic hemispheres of Lepisosteus possessed a scarce and faintly NOS-ir population of small cells located in the dorsolateral and ventrolateral zones of the dorsal telencephalic area (Dld, Dlv; Fig. 3a-c, 4g). These cells were separated from the ventricle and were intermingled with CB-ir cells, with some being doubly labeled (Fig. 8a). In clear contrast with the scarce presence of NOS-ir cells in the pallium of gars, the subpallium was the telencephalic region with a more prominent presence of nitrergic elements (Fig. $3 \mathrm{a}-\mathrm{d})$. In particular, the most conspicuous nitrergic cell group was located in the dorsal part of the ventral telencephalic area (Vd; Fig. 3a, b, 4b-e). At rostral levels, this group was formed by round, intensely NOS-ir cells that were densely packed and showed long processes directed laterally and laterodorsally (Fig. $4 \mathrm{~b}, \mathrm{c}, 8 \mathrm{~b}$, d). The tight clustering of these cells makes it difficult to recognize individual neurons, but more caudally in the Vd (the caudodorsal part of ventral telencephalic area; $\mathrm{Vdc}$ ) the cell density was lower and the nitrergic cells were more separated, making their observation easier (Fig. 2a, 4d-f). Some of these cells in the $\mathrm{Vdc}$ were doubly labeled with CB (Fig. 8e) but not with CR, the cells of which were intermingled with the nitrergic population. In contrast, dorsal to the Vd and just at the pallial-subpallial border, the 'nother nucleus $(\mathrm{Vn})$, and the lateral part of the ventral telencephalic area (VL) were devoid of nitrergic elements (Fig. 3a, b, 4b-g, 8b). In the double-labeling experiments, the NOS-ir part of the Vd showed a prominent plexus of 5-HT-ir varicose fibers (Fig. 8c), and remarkable $\mathrm{TH}$-ir cells and fibers were detected in the lateral part of $\mathrm{Vd}$ (Fig. 8b). In addition, CB-ir cells, which did not colocalize with NOS, were found in the $\mathrm{Vd}$, although they were especially notable in the Vn (Fig. 8d). The Vv also housed a population of nitrergic cells (Fig. 3a, b, 4c, g), some of which were near the ventricle and exhibited short processes contacting the cerebrospinal fluid (CSF). These NOS-ir cells, which were more numerous in L. platyrhincus than in L. oculatus, were strongly intermingled with

Nitrergic Neuronal System in Holosteans
CB-ir cells, although no colocalization was detected (Fig. 8d).

In the caudal telencephalon, several populations of nitrergic neurons were observed in the supracommissural part and posterior nucleus of the ventral telencephalic area (Vs and Vp; Fig. 3c, d, 4g-i). The cells of the Vs were generally multipolar neurons of large size and intense immunoreactivity that formed a disperse group (Fig. 4i, 8f). At this level, many nitrergic fibers were seen in the anterior commissure (Fig. 4i). Despite their proximity, $\mathrm{CB}$ and CR were not found in the NOS-ir cells in the Vs. The nitrergic cells in the $\mathrm{Vp}$ were small, rounded, and tightly packed near the ventricle (Fig. 3d, 4h), forming a prominent group in the caudal telencephalon (Fig. 4g, 9a).

In the caudoventral telencephalon, a group of moderate to intense immunoreactive nitrergic cells was observed near the ventricle of the preoptic recess, showing long lateral and short CSF-contacting processes (Fig. 3c, $\mathrm{d}, 4 \mathrm{~g}, \mathrm{i}, \mathrm{j}, 8 \mathrm{n})$. These cells were near to or intermingled with other cells labeled for $\mathrm{TH}, \mathrm{CB}$ or ChAT, but no double-labeled cells were observed (Fig. 7a, 8f).

According to the prosomeric model [Puelles and Rubinstein, 2003, 2015], a small group of faintly immunoreactive cells was observed in the paraventricular area that constitutes the dorsalmost part of the alar hypothalamus (Pa; Fig. 3d, 8n). These round and small nitrergic cells were periventricularly located and some of them showed short CSF-contacting processes. Lateral to the paraventricular hypothalamic area, thick and intensely immunoreactive fibers were seen in the forebrain bundle (fb; Fig. 3d, e, 4k). In the ventral part of the alar hypothalamus, a group of nitrergic cells was moderately labeled in the suprachiasmatic nucleus (SC; Fig. 3e, 8g). This cell population, which was more prominent in L. oculatus than in L. platyrhincus, showed double NOS/TH cells (Fig. $8 \mathrm{~g}-\mathrm{i}, \mathrm{n}$ ) and the cholinergic cell population in the suprachiasmatic region [Morona et al., 2013; present results] was located ventromedial to the NOS-ir neurons.

The nitrergic cells in the basal hypothalamus were significantly more numerous than in the alar region. Thus, the most prominent NOS-ir cell population in the hypothalamus was found in the tuberal region and within the conspicuous large inferior lobes characteristic of this group of fishes (Fig. 3f-j, 4l-n, 8k, l, n, 10). Most cells in these regions were periventricular NOS-ir neurons and many of them were bipolar with short CSF-contacting processes and long lateroventrally oriented processes (Fig. 4p, 8r). The tuberal nitrergic cells were intermingled with CB-ir cells without colocalization of both markers in the same neurons (Fig. 8j). In the ventral part of the tu- 

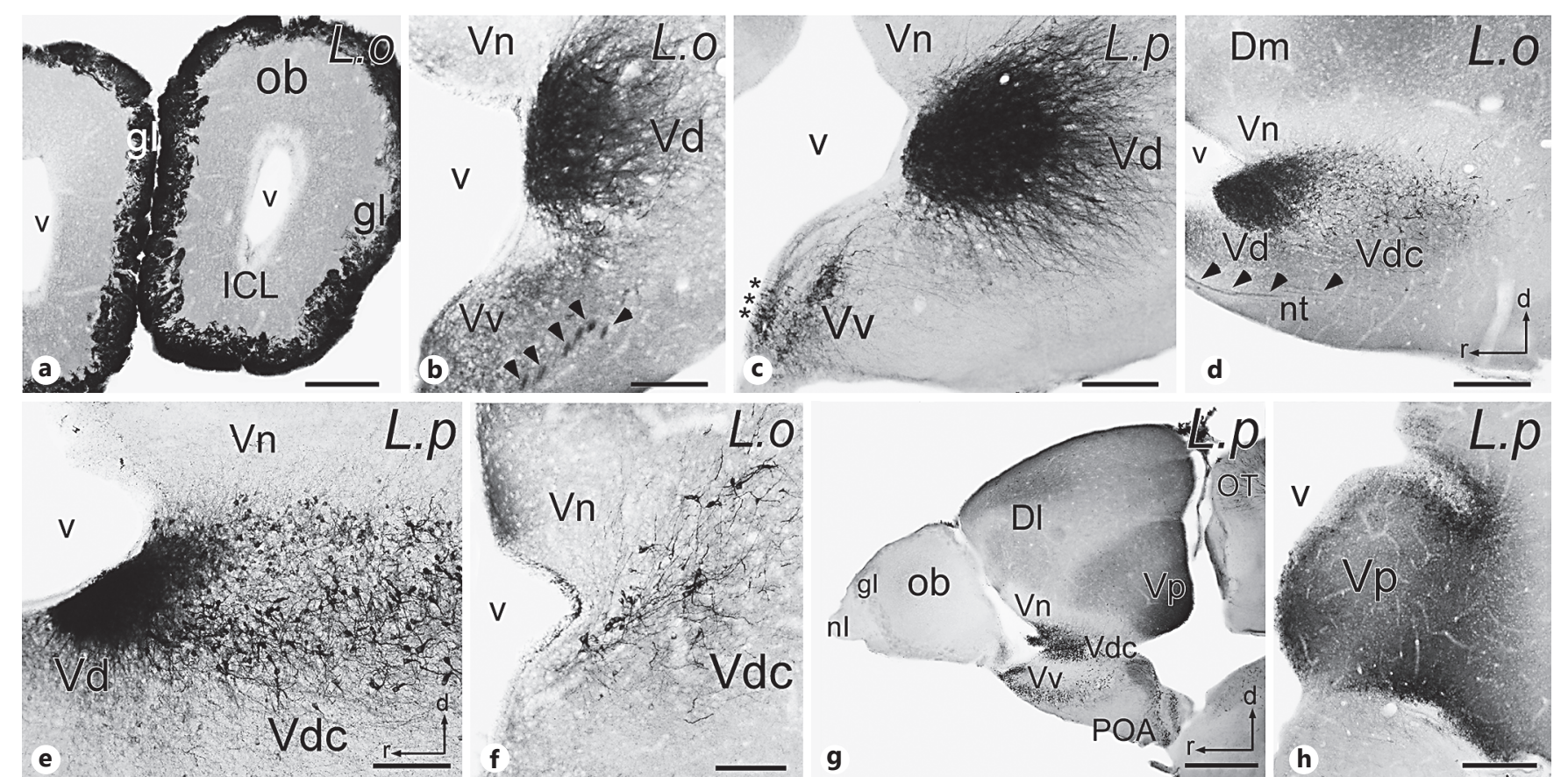

L. 0
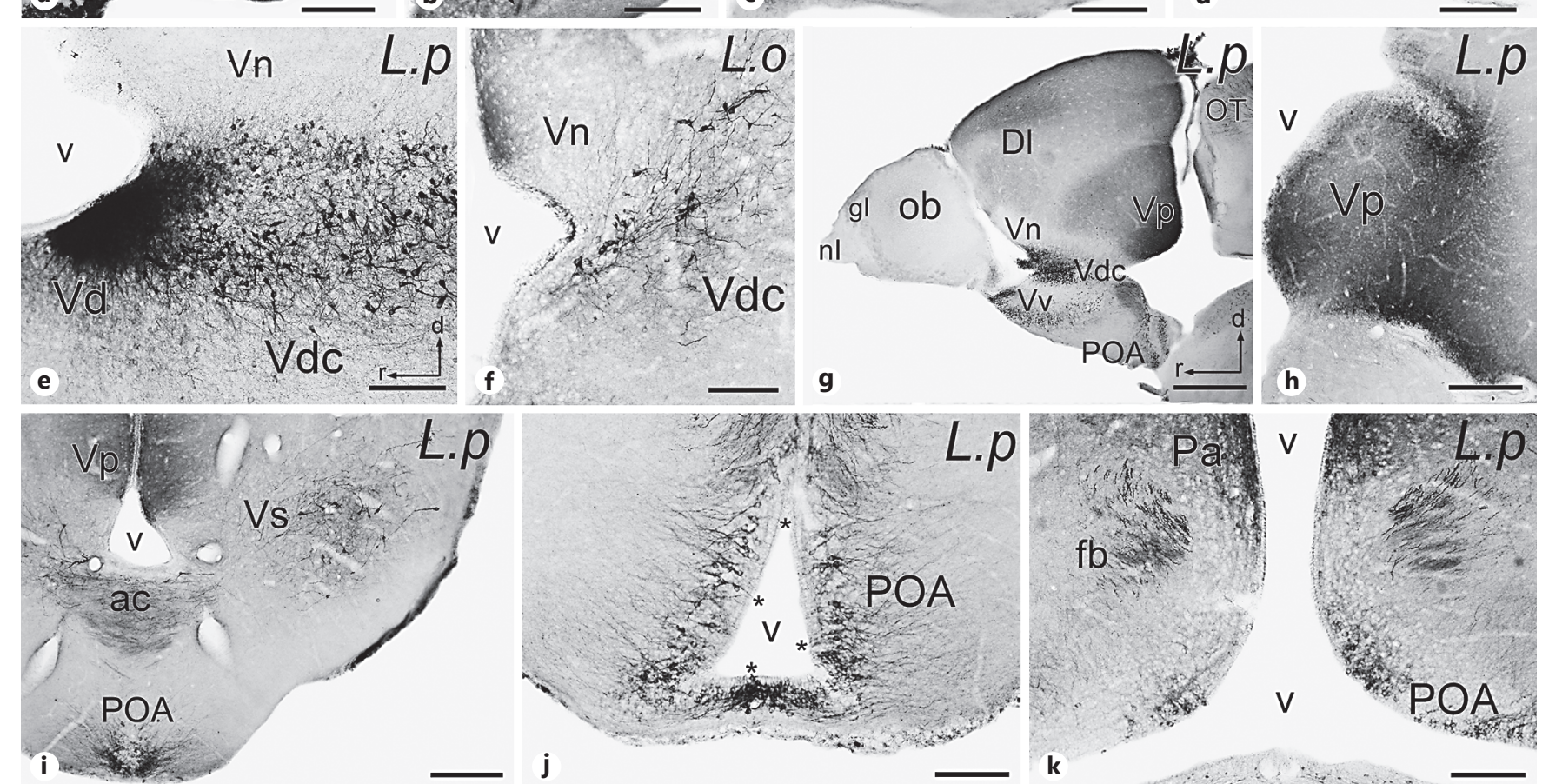

$\mathrm{Vn}$
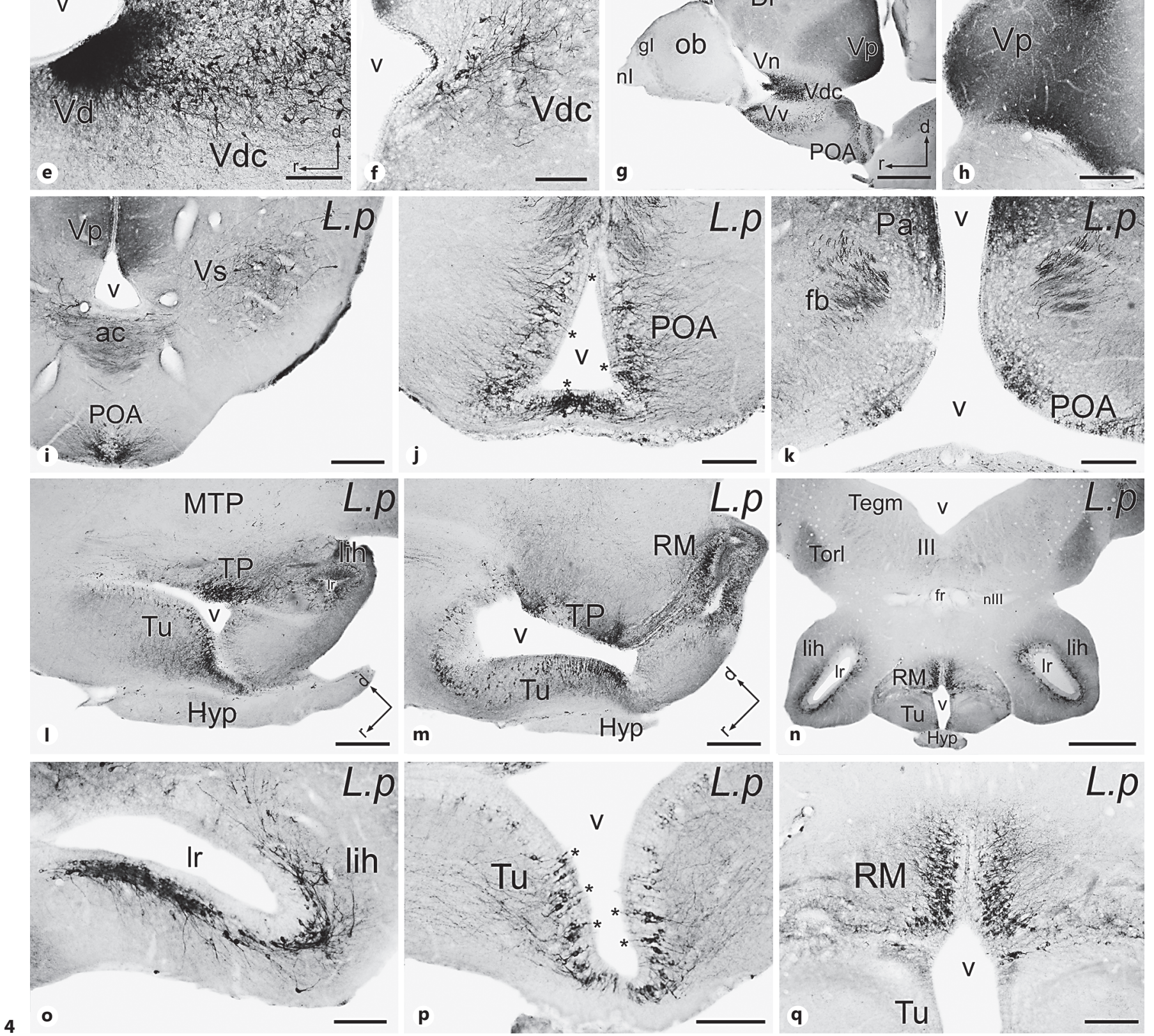

(For legend see next page.) 
beral hypothalamus (caudal in classical transverse sections), many of the NOS-ir cells were doubly labeled with CR (Fig. 8s). In addition, nitrergic fibers were found in the outer fiber zone of the tuberal region and many of them coursed ventrocaudally toward the median eminence (Fig. 3g-j). The large inferior hypothalamic lobes of Lepisosteus represent a lateral expansion of the tuberal region and housed a remarkable nitrergic cell population periventricularly in the nucleus of the lateral recess (lih; Fig. 3h-j, 4l, n, 8k, 1, 9a), whereas the central and diffuse nuclei were devoid of labeling. Of note, these intense NOS-ir cells lacked CSF-contacting processes (Fig. 4o) and were intermingled with CB-ir and CR-ir cells constituting separate subpopulations (Fig. 8j). The last nitrergic cell group detected in the hypothalamus of gars was observed in the caudoventral part of the basal hypothalamus (dorsocaudal in classical transverse sections) within the retromamillary area (RM; Fig. 3j, 4n, 8s, 10). These cells were moderately NOS-ir and showed laterally oriented processes (Fig. 4q), distinct from the TH-ir cells located in the RM, which showed CSF-contacting processes (Fig. 8q). It is noteworthy that the hypophysis of gars was devoid of NOS-ir cells.

In the caudal portion of the forebrain, the diencephalon is divided into 3 caudorostral segments or prosomeres (p1-p3), the alar plates of which give rise to the pretectal area, thalamus (former dorsal thalamus), and prethalamus (former ventral thalamus), respectively, and the basal plates form different tegmental regions that are generally smaller than the alar regions (Fig. 10). Following the description from rostral to caudal regions, in the ventral part (caudal in classical transverse sections) of alar plates of $\mathrm{p} 3$, a group of small and intensely NOS-ir cells was detected near the ventricle in the prethalamus (Fig. $3 \mathrm{~g}, 8 \mathrm{l}, \mathrm{m}, 10$ ). These cells lacked CSF-contacting processes and were located medial to the prominent serotoninergic group of the paraventricular organ (Fig. 8r). A distinct cell population of large TH-ir cells was observed lateral to the prethalamic

Fig. 4. Photomicrographs of transverse (a-c, $\mathbf{f}, \mathbf{h}-\mathbf{k}, \mathbf{n}-\mathbf{q})$ and sagittal (d, e, $\mathbf{g}, \mathbf{I}, \mathbf{m})$ sections through the forebrain of $L$. oculatus (L.o.) and L. platyrhincus (L.p.; indicated in the upper right corner of each photomicrograph), illustrating NADPH-d-positive cell bodies and fibers in the olfactory bulb (a), rostral and caudal parts of Vd (b-f), terminal nerve (arrowheads in $\mathbf{b}, \mathbf{d}), \mathrm{Vp}(\mathbf{g}-\mathbf{i}), \mathrm{Vs}(\mathbf{i})$, preoptic area $(\mathbf{i}-\mathbf{k})$, paraventricular area $(\mathbf{k})$, tuberal hypothalamus and TP $(\mathbf{I}, \mathbf{m}, \mathbf{p})$, retromammillary hypothalamic area $(\mathbf{m}, \mathbf{n}, \mathbf{q})$, and inferior hypothalamic lobes $(\mathbf{n}, \mathbf{o})$. Asterisks in $\mathbf{c}, \mathbf{j}, \mathbf{p}$ indicate CSF-contacting cell processes. See list of abbreviations. Scale bars, $100 \mu \mathrm{m}(\mathbf{b}, \mathbf{c}, \mathbf{e}, \mathbf{f}, \mathbf{j}, \mathbf{k}, \mathbf{o}-\mathbf{q}), 200 \mu \mathrm{m}(\mathbf{a}, \mathbf{d}, \mathbf{h}, \mathbf{i}, \mathbf{I}, \mathbf{m}), 500 \mu \mathrm{m}(\mathbf{g}, \mathbf{n})$. nitrergic group (Fig. 7b, 8l). In addition, CB-ir cells were largely intermingled with the NOS-ir cells, although colocalization of both markers was not detected in double-labeled sections (Fig. $8 \mathrm{~m}$ ). The most conspicuous nitrergic cell group of the diencephalon was detected in the posterior tubercle (TP), within the basal plate of $\mathrm{p} 3$ (Fig. 3h, i, $41, \mathrm{~m}, 10)$. These intensely NOS-ir cells exhibited thick and long laterodorsal processes and formed a separate group from the $\mathrm{TH}$-ir cells located more dorsally in the TP (Fig. $7 \mathrm{c}, 8 \mathrm{k}, \mathrm{o}, \mathrm{p}$ ). In addition, small and rounded CB-ir cells were observed in the TP intermingled with the NOSir cells, but no double-labeled cells were detected (Fig. 8j).

In the dorsal part of the alar p2 (epithalamus), the asymmetric habenula showed a nitrergic group of rounded and moderately immunoreactive cells in the ventrolateral part of both the large right habenula and the small left habenula (Fig. 3e, 5a, b, 10). Of note, the cholinergic (ChAT-ir) cell group that characterizes the habenula of gars was located dorsal to the NOS-ir cells [Morona et al., 2013; present results] forming distinct subpopulations, whereas some NOS-ir cells were doubly labeled with $\mathrm{CB}$ (Fig. 8t). Ventral to the habenula, a group of slight to moderate NOS-ir cells was seen in the thalamus (Fig. $3 \mathrm{e}-\mathrm{g}, 10)$. This group constituted a column of small cells located close to the ventricle, with long lateral processes but without CSF-contacting processes (Fig. 5c). In the dorsal part (rostral in conventional transverse sections) of this thalamic group, many NOS-ir cells coexpressed CB, but no colocalization was observed for NOS and CR (Fig. 8u).

The most caudal diencephalic NOS-ir cells were observed at the level of the posterior commissure in the alar plate of p1 (Fig. 3f, 10). They formed a small group of faintly immunoreactive cells with lateral oriented processes located immediately dorsal to the fasciculus retroflexus (Fig. 3f, see arrowheads in Fig. 5c). At this level a plexus of nitrergic fibers was observed in the dorsolateral zone of the pretectal area (Fig. 5c), which was more prominent in L. platyrhincus than in L. oculatus.

\section{Midbrain}

A remarkably numerous nitrergic cell population was localized throughout the optic tectum within the alar mesencephalon (Fig. 3e-k, 5g, 9a, 10). These moderate immunoreactive cells showed pear-shaped somata and were mainly located in the inner zone of the periventricular tectal layer [Meek and Nieuwenhuys, 1998]. They possessed long apical processes directed toward the pial surface (spv; Fig. 5d-g) and were identified as neurons of type XIV [according to Meek and Nieuwenhuys, 1998; Kinoshita et al., 2006]. The apical processes ramified es- 


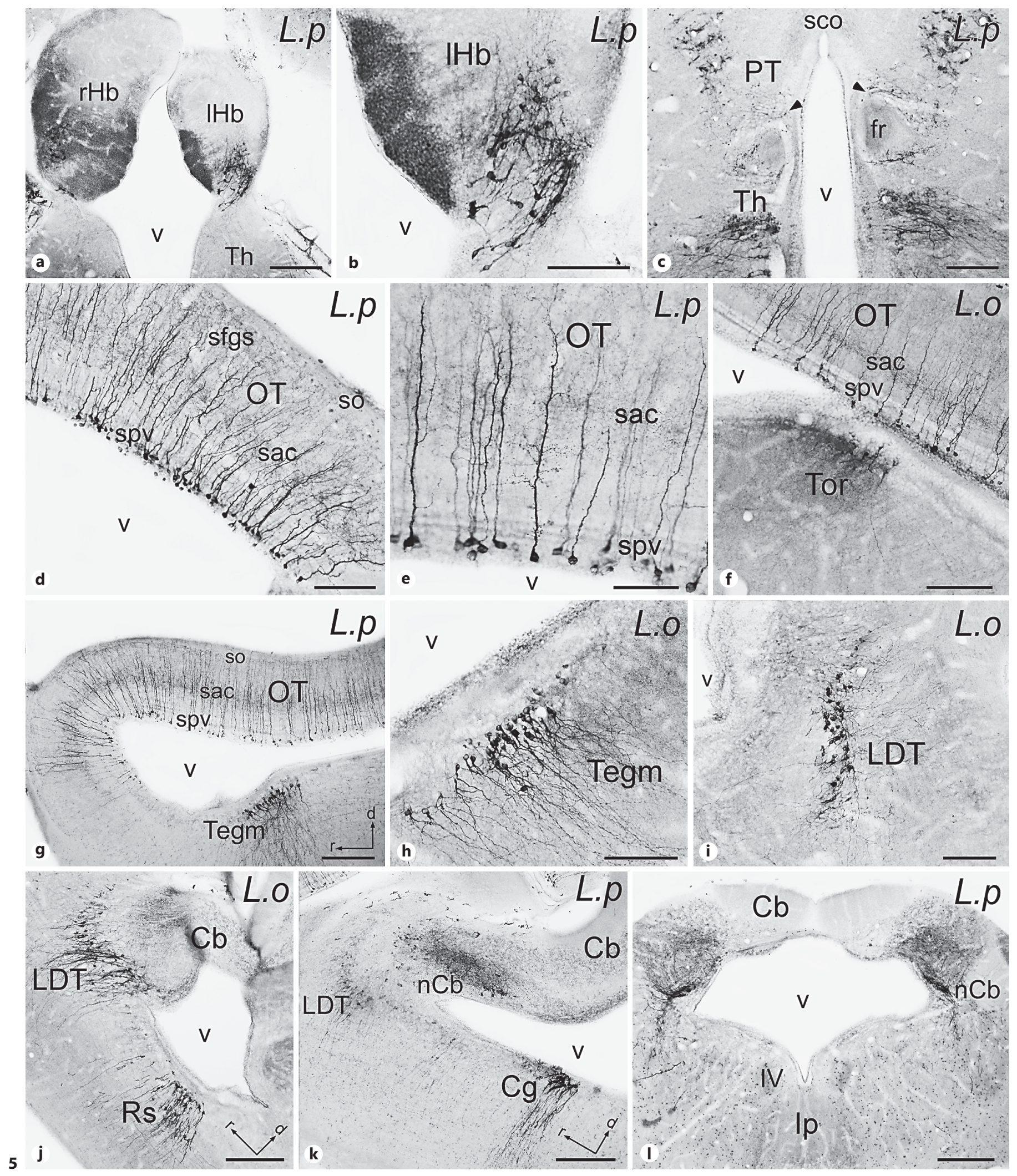

(For legend see next page.) 
pecially in the stratum album centrale (sac; Fig. 5e) and showed varicose swellings. In double-immunolabeling experiments, ChAT-ir, CB-ir, and CR-ir cell populations have also been detected in the optic tectum of gars [Morona et al., 2013; present results], which were generally located in the outer zones of the periventricular layer of the mesencephalic tectum and constituted separate populations from the nitrergic group because no colocalization with these neuromarkers was observed (Fig. 7d; 9b, c).

In contrast to the optic tectum, the torus semicircularis housed a small group of slight to moderate immunoreactive nitrergic cells in its caudal part (Fig. 3i, j, 5f). In the large torus lateralis, a group of scarce and faintly NOS-ir cells was observed (Fig. 3i, 4n), and these cells were more numerous in L. platyrhincus than in L. oculatus, whereas the torus longitudinalis of both species lacked NOS-ir elements (Fig. 2c, 3g-j).

Within the basal part of the midbrain, a numerous population of strongly immunoreactive cells was observed in the tegmentum at rostral mesencephalic levels (Fig. 2c, d, 3h, 5g, 9a). These tegmental cells were located near the ventricle and showed very long lateroventral processes (Fig. 2c, 5h). They were profusely innervated by $\mathrm{TH}$-ir fibers and were clearly separated from the tegmental cholinergic cells that were farther from the ventricle and more caudally in the mesencephalon [Morona et al., 2013; present results]. CB-ir and CR-ir cell populations were also observed in the tegmentum, but only some nitrergic cells were doubly labeled with CR (Fig. 9a).

\section{Hindbrain}

Several groups of NOS immunopositive and NADPH$d$ reactive cells were identified in the hindbrain of the gar species studied and will be described from rostral to caudal in relation to the segmental organization of the rhombencephalon into rhombomeres 0-8 (r0-r8; Fig. 10). Interestingly, the cholinergic cells in the rhombencephalic motor nuclei and the serotonergic cells in the

Fig. 5. Photomicrographs of transverse (a-f, h, i, I) and sagittal ( $\mathbf{g}$, j, k) sections through the diencephalon, midbrain, and rostral rhombencephalon of L. oculatus (L.o.) and L. platyrhincus (L.p.; indicated in the upper right corner of each photomicrograph), illustrating NADPH-d-positive cell bodies and fibers in the asymmetric habenula (a), left habenula (b), thalamus and pretectum (c; arrowheads point to faintly reactive pretectal cells), optic tectum $(\mathbf{d}-\mathbf{g})$, torus semicircularis (f), tegmental mesencephalic nucleus $(\mathbf{g}, \mathbf{h})$, LDT (i-k), Rs (j), central rhombencephalic gray $(\mathbf{k})$, and cerebellar nucleus $(\mathbf{k}, \mathbf{I})$. See list of abbreviations. Scale bars, $50 \mu \mathrm{m}$ (e), $100 \mu \mathrm{m}$ (b-d, f, h, i), $200 \mu \mathrm{m}(\mathbf{a}, \mathbf{g}, \mathbf{j}-\mathbf{l})$.

Nitrergic Neuronal System in Holosteans raphe column described in this group of fishes [Parent and Northcutt, 1982; Chiba and Oka, 1999; Morona et al., 2013] were devoid of nitrergic labeling (Fig. 5l, 6a, e, j, 7h, $\mathrm{i}, 1-\mathrm{n})$. In the basal part of the rostral rhombencephalon, the interpeduncular nucleus also lacked nitrergic cells (Fig. 3k, 1, 5l). In the alar plate of $\mathrm{r} 1$ a group of small nitrergic cells with long lateral and laterodorsal processes was labeled in the putative cerebellar nucleus, considering their position and nitrergic nature (Fig. 3k; 5k, 1; 7f), whereas the corpus and the auricles of the cerebellum were devoid of NOS-ir cells. This nitrergic cerebellar group was more prominent in L. platyrhincus than in $L$. oculatus. Also in the alar plate of $\mathrm{r} 1$, a population of NOSir cells was located in the region close to the locus coeruleus (TH-ir) and the prominent cholinergic laterodorsal tegmental nucleus (LDT) [Morona et al., 2013] (Fig. 31, $5 i, 7 f)$, but the double-labeling technique revealed that the nitrergic cells were located more dorsolaterally without colocalization (Fig. 7e-g). In contrast, CB-ir and CR-ir cells were observed highly intermingled in the LDT, and some nitrergic cells were doubly labeled with CB and CR (Fig. 9d). Of note, the NOS-ir cell group located close to the cholinergic LDT was more numerous in L. oculatus than in L. platyrhincus (Fig. 5j, k).

In the basal part of $\mathrm{r} 1-\mathrm{r} 2$ in L. oculatus and slightly more caudally in L. platyrhincus, a remarkable group of nitrergic cells was observed in the rhombencephalic central gray (Cg; Fig. 3m; 5k; 6a). These intensely NOS-ir cells with long ventral processes (Fig. 6b) formed a distinct subpopulation more laterally located to the CB-ir, $\mathrm{CR}$-ir, and ChAT-ir cell groups located in this area [Morona et al., 2013; present results] (Fig. 9e). In the reticular formation, the superior, middle, and inferior nuclei possessed nitrergic cells (Fig. 10). Thus, large cells with long ventral and ventrolateral processes were observed in the superior reticular nucleus (Rs) within the basal part of caudal $\mathrm{r} 1$ and $\mathrm{r} 2$, just lateral and extending caudal to the group of the central gray (Fig. 31; 5j; 6a). This population was more conspicuous in L. oculatus than in L. platyrhincus and was coincident with the nitrergic cells of the rhombencephalic central gray (Fig. 6b). Several populations of NOS-ir, ChAT-ir, and CR-ir neurons were seen in the Rs, although no double-labeled cells were detected (Fig. 9e).

At mid rhombencephalic levels, the most prominent reticular NOS-ir group was found in the middle reticular nucleus (Rm; Fig. 2e, 3n, o, 6d), constituting of large and intensely immunoreactive multipolar cells (Fig. 2e, f). This group formed a long and continuous column from $\mathrm{r} 3$, coinciding with the caudal pole of the trigeminal mo- 


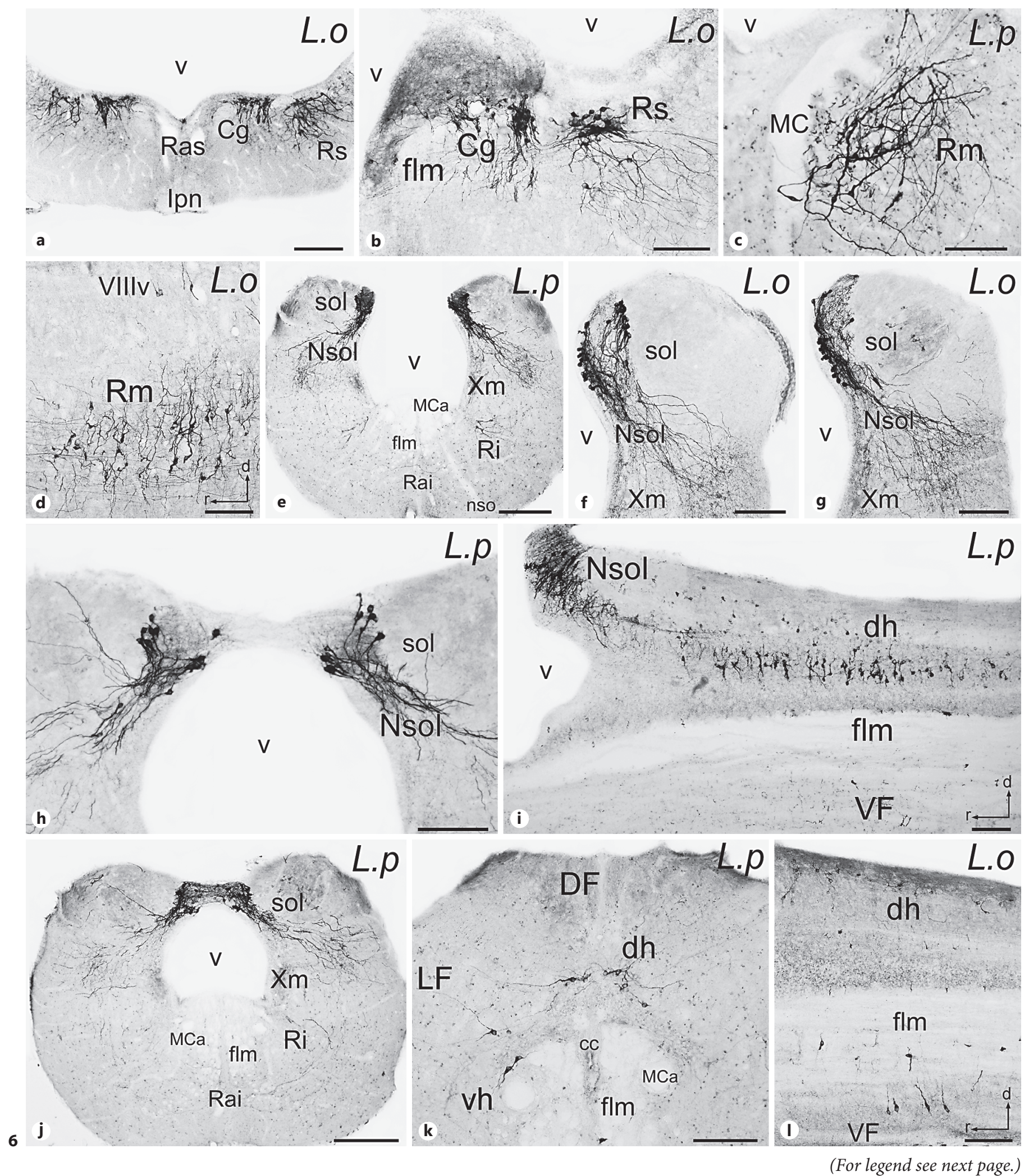


tor nucleus (Fig. 7h), to the caudal part of the abducens nucleus in r6 (Fig. 7i). In r4, this group was observed lateral to the giant Mauthner cells, which were devoid of nitrergic labeling (Fig. 6c). The reticular NOS-ir cells were intermingled with the CB-ir and CR-ir cell populations also found in the $\mathrm{Rm}$, but no double-labeled cells were observed (Fig. 9f, g). In the alar plate of the r3, a scarce group of moderate to intense NOS-ir cells was observed in the ventral octavolateral area, dorsal to the conspicuous Rm (Fig. 3n, o, 6d, 7h). The cells in this group extended caudally to the rostral pole of the abducens nucleus in r5, were more numerous in L. platyrhincus than in L. oculatus, and were intermingled with CB-ir and CRir cells without colocalization (Fig. 9f, g).

At caudal rhombencephalic levels, within the alar plate of r6-r8, a long column of nitrergic cells was observed medial and ventromedial to the solitary tract, in the nucleus of the same name (Nsol; Fig. 3p-s, 6e, h, i, 7l-n). This group extended caudal to the obex and was formed by small and strongly immunoreactive cells with long ventrolateral processes, some of which crossed in the midline (Fig. 2g, 6e-h, j, 7n). Some of these nitrergic cells were situated near the ventricle, whereas other slightly larger cells were observed in inner locations (Fig. $2 \mathrm{~g}, \mathrm{~h}$, $6 f)$. In addition, a few cells were intermingled with the fibers coursing in the solitary tract (Fig. 6g). At the level of the glossopharyngeal motor nucleus, the nitrergic cells of Nsol were located medially to the cholinergic cells of the nucleus intermedius of the octavolateral zone [Morona et al., 2013; present results]. TH-ir and CB-ir cell populations were also present in the Nsol, and only some double-labeled cells were detected in the caudal part of the nitrergic column, near the obex, that also received a strong serotoninergic innervation (Fig. 9m). The TH-ir and CR-ir cells of Nsol were located ventrally to the nitrergic cell population (Fig. 9h, i, l), whereas the CB-ir cells were highly intermingled with the NOS-ir cells (Fig. 9j, k).

Finally, a scarce cell group was NOS-ir in the caudal reticular formation ( $\mathrm{r} 8)$ in the inferior reticular nucleus (Ri; Fig. 3r, s). This group of small and moderately reac-

Fig. 6. Photomicrographs of transverse (a-c, e-h, j, $\mathbf{k}$ ) and sagittal $(\mathbf{d}, \mathbf{i}, \mathbf{I})$ sections through the rhombencephalon and spinal cord of L. oculatus (L.o.) and L. platyrhincus (L.p.; indicated in the upper right corner of each photomicrograph), illustrating NADPH-dpositive cell bodies and fibers in the Rs and central gray (a, b), Rm (c, d), Nsol (e-j), and spinal cord (i, $\mathbf{k}, \mathbf{l})$. See list of abbreviations. Scale bars, $100 \mu \mathrm{m}(\mathbf{b}-\mathbf{d}, \mathbf{f}-\mathbf{i}, \mathbf{k}, \mathbf{I}), 200 \mu \mathrm{m}(\mathbf{a}, \mathbf{e}, \mathbf{j})$.

Nitrergic Neuronal System in Holosteans tive cells (Fig. 6e) was more numerous in L. platyrhincus than in L. oculatus, and extended caudally to the obex (Fig. 6j). These cells were intermingled with the cholinergic population of the Ri [Morona et al., 2013; present results], but no double-labeled cells were found (Fig. 7j).

\section{Spinal Cord}

The spinal cord of both species was studied along its rostrocaudal extent revealing a nitrergic cell population situated in the dorsal horn of the spinal gray (Fig. 3t). These small cells with moderate to intense immunoreactivity showed long lateral and laterodorsal processes (Fig. 6k), and formed a long column in the dorsal horn, more numerous in L. platyrhincus than in L. oculatus (Fig. 6i, l), from rostral to caudal spinal levels, although the number of nitrergic cells clearly decreased caudally (Fig. 7p). Some of these cells were doubly labeled with CR. In addition, nitrergic cells with long lateral and lateroventral processes were detected in the ventral horn and intermediate spinal gray (Fig. 6k, 1), but the large cholinergic neurons of the ventral somatomotor column lacked nitrergic labeling (Fig. 7p, q). Scarce NOS-ir cells were observed in the midline or around the fasciculus longitudinalis medialis in the ventral aspect of spinal cord (Fig. 7o). In double immunohistofluorescence experiments, these cells were doubly labeled with CB (Fig. 9n). The spinal catecholaminergic and serotonergic cells, located ventral to the central canal and with liquor contacting processes [Chiba and Oka, 1999; present results], were clearly separated from the NOS-ir cells (Fig. 7o), confirming separated populations of spinal nitrergic and monoaminergic cells.

The nitrergic innervation was more prominent in rostral than caudal spinal levels, and was abundant in the dorsal and lateral funiculi (Fig. 3t, 6k) and reduced in the ventral funiculus. Most of this innervation probably represented the caudal continuation of the nitrergic fiber tracts observed in the ventrolateral aspect of the rhombencephalon (Fig. $3 \mathrm{~m}-\mathrm{s}$ ), mainly arising in the NOS-ir reticular nuclei.

\section{Retina}

The presence of nitrergic cells in the retina of gars was demonstrated using the immunodetection of NOS and the NADPH-d histochemical techniques. Thus, a population of nitrergic amacrine cells was detected in the inner nuclear layer (INL; Fig. 7r, s, 9o). These cells of round aspect showed short processes that entered the inner plexiform layer. No nitrergic ganglion cells, bipolar cells or displaced amacrine cells within the ganglion cell layer were detected in the retina of the 2 species studied. Dou- 


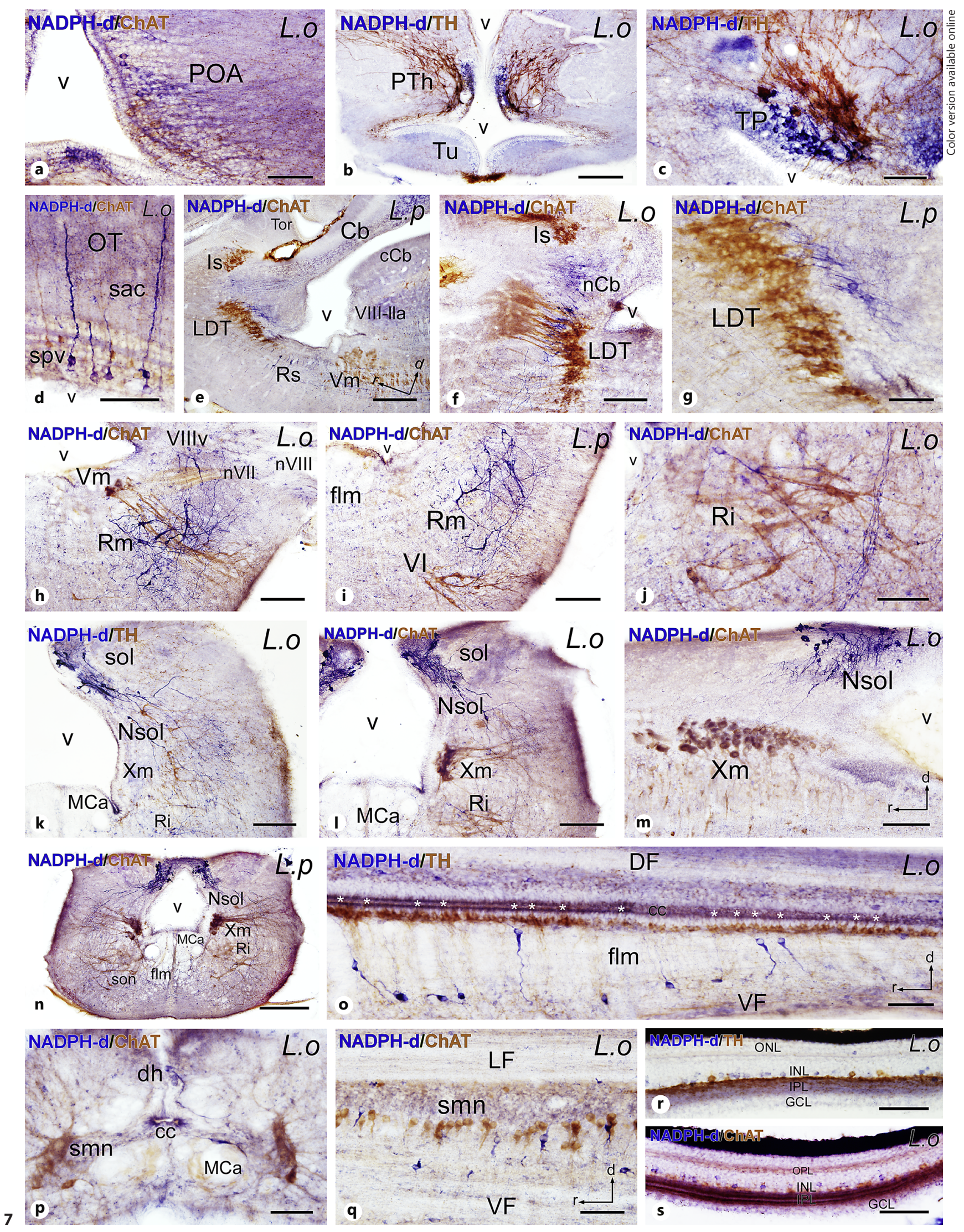

(For legend see next page.) 
ble-labeling experiments revealed other subpopulations of TH-ir, ChAT-ir, 5-HT-ir, CB-ir, and CR-ir amacrine cells in the inner nuclear layer. The catecholaminergic and serotonergic amacrine cells were larger in size and less numerous than the nitrergic cells (Fig. 7r, 9o), whereas the CB-ir, CR-ir, and cholinergic amacrine subpopulations were more abundant and highly intermingled with the NOS-ir cell subpopulation (Fig. 7s). All these retinal cells generally formed separated amacrine subpopulations with the exception of some nitrergic cells doubly labeled with CR (Fig. 9p).

\section{Discussion}

The present study on the brain of the small fish group of holosteans expands the knowledge of the organization of the nitrergic system in vertebrates from the point of view of comparative neuroanatomy. The phylogenetic position of this group of fishes is important in the analysis of primitive brain features likely present in the earliest neopterygian fishes. Although the actual NOS protein has not yet been isolated and characterized in this group, the control series of experiments and the similar and conserved structure of this enzyme through vertebrates [Andreakis et al., 2011] support the specificity of NOS immunodetection. In addition, the pattern of labeling obtained with the NADPH-d histochemical technique matches that of NOS immunohistochemistry, with mismatches only observed in the olfactory system and terminal nerve of $L$. oculatus, strongly reactive for NADPH-d histochemistry but NOS immunonegative. The general colocalization of NOS immunolabeling and NADPH-d activity in the same neuronal elements supports that NOS catalytic activity is revealed by the NADPH-d staining [Darius et al., 1995]. This is reinforced by the lack of $\mathrm{NADPH}-\mathrm{d}$ staining observed in transgenic knockout

Fig. 7. Photomicrographs of transverse (a-d, $\mathbf{f}-\mathbf{I}, \mathbf{n}, \mathbf{p}, \mathbf{r}, \mathbf{s})$ and sagittal $(\mathbf{e}, \mathbf{m}, \mathbf{o}, \mathbf{q})$ double-labeled sections through the brain, spinal cord, and retina of L. oculatus (L.o.) and L. platyrhincus (L.p.; see the upper right corner of each photomicrograph), showing staining for NADPH-d (blue) and TH or ChAT (brown), indicated in the upper left corner of each photomicrograph. The relationship between the distinct reactive elements is illustrated for the preoptic area (a), prethalamus (b), TP (c), optic tectum (d), LDT (e-g), Rm $(\mathbf{h}, \mathbf{i})$, Ri (j), Nsol (k-n), spinal cord $(\mathbf{o}-\mathbf{q})$, and retina $(\mathbf{r}, \mathbf{s})$. The asterisks in $\mathbf{o}$ indicate CSF-contacting cell processes to the central canal. See list of abbreviations. Scale bars, $50 \mu \mathrm{m}(\mathbf{a}, \mathbf{c}, \mathbf{d}, \mathbf{g}, \mathbf{j}, \mathbf{0}-\mathbf{s})$, $100 \mu \mathrm{m}(\mathbf{f}, \mathbf{h}, \mathbf{i}, \mathbf{k}-\mathbf{m}), 200 \mu \mathrm{m}(\mathbf{b}, \mathbf{e}, \mathbf{n})$. See online version for colors.

Nitrergic Neuronal System in Holosteans mice for NOS [Huang et al., 1993]. The lack of correlation in the olfactory system, noted in several species, including cladistians, teleosts, amphibians, and mammals [González et al., 1996; Porteros et al., 1996; Virgili et al., 2001; López and González, 2002; Moreno et al., 2002; Giráldez-Pérez et al., 2008, 2013; López et al., 2016], was explained by the presence of cytochrome P-450 reductase, which has close homology with NOS [Bredt et al., 1991] and presents NADPH-d activity. It should be mentioned that although we have referred here to "terminal nerve" fibers, it might be the case that these fibers represent extrabulbar olfactory projections, demonstrated for other actinpterygians and amphibians [Pinelli et al., 2004; Gayoso et al., 2011]. Of note, in some cases mismatches between both techniques were noted in the cerebral cortex [Kharazia et al., 1994; Sobreviela and Mufson, 1995] and spinal cord [Vizzard et al., 1994] of mammals. However, these mismatches are not observed in the pallium or spinal cord of gars. Furthermore, in the rainbow trout, NADPH-d staining was reported in oligodendrocytes [Pérez et al., 1996] but they were not labeled in our study. For reasons of comparability, the methods used in this study were the same as in our former studies. The detailed pattern of the nitrergic system obtained in the 2 species of the genus Lepisosteus enables direct comparison with the profuse data in other groups of vertebrates (Table 2), thus highlighting shared and derived traits of its organization. According to the organization of the results, the pattern of distribution of nitrergic cell bodies and fibers is discussed below following a regional rostrocaudal order.

\section{Forebrain}

The olfactory bulbs in holosteans, like in cladistians, chondrosteans, and some teleosts, arise as rostral evaginations of the telencephalic hemispheres and enclose central ventricles. NOS-ir cells or fibers were not observed in the olfactory bulbs of gars, in line with results obtained in most actinopterygians [López et al., 2016]. However, nitrergic cells in the olfactory bulbs have been reported in a teleost fish [Singru et al., 2003], a cartilaginous fish [Ferrando et al., 2012], a lungfish [Northcutt, 2009a], and urodele and gymnophionan amphibians [González et al., 1996, 2002b]. In addition, they are present in all species of mammals studied [Kishimoto et al., 1993; Hopkins et al., 1996; Kendrick et al., 1997; Alonso et al., 1998]. Consequently, this is a variable feature that appears several times in evolution, and it is generally absent in actinopterygian fishes.

Holosteans have hemispheric hypertrophy and in gars the dorsal (pallial) part shows slight eversion [Northcutt 


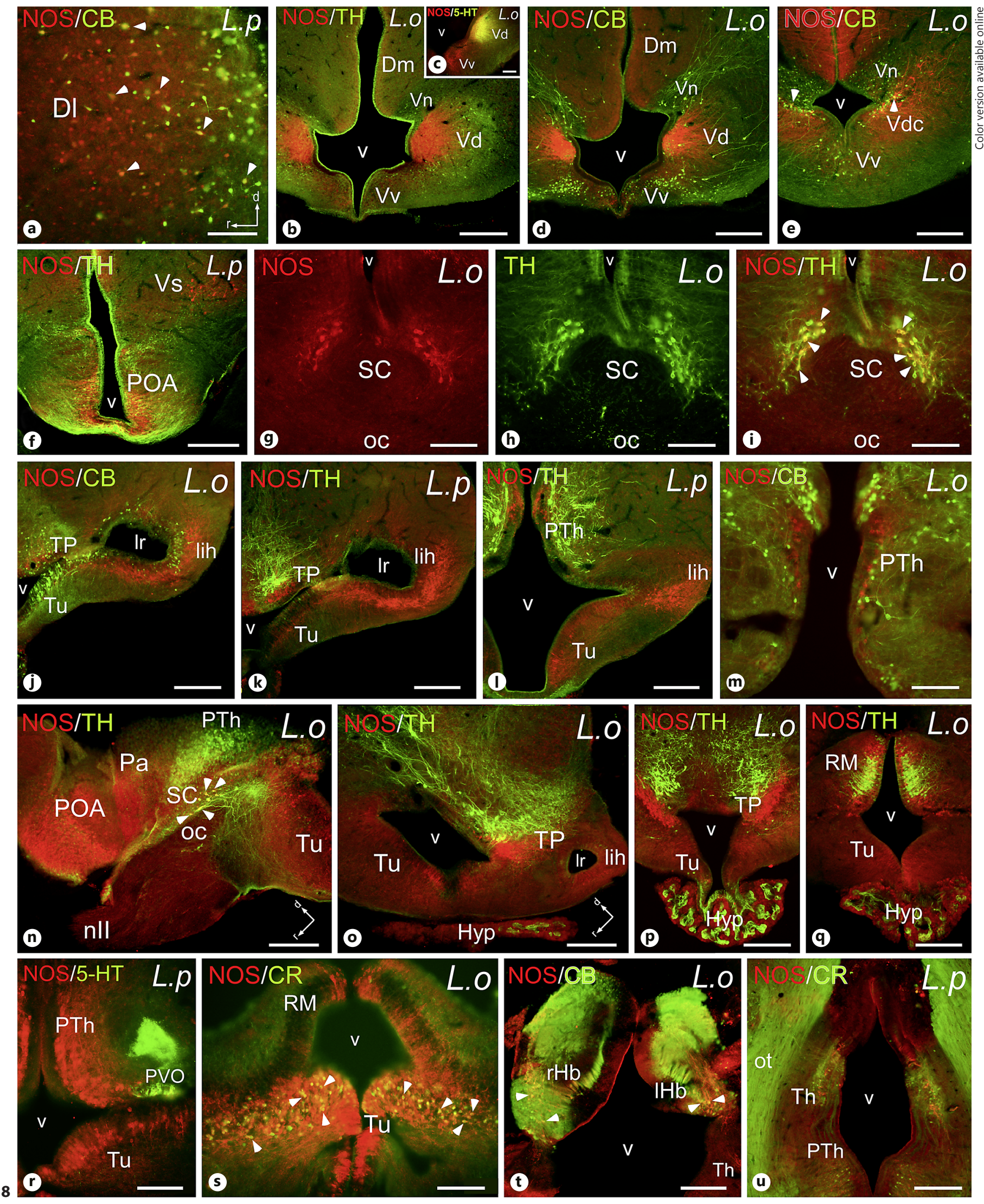

(For legend see next page.) 
and Braford, 1980]. In the pallium, gars possess scattered and faintly NOS-ir cells separated from the ventricle in the lateral zone of the dorsal telencephalic area (Dl), largely comparable to the nitrergic population observed in the pallial field P3 of cladistians [López et al., 2016]. In teleosts, a common pattern is seen in the pallium with nitrergic cells in the $\mathrm{Dl}$ and in dorsal and medial zones of the dorsal telencephalic area, although in some species the total lack of nitrergic elements in the pallium has been reported [Arévalo et al., 1995; Gaikwad et al., 2009]. Because of the eversion process, the pallial $\mathrm{Dl}$ of gars, as the pallial P3 of cladistians, has been interpreted as the homolog of the medial pallium of the noneverted telencephalon of tetrapods [Bruce and Braford, 2008; Braford, 2009; Nieuwenhuys, 2011], and the presence of similar scattered nitrergic cells described in the medial pallium of lungfishes [González and Northcutt, 2009] and amphibians [González et al., 1996; Muñoz et al., 1996; López et al., 2002] supports this homology. Comparatively, in vertebrates (Table 2) the presence of pallial/cortical nitrergic cells seems to be a general pattern. However, using only the NADPH-d method, putative pallial nitrergic cells were not detected in larval lampreys [Schober et al., 1994a], 2 species of teleosts, and 2 reptiles [Bennis et al., 1996; Jiang and Terashima, 1996]. As demonstrated in mammals, the pallial/cortical nitrergic cells constitute an important population of interneurons that regulate the neuronal activity by lateral inhibition and are involved in synaptic plasticity [Shlosberg et al., 2012].

Almost all subpallial regions in the telencephalon of gars possess remarkable populations of nitrergic cells, with the exceptions of the Vn and VL nuclei of the ventral telencephalic area, which form a c-shaped configuration exclusive of this group of fishes [Braford, 2009]. The dorsorostral Vd showed similar staining patterns for TH, 5-HT, and calcium binding proteins as in Polyp-

Fig. 8. Photomicrographs of transverse (b-m, p-u) and sagittal (a, $\mathbf{n}, \mathbf{0}$ ) double-labeled sections through the brain of L. oculatus (L.o.) and L. platyrhincus (L.p.; see the upper right corner of each photomicrograph), showing staining for NOS (red fluorescence) and $\mathrm{TH}, 5-\mathrm{HT}, \mathrm{CB}$ or CR (green fluorescence), indicated in the upper left corner of each photomicrograph. The relationship between the immunoreactive cell populations is illustrated for the $\mathrm{Dl}(\mathbf{a})$, the rostral and caudal parts of $\mathrm{Vd}(\mathbf{b}-\mathbf{e})$, the preoptic area (f), the suprachiasmatic nucleus $(\mathbf{g}-\mathbf{i}, \mathbf{n})$, the tuberal hypothalamus $(\mathbf{j}, \mathbf{s}), \mathrm{TP}$ $(\mathbf{j}, \mathbf{k}, \mathbf{o}, \mathbf{p})$, the prethalamus $(\mathbf{I}, \mathbf{m}, \mathbf{r})$, retromammillary hypothalamic area $(\mathbf{q}, \mathbf{s})$, the habenula $(\mathbf{t})$, and the thalamus $(\mathbf{u})$. Doublelabeled cells in $\mathbf{a}, \mathbf{e}, \mathbf{i}, \mathbf{n}, \mathbf{s}$, and $\mathbf{t}$ are indicated with arrowheads. See list of abbreviations. Scale bars, $100 \mu \mathrm{m}(\mathbf{a}, \mathbf{c}, \mathbf{g}-\mathbf{i}, \mathbf{m}, \mathbf{r}, \mathbf{s}), 200 \mu \mathrm{m}$ $(\mathbf{b}, \mathbf{d}-\mathbf{f}, \mathbf{j}-\mathbf{I}, \mathbf{n}-\mathbf{q}, \mathbf{t}, \mathbf{u})$. See online version for colors.

Nitrergic Neuronal System in Holosteans terus [Chiba and Oka, 1999; González et al., 2014; López et al., 2016; present results], and the distribution of several transcription factors strengthened its homology with the striatum [González et al., 2014]. The conspicuous nitrergic staining observed in our study and in a previous analysis of this region [Braford, 2009] strongly supports this homology. However, the Vdc, which contains fewer nitrergic cells, is strongly NADPH-d reactive, and often coexpresses CB, seems to represent a distinct region. Comparison with similarly stained regions in topologically homologous subpallial areas leads to the proposition that the $\mathrm{Vdc}$ represents the central amygdala (striatal part of the amygdaloid complex) of other vertebrates [Moreno and González, 2005a; González and Northcutt, 2009].

In a previous study, staining for the transcription factor Nkx2.1 showed an intense labeling of the ventricular zone of all ventral parts of the ventral telencephalic area at mid and caudal levels, and the dorsal limit of expression marked the boundary with the region identified as the striatum of gars [González et al., 2014]. By comparison with tetrapods, this Nkx2.1-labeled region is topologically the counterpart of the septopallidal region of tetrapods [Moreno et al., 2009; Medina et al., 2014]. Therefore, the nitrergic cell populations observed in the $\mathrm{Vv}$ in our study would correspond to the septopallidal populations observed in tetrapods (Table 2). The nitrergic cells located in the Vs might correspond to similar cells in the medial amygdala of lungfishes and tetrapods because of its position and expression of specific transcription factors, such as Otp (orthopedia) [Moreno and González, 2003; Bardet et al., 2008; González et al., 2014]. In turn, the conspicuous nitrergic cells in the $\mathrm{Vp}$ might represent the lateral amygdala (pallial component of the amygdaloid complex), which in lungfishes and amphibians is characterized by a conspicuous population of nitrergic cells [Moreno and González, 2004, 2006, 2007a, b; González and Northcutt, 2009]. According to this view, the $\mathrm{Vn}-\mathrm{Vp}$ complex would constitute the ventral pallial region in gars, and not the medial zone of the dorsal telencephalic area, as was previously proposed [Braford, 2009]. However, previous hodological studies challenge this proposal since torus lateralis projections to the medial zone of the dorsal telencephalic area (and not to VnVp) have been described in gars [Northcutt, 2009b]. It should be noted that the homologies proposed are based on the scarce data available in holosteans and it is clear that more neurochemical, hodological, and developmental data are needed to confirm these ideas. Comparatively, with the special exception of the larval lamprey that lacks

Brain Behav Evol 2017;89:117-152 

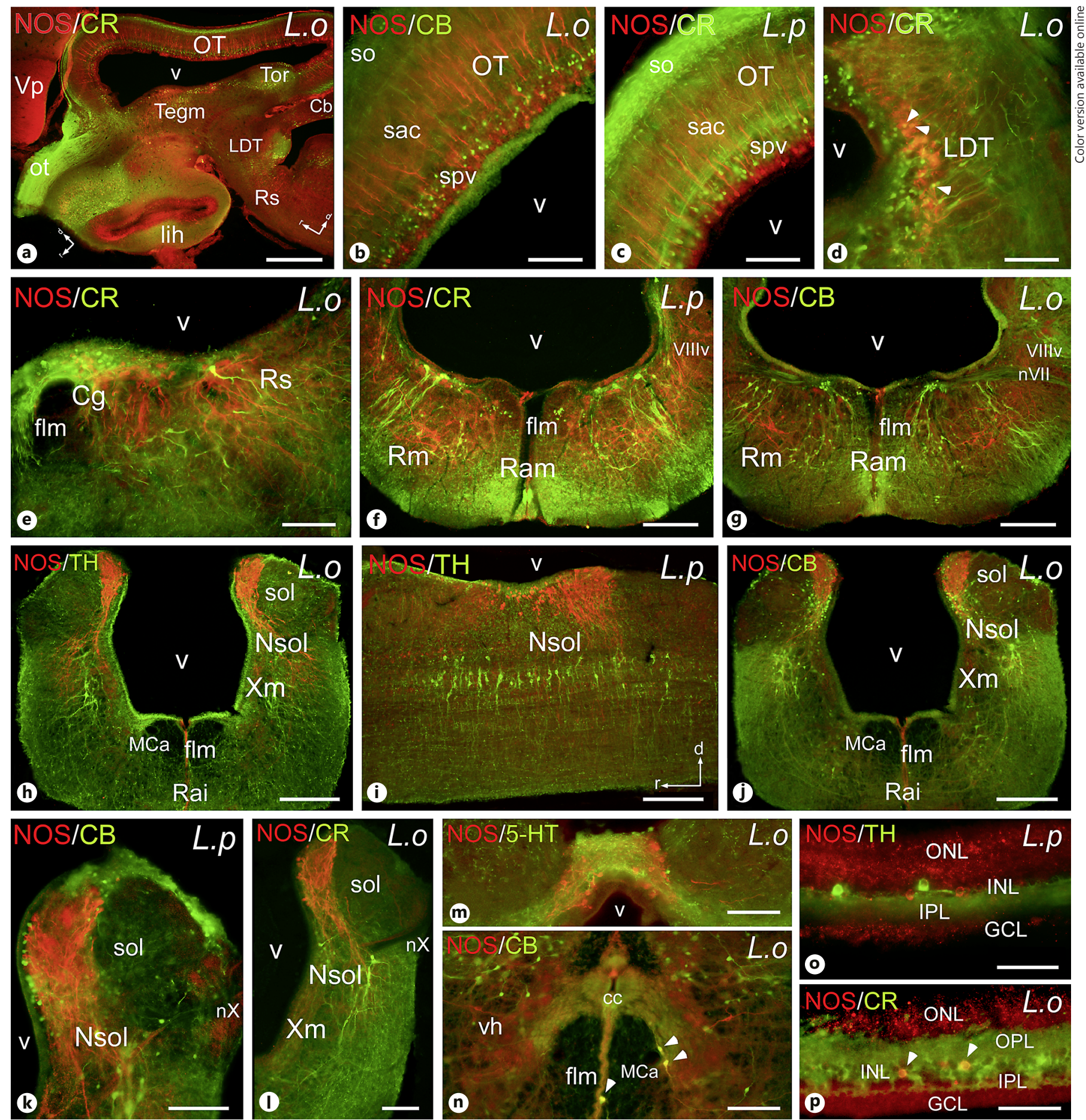

Fig. 9. Photomicrographs of transverse ( $\mathbf{b}-\mathbf{h}, \mathbf{j}-\mathbf{p})$ and sagittal (a, i) double-labeled sections through the brain and retina of $L$. oculatus (L.o.) and L. platyrhincus (L.p.; see the upper right corner of each photomicrograph), showing staining for NOS (red fluorescence) and TH, 5-HT, CB or CR (green fluorescence), indicated in the upper left corner of each photomicrograph. The relationship between the immunoreactive cell populations is illustrated for the inferior hypothalamic lobe (a), the optic tectum $(\mathbf{b}, \mathbf{c})$, the LDT (d), the Rs and central gray (e), the Rm $(\mathbf{f}, \mathbf{g})$, the Nsol (h-m), the spinal cord (n), and the amacrine cells in the retina $(\mathbf{o}, \mathbf{p})$. Arrowheads in $\mathbf{d}, \mathbf{n}$, and $\mathbf{p}$ indicate double-labeled cells. See list of abbreviations. Scale bars, $50 \mu \mathrm{m}(\mathbf{o}, \mathbf{p}), 100 \mu \mathrm{m}(\mathbf{d}, \mathbf{e}, \mathbf{k}-\mathbf{n}), 200 \mu \mathrm{m}$ (b, c, $\mathbf{f}-\mathbf{j}), 500 \mu \mathrm{m}(\mathbf{a})$. See online version for colors. 


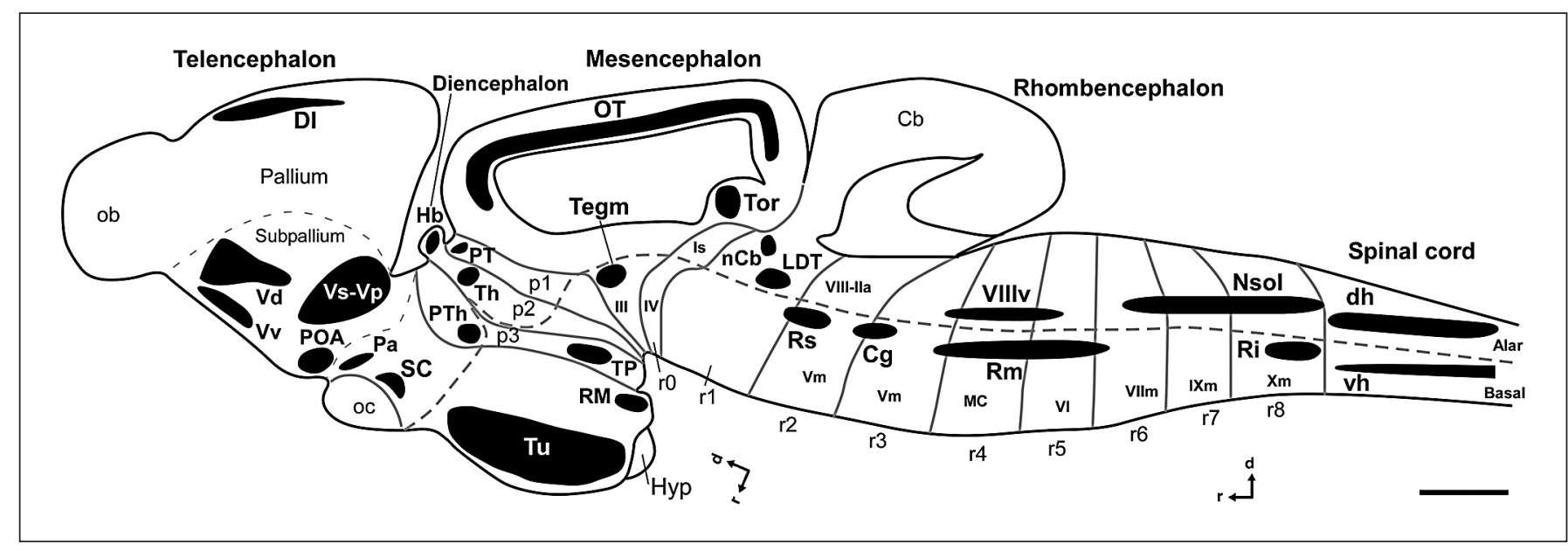

Fig. 10. Schematic reconstruction of the sagittal series of sections of the brain showing the locations of the nitrergic cell groups in L. platyrhincus according to a segmental interpretation of the brain. See list of abbreviations.

nitrergic subpallial cells [Schober at al., 1994a], the existence of nitrergic cells in the subpallium is a commonly observed feature in the brain of vertebrates (Table 2), in line with the known relevant function of $\mathrm{NO}$ in motor control [West and Grace, 2000; Lorenc-Koci and Czarnecka, 2013] and in emotion/behavior control [Gulati and Ray, 2014].

The preoptic area of gars houses a remarkable population of nitrergic cells distinct from the TH-ir, ChAT-ir, and $\mathrm{CB}$-ir populations also observed in this region. The presence of nitrergic cells in the preoptic area is a highly conserved feature observed in all anamniotes studied (Table 2), whereas it is a more variable feature in amniotes, being present in birds [Brüning, 1993; Cozzi et al., 1997; Atoji et al., 2001] and some species of reptiles [Smeets et al., 1997] and mammals [Hadeishi and Wood, 1996; Domínguez et al., 2006; Nutsch et al., 2014], where the role of NO in sexual behavior has been demonstrated [Nutsch et al., 2014]. It should be noted that gene expression data have highlighted that the preoptic area does not belong to the hypothalamus but it is part of the subpallial telencephalic territory [see Moreno and González, 2011; Domínguez et al., 2015] that is topologically adjacent to the dorsal hypothalamic territory, and similar observations have been obtained for gars [González et al., 2014].

In our description of the results, we have considered the main hypothalamic alar and basal regions currently interpreted by the prosomeric model [Puelles and Rubenstein, 2015]. From dorsal to caudal, the paraventricular and subparaventricular subdivisions constitute the alar hypothalamus, and tuberal and mammillary regions form the basal portion. Within the paraventricular area of gars only a small group of nitrergic cells is slightly immunoreactive and projections to the hypophysis could not be confirmed. Comparatively, intensely NOS-ir cells are present in the paraventricular area of cladistians [López et al., 2016] and their projections could be followed towards the neurohypophysis. Similar nitrergic groups with hypothalamo-hypophysial projections have been reported in the electric ray [Pérez et al., 1995], in the teleost Clarias batrachus [Gaikwad et al., 2009], and in anuran amphibians [Allaerts et al., 1997; Prasada Rao et al., 1997], although some amphibian species may lack nitrergic cells in the paraventricular region [Pinelli et al., 2014]. In mammals, the NADPH-d-reactive cells of the neurosecretory hypothalamic nuclei coexpress vasopressin/oxytocin [Arévalo et al., 1992; Miyagawa et al., 1994; Sánchez et al., 1994], where the NO probably regulates the release of these neurohormones [Vanhatalo and Soinila, 1995], whereas this colocalization is absent in the hypothalamus of birds [Sánchez et al., 1996].

Nitrergic cells in the subparaventricular area of gars are found in the suprachiasmatic nucleus, the cells of which predominantly coexpress $\mathrm{TH}$. Compared to other vertebrates, the presence of nitrergic cells in the suprachiasmatic nucleus is a generally conserved feature (Table 2) that has been reported in most species of teleosts and reptiles, although with some exceptions [Jiang and Terashima, 1996; Gaikwad et al., 2009], in birds and some species of amphibians [Lázár and Losonczy, 1999; González et al., 
Table 2. Summary of the distribution of nitrergic cells in different areas of the CNS of the vertebrate groups studied

\begin{tabular}{|c|c|c|c|c|c|c|c|c|c|c|c|}
\hline & Agnathans & $\begin{array}{l}\text { Chondrich- } \\
\text { thyes }\end{array}$ & Cladistians & $\begin{array}{l}\text { Chondros- } \\
\text { teans }\end{array}$ & Gars & Teleosts & $\begin{array}{l}\text { Lungfis- } \\
\text { hes }\end{array}$ & $\begin{array}{l}\text { Amphibi- } \\
\text { ans }\end{array}$ & Reptiles & Birds & $\begin{array}{l}\text { Mam- } \\
\text { mals }\end{array}$ \\
\hline Olfactory bulb & - & + & - & $?$ & - & $+/-$ & + & $+/-$ & - & - & + \\
\hline Pallium/cortex & - & $?$ & + & $?$ & + & $+/-$ & + & + & $+/-$ & + & + \\
\hline Striatum & - & $?$ & + & $?$ & + & $+/-$ & + & + & $+/-$ & + & + \\
\hline Septum & - & $?$ & + & $?$ & + & $+/-$ & + & + & $+/-$ & + & $+/-$ \\
\hline Pallidum & - & $?$ & + & $?$ & + & $+/-$ & + & + & $+/-$ & + & $+1-$ \\
\hline Amygdaloid complex & - & $?$ & + & $?$ & + & $+/-$ & + & + & $+/-$ & + & + \\
\hline Preoptic area & - & $?$ & + & $?$ & + & + & + & + & $+/-$ & + & $+/-$ \\
\hline Paraventricular area & - & + & + & $?$ & + & + & $?$ & $+/-$ & + & + & + \\
\hline Suprachiasmatic nucleus & - & $?$ & + & $?$ & + & $+/-$ & $?$ & $+/-$ & $+/-$ & + & $+/-$ \\
\hline Basal hypothalamus & - & $?$ & + & + & + & + & $?$ & + & $+/-$ & + & + \\
\hline Hypophysis & - & $?$ & - & $?$ & - & $+1-$ & $?$ & - & $?$ & $?$ & $+1-$ \\
\hline Prethalamus & - & $?$ & + & - & + & $+/-$ & $?$ & $+/-$ & - & - & $+/-$ \\
\hline Habenula & + & $?$ & + & $?$ & + & $+/-$ & $?$ & $+/-$ & - & $+/-$ & - \\
\hline Thalamus & - & $?$ & + & + & + & $+/-$ & $?$ & $+/-$ & $+1-$ & $+/-$ & $+1-$ \\
\hline Pretectum & - & $?$ & - & $?$ & + & $+/-$ & $?$ & $+/-$ & $+/-$ & + & $+/-$ \\
\hline Posterior tubercle VTA/substantia nigra & $?$ & $?$ & + & $?$ & + & $+/-$ & $?$ & $+/-$ & $+/-$ & + & $+/-$ \\
\hline Optic tectum/superior colliculus & $?$ & $?$ & + & + & + & + & $?$ & + & + & + & + \\
\hline Torus semicircularis/inferior colliculus & $?$ & $?$ & + & $?$ & + & + & ? & + & $+/-$ & $+/-$ & $+1-$ \\
\hline Mesencephalic tegmentum & $?$ & $?$ & + & $?$ & + & + & $?$ & + & + & + & + \\
\hline Interpeduncular nucleus & $?$ & $?$ & + & $?$ & - & $+/-$ & $?$ & $+1-$ & $+/-$ & + & $+/-$ \\
\hline Cerebellum & $?$ & $?$ & - & + & - & + & $?$ & $+/-$ & $+1-$ & $+/-$ & + \\
\hline Cerebellar nucleus & $?$ & + & + & $?$ & + & $?$ & $?$ & $+/-$ & $+1-$ & $+/-$ & $+1-$ \\
\hline \multicolumn{12}{|l|}{ Nonmotor nuclei in the upper } \\
\hline rhombencephalon: LDT/PPT/Rs & $?$ & $?$ & - & $?$ & - & $+/-$ & $?$ & + & + & + & + \\
\hline Locus coeruleus & $?$ & $?$ & - & $?$ & - & $+/-$ & $?$ & - & - & $+/-$ & - \\
\hline Reticular formation & + & $?$ & + & + & + & + & $?$ & + & + & + & + \\
\hline Octavolateral area & $?$ & $?$ & + & $?$ & + & + & $?$ & $+/-$ & $+/-$ & + & + \\
\hline Raphe nuclei & $?$ & $?$ & - & $?$ & - & $+/-$ & $?$ & $+/-$ & $+/-$ & $+/-$ & $+/-$ \\
\hline Motor nuclei of the cranial nerves & $?$ & $?$ & - & $?$ & - & $+/-$ & $?$ & $+/-$ & $+1-$ & $+/-$ & $+1-$ \\
\hline Solitary tract nucleus & $?$ & $?$ & + & $?$ & + & $+/-$ & $?$ & $+/-$ & $+/-$ & + & $+/-$ \\
\hline Spinal cord & + & $?$ & + & $?$ & + & + & $?$ & + & + & + & + \\
\hline Retina & $?$ & + & + & $?$ & + & + & $?$ & + & + & + & + \\
\hline
\end{tabular}

+ , presence of NOS-ir cells; -, absence of NOS-ir cells; +/-, presence of NOS-ir cells in some species of the group; ?, no data available; PPT, pedunculopontine tegmentum.

References: agnathans: Schober et al., 1994a; Kyriakatos et al., 2009; chondrichthyes: Shiells and Falk, 1992; Pérez et al., 1995; Álvarez-Otero et al., 1996; Funakoshi et al., 1997; Ferrando et al., 2012; Pose-Mendez et al., 2014; cladistians: López et al., 2016; chondrosteans: Pushchina and Obukhov, 2012; teleosts: Holmqvist et al., 1994, 2000; Ostholm et al., 1994; Arévalo et al., 1995; Brüning et al., 1995; Anken and Rahmann, 1996; Cioni et al., 1997; Pottek et al., 1997; Funakoshi et al., 1999; Baby et al., 2000; Oyan et al., 2000; Haamedi and Djamgoz, 2002; Bordieri et al., 2003, 2005; Singru et al., 2003; Ando et al., 2004; Bordieri and Cioni, 2004; Pushchina and Diǔzzen, 2004; Pushchina, 2007; Pushchina et al., 2007; Giráldez-Pérez et al., 2008, 2013; Gaikwad et al., 2009; Pushchina and Obukhov, 2010; Ganz et al., 2012; lungfishes: Schober et al., 1994b; Northcutt, 2009; amphibians: Nöll et al., 1994; Crowe et al., 1995; Kurenni et al., 1995; Brüning and Mayer, 1996; González et al., 1996, 2002b; Muñoz et al., 1996, 2000; Lázár and Losonczy, 1999; López and González, 2002; Pisu et al., 2002; López et al., 2005; Huynh and Boyd, 2007; Blom et al., 2009; Pinelli et al., 2014; reptiles: Luebke et al., 1992; Brüning et al., 1994b; Bennis et al., 1996; Jiang and Terashima, 1996; Blute et al., 1997; Radmilovich et al., 1997; Smeets et al., 1997; Haverkamp et al., 1998, 2000; Cuenca et al., 2000; Cao and Eldred, 2001; Morona et al., 2006, 2007; birds: Brüning, 1993; Brüning et al., 1994a; Panzica et al., 1994; Cozzi et al., 1997; Yamakawa et al., 1997; Fischer and Stell, 1999; Atoji et al., 2001; Nie and Wang, 2002; Necker, 2004, 2005; Scicolone et al., 2006; Wilson et al., 2011; Tekmen-Clark and Gleason, 2013; mammals: Mizukawa et al., 1989; Skinner et al., 1989; Dun et al., 1992, 1993, 1994; Vincent and Kimura, 1992; Wolff and Datto, 1992; Terenghi et al., 1993; Egberongbe et al., 1994; Harper et al., 1994; Rodrigo et al., 1994; Vizzard et al., 1994, 1997; Amir et al., 1995; Darius et al., 1995; Lloyd et al., 1995; Satoh et al., 1995; Vanhatalo and Soinila, 1995; Hadeishi and Wood, 1996; Wang and Morris, 1996; Bertini and Bentivoglio, 1997; Desvignes et al., 1997; Alonso et al., 1998; Iwase et al., 1998; Léger et al., 1998; Doone et al., 1999; Ng et al., 1999; Fabris et al., 2000; Saxon and Beitz, 2000; Takumida and Anniko, 2000a, b; Varathan et al., 2001; Kluchová et al., 2002; Lukácová et al., 2002; Wu et al., 2002; Golombek et al., 2004; Gotti et al., 2005; Papantchev et al., 2005; Domínguez et al., 2006; Abe et al., 2010; Blom et al., 2012; Vielma et al., 2012; Bombardi et al., 2013; Chertok and Kotsuba, 2013; Czarnecka et al., 2013; Nutsch et al., 2014; Santos-Lobato et al., 2016.

2002b; Huynh and Boyd, 2007] and mammals [Amir et al., 1995; Wang and Morris, 1996; Agostino et al., 2004], but not in other species of these groups [Mizukawa et al., 1989; Vincent and Kimura, 1992; Egberongbe et al., 1994;
Brüning and Mayer, 1996; González et al., 1996; Pinelli et al., 2014]. The colocalization of NOS and TH in the suprachiasmatic neurons of gars seems to be a specific feature of this group of fishes, since it has not been observed 
by double-labeling techniques in cladistians, amphibians, and reptiles [Smeets et al., 1997; López et al., 2005, 2016].

Within the basal hypothalamus of gars, like in cladistians, nitrergic cell populations are located in the tuberal and mammillary areas. In particular, the brain part termed the retromammillary region houses an important nitrergic group that was demonstrated to be different from the catecholaminergic group (TH-ir) characteristically found in this region [López et al., 2016; present results]. The presence of nitrergic cells in specific locations of the basal hypothalamus is a shared and highly conserved feature reported in all vertebrate groups (Table 2), with the only exception reported in the snake Trimeresurus flavoviridis, which lacks NADPH-d-reactive cells in the whole basal hypothalamus [Jiang and Terashima, 1996]. In addition, the large inferior hypothalamic lobes of gars also show a prominent population of NOS-ir cells located in the nucleus of the lateral recess. This peculiar brain structure in the hypothalamus of teleosts shows similar nitrergic cells in the nucleus of the lateral recess, but also in the central and diffuse nuclei of the inferior hypothalamic lobes [Arévalo et al., 1995; Brüning et al., 1995; Bordieri et al., 2003; Ando et al., 2004; GiráldezPérez et al., 2008], with the exceptions of C. batrachus and Haplochromis burtoni [Jadhao and Malz, 2004; Gaikwad et al., 2009]. The inferior hypothalamic lobes of teleosts are related to feeding and aggressive biting [Demski and Knigge, 1971], receiving indirect visual information from the pretectum [Wullimann and Meyer, 1990; Wullimann et al., 1991], taste information from secondary gustatory centers [Finger and Kanwal, 1992; Lamb and Caprio, 1993; Folgueira et al., 2003] and general visceral centers [Yoshimoto and Yamamoto, 2010; Kato et al., 2011] to produce a brainstem motor response that implicates activation of the trigeminal and facial motor nuclei. In addition, the nucleus of the lateral recess gives rise to descending projections to the secondary gustatory and visceral nuclei in the isthmic region [Yáñez et al., 2017], and, thus, the NO could modulate these input and output connections.

In relation to the hypothalamus, the hypophysis of gars is devoid of NOS-ir cells, as is also the case for most vertebrates studied (Table 2), although exceptions have been reported for some teleosts [Anken and Rahmann, 1996; Ando et al., 2004; Gaikwad et al., 2009] and mammals [Wolff and Datto, 1992; Lloyd et al., 1995].

In the diencephalon, the prethalamus in the rostral prosomere $\mathrm{p} 3$ contains a discrete group of nitrergic cells in periventricular locations, separated from prethalamic $\mathrm{TH}$-ir and CB-ir cell populations. Two groups of nitrergic cells in the prethalamus, also separated from $\mathrm{TH}$-ir and CB-ir cells, have been described in cladistians [López et al., 2016] and most teleosts studied also showed prethalamic nitrergic cells [Arévalo et al., 1995; Brüning et al., 1995; Ando et al., 2004; Giráldez-Pérez et al., 2008]. However, this feature appears only in some species of amphibians [Brüning and Mayer, 1996; Pinelli et al., 2014] and amniotes generally lack nitrergic prethalamic cells, with an exception found exclusively in the ventromedial thalamic nucleus of rats [Bertini and Bentivoglio, 1997]. Therefore, this trait seems to be a general feature present in actinopterygian fishes, whereas it is uncommon among tetrapods. The TP in the basal part of $\mathrm{p} 3$ houses the most prominent diencephalic NOS-ir cell group of gars, forming distinct and separated populations from the characteristic TH-ir and CB-ir cell populations observed in this brain area. Most of the species of cladistians, teleosts, and amphibians studied showed nitrergic cells in the TP, although a few exceptions have been noted [González et al., 1996; Gaikwad et al., 2009]. In the TP of teleosts, a dopaminergic cell group with ascending projections to the subpallium has been identified [Rink and Wulliman, 2001, 2002; Yamamoto et al., 2011], and it was considered equivalent to the ventral tegmental area/substantia nigra complex of amniotes. In amphibians, a comparable connectivity from $\mathrm{TP} /$ mesencephalic tegmentum to basal ganglia has been confirmed [Marín et al., 1998a, b]. Of note, some species of teleosts and anurans showed colocalization of NOS/TH in the TP [López et al., 2005; Pushchina and Obukhov, 2010]. Interestingly, NOS/TH colocalization was found in the ventral tegmental area/substantia nigra of reptiles and birds [Panzica et al., 1996; Smeets et al., 1997], whereas the presence of nitrergic cells in the substantia nigra of mammals remains controversial because lack of nitrergic reactivity was first described in rats, cats, and humans [Mizukawa et al., 1989; Vincent and Kimura, 1992; Egberongbe et al., 1994], but subsequent studies indicated the contrary, at least in mice and rats [Abe et al., 2010; Czarnecka et al., 2013].

In the dorsalmost part of alar p2, the asymmetric habenula of gars contains nitrergic cell populations in the ventrolateral part of the large right habenula and the smaller left habenula that are separated from the cholinergic population. In cladistians, nitrergic cells were only observed in the ventral part of left habenula also separated from the cholinergic population [López et al., 2016]. The presence of nitrergic cells in the habenula is variable in teleosts and amphibians. Thus, NOS-ir cells were observed dorsally located in the habenula of the goldfish and almost a third of them colocalized ChAT [Giráldez-Pérez 
et al., 2008, 2009], whereas in amphibians nitrergic cells have been described only in the ventral habenula of Rana and Dermophis [Muñoz et al., 1996; González et al., 2002b], and nitrergic habenular asymmetry was found only in R. esculenta [Guglielmotti and Fiorino, 1999]. Habenular nitrergic cells in amniotes seem rare and have been described in just 2 avian species [Brüning, 1993; Atoji et al., 2001]. The NO in the habenula could be implicated in the regulation of fear and the reward system [Agetsuma et al., 2010; Jesuthasan, 2012]. Also in the alar plate of p2 and ventral to the habenula, the thalamus of gars houses a modest nitrergic cell population in rostral and median diencephalic levels. The existence of nitrergic cells in the thalamus is a shared feature with other anamniotes, like cladistians, chondrosteans, teleosts, and amphibians (especially remarkable in anurans; Table 2), with the exceptions of the teleost C. batrachus [Gaikwad et al., 2009] and the urodele amphibian Pleurodeles waltl [González et al., 1996]. In contrast, this feature is unusual in amniotes, and it has only been reported in the thalamus of the lizard Gekko gecko [Smeets et al., 1997], in the Japanese quail and budgerigar [Panzica et al., 1994; Cozzi et al., 1997], and in the rat [Vincent and Kimura, 1992]. Therefore, the importance of NO in the thalamic relay of sensory information to the telencephalon seems to be more relevant in anamniotes than amniotes.

Finally, a small group of faintly NOS-ir cells is present in gars within the alar part of $\mathrm{p} 1$ in the pretectum, in the caudal diencephalon. In contrast, the pretectum of cladistians is devoid of nitrergic cells [López et al., 2016], whereas pretectal NOS-ir cells are common in teleosts and amphibians, although with some exceptions [Brüning et al., 1995; González et al., 1996; Pinelli et al., 2014]. This feature is also present in birds, and more rarely in reptiles and mammals, where pretectal cells have been described in a lizard [Smeets et al., 1997] and the rat [Vincent and Kimura, 1992].

\section{Midbrain}

Gars, like most teleosts, are highly visual predators with large, well-laminated optic tecta that mainly receive retinal projections [Northcutt and Butler, 1976, 1980, 1993]. An important nitrergic cell population is present in the inner zone of the periventricular layer of the optic tectum throughout its rostrocaudal and mediolateral extent. These cells are probably interneurons of type XIV morphology [Meek and Nieuwenhuys, 1998] and are intermingled with ChAT-ir, CB-ir, and CR-ir cells of similar morphology, but forming separated tectal subpopulations. Similar observations have been described in the op- tic tectum of cladistians [López et al., 2016] and teleosts, although in the goldfish up to a 3\% of NOS-ir cells in the optic tectum coexpress ChAT [Giráldez-Pérez et al., 2009]. The presence of nitrergic cells in periventricular tectal locations is a conserved feature observed in all groups of vertebrates (Table 2). However, in chondrostean fishes and birds there are also nitrergic cells in outer tectal layers [Brüning, 1993; Cozzi et al., 1997; Atoji et al., 2001; Scicolone et al., 2006; Pushchina and Obukhov, 2012], whereas in mammals these cells are present in inner, intermediate, and outer layers of the superior colliculus [Mizukawa et al., 1989; Vincent and Kimura, 1992; Egberongbe et al., 1994]. The tectal nitrergic cells are likely related to the processing of visual information, but may also be involved in multisensory integration, and in mammals these cells have been proposed to be interneurons that convey cortical influences onto superior colliculus output neurons [Fuentes-Santamaría et al., 2008].

Only modest numbers of nitrergic cells are detected in gars within the torus semicircularis and torus lateralis, as has also been observed in cladistians [López et al., 2016]. Toral nitrergic cells, likely intervening in the processing of auditory information [Grassi et al., 1995; Wu et al., 2008], have been reported in most groups of vertebrates (Table 2), although it should be noted that NADPH-d reactive neurons could not be demonstrated in the torus of the snake T. flavoviridis [Jiang and Terashima, 1996], the budgerigar Melopsittacus undulatus [Cozzi et al., 1997], and the cat [Mizukawa et al., 1989].

A prominent group of intensely NOS-ir cells is located within the rostral mesencephalic tegmentum of gars, and some of these cells also contain CR. Conversely, the large cholinergic neurons of the oculomotor nucleus lack nitrergic labeling. A comparable nitrergic cell population has been observed in the mesencephalic tegmentum of cladistians, although it was described in the mid and caudal levels [López et al., 2016]. All groups of vertebrates studied show a characteristic nitrergic cell population in the mesencephalic tegmentum, representing another primitive and conserved feature (Table 2). A shared feature of amniotes is the presence of the dopaminergic ventral tegmental area/substantia nigra (VTA/SN) complex in the midbrain tegmentum [Smeets and Gonzéz, 2000]. By means of double-labeling techniques, many of these dopaminergic cells have been demonstrated to coexpress NOS in some species of reptiles, birds, and mammals [Johnson and Ma, 1993; Panzica et al., 1996; Smeets et al., 1997]. However, as previously mentioned, the counterpart of the VTA/SN complex in gars most likely lies in the diencephalic TP, where abundant nitrergic cells are located. 


\section{Hindbrain}

The segmental organization of the rhombencephalon can be inferred in gars by the localization of the cholinergic motor nuclei and other well-established landmarks [Morona et al., 2013]. Thus, we have referred the localization of the nitrergic structures to the rhombomeres $0-8$ (r0-r8; Fig. 10). In the rostral rhombencephalon of gars, both the interpeduncular nucleus and the cerebellum (a dorsal derivative structure from $\mathrm{r} 1$ ) are devoid of nitrergic cells. The absence of this type of cell in the interpeduncular nucleus is a general feature observed in most anamniotes and reptiles, with the exceptions of cladistians [López et al., 2016], the teleost Carassius auratus [Giráldez-Pérez et al., 2008], the anuran amphibian Hyla septentrionalis [Pinelli et al., 2014], and the turtle Pseudemys scripta elegans [Brüning et al., 1994b]. In contrast, nitrergic cells were reported in all species of birds studied and in most mammals, with the remarkable exception of humans [Egberongbe et al., 1994]. The absence of cerebellar nitrergic cells is a variable trait reported in cladistians and gars [López et al., 2016; present results], in urodele and gymnophionan amphibians [González et al., 1996, 2002b], in a chameleon and a snake [Bennis et al., 1996; Jiang and Terashima, 1996], and in the pigeon [Atoji et al., 2001]. However, distinct nitrergic neurons were described in different cerebellar layers of a sturgeon [Pushchina and Obukhov, 2012], several teleosts [Arévalo et al., 1995; Brüning et al., 1995; Ando et al., 2004; GiráldezPérez et al., 2008], anurans [Lázár and Losonczy, 1999; Huynh and Boyd, 2007; Pinelli et al., 2014], reptiles [Brüning et al., 1994b; Smeets et al., 1997], birds [Brüning, 1993; Cozzi et al., 1997], and mammals [Vincent and Kimura, 1992; Egberongbe et al., 1994; Iwase et al., 1998].

Like in the early diverged cladistians, gars show a group of nitrergic cells in the alar part of $\mathrm{r} 1$, tentatively identified as a cerebellar nucleus according to its localization [López et al., 2016; present results], although hodological data are necessary to corroborate this designation. In elasmobranchs this nucleus is prominent and reactive for the NADPH-d histochemical technique [Álvarez-Otero et al., 1996; Pose-Méndez et al., 2014], whereas a similar nucleus has not been identified in teleosts. Nitrergic cells in cerebellar nuclei are more frequently described in tetrapods, including several species of amphibians [Lázár and Losonczy, 1999; Huynh and Boyd, 2007], reptiles [Brüning et al., 1994; Smeets et al., 1997], birds [Cozzi et al., 1997; Atoji et al., 2001], and mammals [Vincent and Kimura, 1992]. Therefore, the presence of nitrergic cerebellar nuclei in vertebrates supposes another variable feature.

Nitrergic Neuronal System in Holosteans
In the dorsal part of $\mathrm{r} 1$ of gars, another group of NOSir cells is observed close to the prominent group of ChATir cells identified as the LDT [Morona et al., 2013]. However, double-labeling experiments do not show nitrergic labeling in the cholinergic cells of this nucleus, in line with results obtained recently in cladistians [López et al., 2016]. In contrast, the LDT and its related pedunculopontine tegmental nucleus contain both ChAT and NOS in amphibians [González et al., 1996; Muñoz et al., 1996, 2000; Marín et al., 1997; González et al., 2002a, 2002b; López and González, 2002] and amniotes [Alonso et al., 2000; Veleanu et al., 2016]. This cholinergic and nitrergic complex is implicated in the control of the sleep-wake cycle, learning, motor control, and reward system [Wang and Morales, 2009], and given the absence of colocalization of NOS in the ChAT-ir cells of the LDT found in nontetrapod vertebrates, gars could represent a primitive neurochemical feature of this important cholinergic group.

The rhombencephalic reticular formation of the 2 species studied contains 3 subpopulations of nitrergic cells in the superior and middle nuclei (Rs and $\mathrm{Rm}$ ), and to a lesser extent in the inferior nucleus. Nitrergic cells in the reticular formation constitute a highly shared feature among vertebrates (Table 2), and these cells are most probably reticulospinal neurons, as has been demonstrated in amphibians [McLean and Sillar, 2000; SánchezCamacho et al., 2001; González and ten Donkelaar, 2007].

At the mid-rostrocaudal level of the rhombencephalon, a group of nitrergic cells is found in the ventral part of the octavolateral area, which in gars is the medullary region containing the termination sites of vestibular as well as acoustic and lateral line fibers [McComick 1981; Song and Northcutt, 1991]. Among anamniotes the presence of nitrergic cells in the octavolateral area is a conserved feature reported in cladistians, teleosts, and most amphibians (Table 2), although with some exceptions [Brüning and Mayer, 1996; González et al., 1996; Pinelli et al., 2014]. In amniotes this feature is present in the vestibular nuclei of birds and mammals, whereas in reptiles similar cells have been observed in turtles and lizards [Brüning et al., 1994b; Smeets et al., 1997] but not in chameleons and snakes [Bennis et al., 1996; Jiang and Terashima, 1996].

The cholinergic neurons of the cranial motor nuclei and the serotonergic cells of the raphe column in the rhombencephalic midline of gars are devoid of nitrergic labeling [Parent and Northcutt, 1982; Chiba and Oka, 1999; Morona et al., 2013; present results], as is also observed in cladistians [López et al., 2016]. The presence of nitrergic staining (generally NADPH-d reactivity) in the 
motor nuclei of the cranial nerves is a feature mentioned in some species of teleosts [Arévalo et al., 1995; Anken and Rahmann, 1996; Pushchina, 2007; Giráldez-Pérez et al., 2009], amphibians [Muñoz et al., 1996; Lázár and Losonczy, 1999; Huynh and Boyd, 2007; Pinelli et al., 2014], reptiles [Bennis et al., 1996; Jiang and Terashima, 1996], birds [Brüning, 1993; Atoji et al., 2001], and mammals [Vincent and Kimura, 1992; Varathan et al., 2001; Chertok and Kotsuba, 2013]. However, reliable evidence obtained with double-immunolabeling techniques for NOS and ChAT has only been performed in the case of goldfish [Giráldez-Pérez et al., 2009] and, therefore, the localization of NOS in rhombencephalic motoneurons is a feature that needs confirmation with the appropriate double-labeling techniques. In addition, the presence of nitrergic cells in the raphe nuclei has been repeatedly reported in representatives of most vertebrate groups, but using exclusively single-labeling techniques. These include teleosts [Arévalo et al., 1995; Pushchina and Diuîzen, 2004; Giráldez-Pérez et al., 2008], amphibians [González et al., 1996; Muñoz et al., 1996; Lázár and Losonczy, 1999; Huynh and Boyd, 2007], reptiles [Smeets et al., 1997], birds [Atoji et al., 2001], and mammals [Vincent and Kimura, 1992; Egberongbe et al., 1994]. However, conclusive data obtained with double-labeling techniques revealed NOS in serotoninergic neurons in the rostral raphe nuclei of the rat [Johnson and Ma, 1993; Dun et al., 1994; Wotherspoon et al., 1994; Wang et al., 1995; Simpson et al., 2003; Lu et al., 2010], but not in the raphe nuclei of mice, guinea pigs, and cats [Leonard et al., 1995; Léger et al., 1998]. Conversely, a previous doublelabeling study in amphibians demonstrated that only the cells in the caudal part of the raphe column also contain NOS [López et al., 2005]. Thus, the presence of NOS in the raphe nuclei seems to be another variable feature that requires precise experimental confirmation in many vertebrate groups.

In the caudal rhombencephalic alar plate abundant and intensely NOS-ir cells are located in the Nsol of gars, which form a separated cell population from the numerous TH-ir, CB-ir, CR-ir, and ChAT-ir cells closely located within this area. Similar data have been reported only in cladistian fishes [López et al., 2016], whereas NADPH-dreactive cells in the Nsol were generally absent in teleosts, with the exception of the tench [Arévalo et al., 1995]. However, this is a characteristic present in most amphibians, with the exception found in H. septentrionalis [Pinelli et al., 2014], in all species of birds studied, and in almost all species of mammals, with the exception of the cat [Mizukawa et al., 1989]. In reptiles this trait is more variable since the Nsol contains nitrergic cells in the turtle and lizard [Brüning et al., 1994b; Smeets et al., 1997], but not in chameleons and snakes [Bennis et al., 1996; Jiang and Terashima, 1996]. In addition, the absence of colocalization of NOS and TH in cells of the Nsol has been confirmed in amphibians and reptiles [Smeets et al., 1997; López et al., 2005]. Of note, the presence of nitrergic cells in the Nsol led to the suggestion that NO may be related to the modulation of visceral sensitive afferents, the control of blood pressure, and the regulation of respiratory frequency [Lawrence et al., 1998; Wu et al., 2002; Granjeiro and Machado, 2009; Kong et al., 2009].

\section{Spinal Cord}

A nitrergic cell population has been observed throughout the spinal cord of gars, mainly located in the dorsal horn of the spinal cord, but cells are also found in the intermediate and ventral spinal gray, and around the medial longitudinal fascicle. Of note, the large cholinergic somatomotor neurons do not colocalize NOS. The occurrence of spinal nitrergic cells mainly located in the dorsal horn is an ancient and highly conserved feature of vertebrates, from lampreys to mammals (Table 2). Comparatively, nitrergic cells have been observed in the intermediate and ventral spinal gray of teleosts [Arévalo et al., 1995; Brüning et al., 1995; Giráldez-Pérez et al., 2008], amphibians [Crowe et al., 1995; Muñoz et al., 1996, 2000; González et al., 1996, 2002b; Huynh and Boyd, 2007], reptiles [Jiang and Terashima, 1996; Radmilovich et al., 1997; Smeets et al., 1997; Morona et al., 2006, 2007], birds [Atoji et al., 2001; Necker, 2004, 2005], and mammals [Dun et al., 1992, 1993; Terenghi et al., 1993; Vizzard et al., 1994, 1997; Doone et al., 1999; Kluchová et al., 2002; Lukácová et al., 2002; Bombardi et al., 2013]. However, colocalization of NOS with ChAT in the spinal motoneurons is an unusual feature that has been described only in some species of teleosts [Pushchina et al., 2007; Giráldez-Pérez et al., 2009] and mammals [Dun et al., 1992; Terenghi et al., 1993; Wetts and Vaughn, 1994]. However, the effect of NO in the regulation of the locomotor activity has been demonstrated in the lamprey spinal cord [Kyriakatos et al., 2009], and other functions for NO in the spinal cord are inhibition of the nociceptive information and pain control [Hervera et al., 2010; Chu et al., 2011; Cury et al., 2011; Jin et al., 2011, 2012].

\section{Retina}

In the retina of the gars studied, a numerous population of small nitrergic cells was observed in the inner nuclear layer with short processes ramifying within the in- 
ner plexiform layer. This nitrergic cells most likely represent a population of amacrine cells that is distinct from the TH-ir, 5-HT-ir, ChAT-ir, and CB-ir amacrine cells, whereas some NOS-ir cells also contain CR. Retinal NO might modulate the neuronal communication between bipolar and ganglion cells, like the transient conversion of synaptic inhibition to excitation [Hoffpauir et al., 2006]. Amacrine cells, either NADPH-d reactive or NOSir, have been thoroughly reported in the retina of teleosts [Ostholm et al., 1994; Pottek et al., 1997; Haamedi and Djamgoz, 2002], amphibians [Nöll et al., 1994; Kurenni et al., 1995; Blom et al., 2009], reptiles [Haverkamp et al., 2000], birds [Fischer and Stell, 1999; Wilson et al., 2011; Tekmen-Clark and Gleason, 2013], and mammals [Vielma et al., 2012], representing a feature shared in all osteichthyes studied. Of note, holosteans, like cladistians, lack other nitrergic cells in the retina [López et al., 2016; present results]. In particular, the lack of nitrergic labeling in the ganglion cell layer is in line with the lack of labeling in the extensive retinal central projections [Northcutt and Butler, 1976].

A greater diversity of nitrergic retinal cell types has been described in other vertebrate groups, probably related with new functions of retinal NO, such as lightadaptive changes [Greenstreet and Djamgoz, 1994; Djamgoz et al., 2000; Angotzi et al., 2002; Sato et al., 2011] or circadian effect in the photoreceptor activity [Ko et al., 2013]. Thus, nitrergic ganglion cells and photoreceptors have been reported in the retina of teleosts [Ostholm et al., 1994; Pottek et al., 1997; Ota et al., 1999; Haamedi and Djamgoz, 2002; Gaikwad et al., 2009], amphibians [Nöll et al., 1994; Kurenni et al., 1995; Blom et al., 2009], reptiles [Blute et al., 1997], birds [Fischer and Stell, 1999; Wilson et al., 2011; Tekmen-Clark and Gleason, 2013], and mammals [Blom et al., 2012], where protoreceptor cells always lack nitrergic labeling. Furthermore, nitrergic bipolar neurons have been described in the retina of chondrichthyes [Shiells and Falk, 1992], amphibians [Nöll et al., 1994; Kurenni et al., 1995; Blom et al., 2009], and reptiles [Cao and Eldred, 2001], whereas horizontal nitrergic cells have been reported only in teleosts [Ota et al., 1999; Haamedi and Djamgoz, 2002] and reptiles [Haverkamp and Eldred, 1998; Cuenca et al., 2000].

\section{Concluding Remarks}

This study represents the first detailed neuroanatomical description of the distribution of the nitrergic cells and fibers in the CNS of holostean fishes. The current results, jointly with those recently reported for the brain of cladistians, show a pattern of organization of the nitrergic structures that is essentially similar in these nonteleost actinopterygian fishes, especially in the subpallial telencephalon, hypothalamus, midbrain, rhombencephalon, spinal cord, and retina. The comparison with other groups of vertebrates identifies several features of the nitrergic system that are highly conserved in the nervous system, such as the presence of nitrergic cells in pallial/ cortical areas, striatum, amygdaloid complex, basal hypothalamus, mesencephalic optic tectum, torus semicircularis and tegmentum, the rhombencephalic reticular formation, the dorsal horn of spinal cord, and the amacrine subpopulation in the retina. This highly conserved pattern of distribution of the nitrergic cells and fibers suggests that NO might have been involved from early stages in the evolution of vertebrates in functions such as motor control, emotion/behavior control, the regulation of the hypothalamic functions, and the modulation of sensitive information in midbrain areas, the spinal cord or the retina. On the contrary, the presence of nitrergic cells in the olfactory bulb, thalamus, pretectum, and cerebellum, or its colocalization with cholinergic motoneurons of cranial nerves/spinal cord and the serotonergic cells in the raphe nuclei, are highly variable features. Furthermore, particular characteristics of the nitrergic system of gars include the absence of nitrergic labeling in certain subpallial areas, like the Vn and VL, the coexpression of NOS and $\mathrm{TH}$ in most of the suprachiasmatic neurons, the prominent nitrergic cell population located exclusively in the nucleus of the lateral recess of the large inferior hypothalamic lobes, and the absence of localization of NOS in the important cholinergic nuclei of the rhombencephalon.

\section{Acknowledgments}

This work was supported by the Spanish Ministry of Economy and Competitiveness (MINECO grant BFU2015-66041-P).

\section{Disclosure Statement}

The authors declare that they have no conflicts of interest. No financial conflict of interest was identified, and the terms of the funding arrangement were reviewed and approved by the Complutense University of Madrid in accordance with its policy on objectivity in research. 


\section{References}

Abe M, Kimoto H, Eto R, Sasaki T, Kato H, Kasahara J, Araki T (2010): Postnatal development of neurons, interneurons and glial cells in the substantia nigra of mice. Cell Mol Neurobiol 30:917-928.

Adams JC (1981): Heavy metal intensification of DAB-based HRP reaction product. J Histochem Cytochem 29:775.

Agetsuma M, Aizawa H, Aoki T, Nakayama R, Takahoko M, Goto M, Sassa T, Amo R, Shiraki T, Kawakami K, Hosoya T, Higashijima S, Okamoto H (2010): The habenula is crucial for experience-dependent modification of fear responses in zebrafish. Nat Neurosci 13: 1354-1356.

Agostino PV, Ferreyra GA, Murad AD, Watanabe Y, Golombek DA (2004): Diurnal, circadian and photic regulation of calcium/calmodulindependent kinase II and neuronal nitric oxide synthase in the hamster suprachiasmatic nuclei. Neurochem Int 44:617-625.

Alderton WK, Cooper CE, Knowles RG (2001) Nitric oxide synthases: structure, function and inhibition. Biochem J 357:593-615.

Allaerts W, Ubink R, de Vente J, Tuinhof R, Jenks BG, Roubos EW (1997): Nitric oxide synthase and background adaptation in Xenopus laevis. J Chem Neuroanat 14:21-31.

Alonso JR, Arévalo R, Weruaga E, Porteros JG, Briñón JG, Aijón J (2000): Comparative and developmental neuroanatomical aspects of the NO system; in Steinbusch HWM, De Vente J, Vincent SR (eds): Functional Neuroanatomy of the Nitric Oxide System. Amsterdam, Elsevier, vol 17, pp 51-109.

Alonso JR, Porteros A, Crespo C, Arévalo R, Briñón JG, Weruaga E, Aijón J (1998): Chemical anatomy of the macaque monkey olfactory bulb: NADPH-diaphorase/nitric oxide synthase activity. J Comp Neurol 402:419-434.

Álvarez-Otero R, Pérez SE, Rodríguez MA, Anadón R (1996): Organisation of the cerebellar nucleus of the dogfish, Scyliorhinus canicula L.: a light microscopic, immunocytochemical, and ultrastructural study. J Comp Neurol 368:487-502.

Amir S, Robinson B, Edelstein K (1995): Distribution of NADPH-diaphorase staining and light-induced Fos expression in the rat suprachiasmatic nucleus region supports a role for nitric oxide in the circadian system. Neuroscience 69:545-555.

Amores A, Catchen J, Ferrara A, Fontenot Q Postlethwait JH (2011): Genome evolution and meiotic maps by massively parallel DNA sequencing: spotted gar, an outgroup for the teleost genome duplication. Genetics 188: 799-808.

Ando H, Shi Q, Kusakabe T, Ohya T, Suzuki N, Urano A (2004): Localization of mRNAs encoding $\alpha$ and $\beta$ subunits of soluble guanylyl cyclase in the brain of rainbow trout: comparison with the distribution of neuronal nitric oxide synthase. Brain Res 1013:13-29.
Andreakis N, D'Aniello S, Albalat R, Patti FP, García-Fernández J, Procaccini G, Sordino P, Palumbo A (2011): Evolution of the nitric oxide synthase family in metazoans. Mol Biol Evol 28:163-179.

Anken RH, Rahmann H (1996): An atlas of the distribution of NADPH-diaphorase in the brain of the highly derived swordtail fish Xiphophorus helleri (Atherinoformes: Teleostei). J Hirnforsch 37:421-449.

Arévalo R, Sánchez F, Alonso JR, Carretero J, Vázquez R, Aijón J (1992): NADPH-diaphorase activity in the hypothalamic magnocellular neurosecretory nuclei of the rat. Brain Res Bull 28:599-603.

Arévalo R, Alonso JR, García-Ojeda E, Briñón JG, Crespo C, Aijón J (1995): NADPH-diaphorase in the central nervous system of the tench (Tinca tinca L., 1758). J Comp Neurol 352: 398-420.

Atoji Y, Yamamoto Y, Suzuki Y (2001): Distribution of NADPH diaphorase-containing neurons in the pigeon central nervous system. Chem Neuroanat 21:1-22.

Baby SM, Ueck M, Prasada Rao PD (2000): Gonadotropin-releasing hormone-immunoreactive neurons and associated nicotamide adenine dinucleotide phosphate-diaphorasepositive neurons in the brain of a teleost, Rhodeus amarus. Gen Comp Endocrinol 120: 44-54.

Baker BI, Bird DJ (2002): Neuronal organization of the melanin-concentrating hormone system in primitive actinopterygians: evolutionary changes leading to teleosts. J Comp Neurol 442:99-114.

Bardet SM, Martínez de la Torre M, Northcutt RG, Rubenstein JL, Puelles L (2008): Conserved pattern of OTP-positive cells in the paraventricular nucleus and other hypothalamic sites of tetrapods. Brain Res Bull 75:231-235.

Bell TD, Pereda AE, Faber DS (1997): Nitric oxide synthase distribution in the goldfish Mauthner cell. Neurosci Lett 226:187-190.

Bennis M, Repérant J, Ward R, Wasowicz M (1996): Topography of the NADPH-diaphorase system in the chameleon brain. J Hirnforsch 37:281-288.

Bertini G, Bentivoglio M (1997): Nitric oxide synthase in the adult and developing thalamus: histochemical and immunohistochemical study in the rat. J Comp Neurol 388:89-105.

Blom JJ, Blute TA, Eldred WD (2009): Functional localization of the nitric oxide/cGMP pathway in the salamander retina. Vis Neurosci 26:275-286

Blom JJ, Giove T, Deshpande M, Eldred WD (2012): Characterization of nitric oxide signaling pathways in the mouse retina. J Comp Neurol 520:4204-4217.

Blute TA, Mayer B, Eldred WD (1997): Immunocytochemical and histochemical localization of nitric oxide synthase in the turtle retina. Vis Neurosci 14:717-729.
Bombardi C, Grandis A, Gardini A, Cozzi B (2013): Nitrergic neurons in the spinal cord of the bottlenose dolphin (Tursiops truncatus). Anat Rec (Hoboken) 296:1603-1614.

Bon CL, Garthwaite J (2003): On the role of nitric oxide in hippocampal long-term potentiation. J Neurosci 23:1941-1948.

Bordieri L, Cioni C (2004): Co-localization of neuronal nitric oxide synthase with argininevasotocin in the preoptic-hypothalamo-hypophyseal system of the teleost Oreochromis niloticus. Brain Res 1015:181-185.

Bordieri L, Persichini T, Venturini G, Cioni C (2003): Expression of nitric oxide synthase in the preoptic-hypothalamo-hypophyseal system of the teleost Oreochromis niloticus. Brain Behav Evol 62:43-55.

Bradley SA, Steinert JR (2016): Nitric oxidemediated posttranslational modifications: impacts at the synapse. Oxid Med Cell Longev 2016:5681036.

Braford MR Jr (2009): Stalking the everted telencephalon: comparisons of forebrain organization in basal ray-finned fishes and teleosts. Brain Behav Evol 74:56-76.

Bredt DS, Glatt CE, Hwang PM, Fotuhi M, Dawson TM, Snyder SH (1991): Nitric oxide synthase protein and mRNA are discretely localized in neuronal populations of the mammalian CNS together with NADPH diaphorase. Neuron 7:615-624.

Bredt DS, Snyder SH (1992): Nitric oxide, a novel neuronal messenger. Neuron 8:3-11.

Brown GC (2010): Nitric oxide and neuronal death. Nitric Oxide 23:153-165.

Bruce L, Braford MRJ (2008): Evolution of the limbic system; in Squire L, Albright T, Bloom F, Gage F, Spitzer N (eds): New Encyclopedia of Neuroscience. San Diego, Elsevier Academic Press.

Brüning G (1993): Localization of NADPH-diaphorase in the brain of the chicken. J Comp Neurol 334:192-208.

Brüning G, Funk U, Mayer B (1994a): Immunocytochemical localization of nitric oxide synthase in the brain of the chicken. Neuroreport 5:2425-2428.

Brüning G, Katzbach R, Mayer B (1995): Histochemical and immunocytochemical localization of nitric oxide synthase in the central nervous system of the goldfish, Carassius auratus. J Comp Neurol 358:353-382.

Brüning G, Mayer B (1996): Localization of nitric oxide synthase in the brain of the frog, Xenopus laevis. Brain Res 741:331-343.

Brüning G, Mayer B (2001): Nitric oxide synthase in the spinal cord of the frog, Xenopus laevis. Cell Tissue Res 305:457-462.

Brüning G, Wiese S, Mayer B (1994b): Nitric oxide synthase in the brain of the turtle Pseudemys scripta elegans. J Comp Neurol 348:183-206.

Bugnon O, Schaad NC, Schorderet M (1994): Nitric oxide modulates endogenous dopamine release in bovine retina. Neuroreport 5:401404. 
Calabresi P, Gubellini P, Centonze D, Sancesario G, Morello M, Giorgi M, Pisani A, Bernardi G (1999): A critical role of the nitric oxide/ cGMP pathway in corticostriatal long-term depression. J Neurosci 19:2489-2499.

Cao L, Eldred WD (2001): Subcellular localization of neuronal nitric oxide synthase in turtle retina: electron immunocytochemistry. Vis Neurosci 18:949-960.

Cioni C, Greco A, Pepe A, De Vito L, Colasanti M (1997): Nitric oxide synthase in the caudal neurosecretory system of the teleost Oreochromis niloticus. Neurosci Lett 238:57-60.

Collin SP, Northcutt RG (1995): The visual system of the Florida garfish, Lepisosteus platyrhincus (Ginglymodi). IV. Bilateral projections and the binocular visual field. Brain Behav Evol 45:34-53.

Cozzi B, Massa R, Panzica GC (1997): The $\mathrm{NADPH}$-diaphorase-containing system in the brain of the budgerigar (Melopsittacus undulatus). Cell Tissue Res 287:101-112.

Crowe MJ, Brown TJ, Bresnahan JC, Beattie MS (1995): Distribution of NADPH-diaphorase reactivity in the spinal cord of metamorphosing and adult Xenopus laevis. Brain Res Dev Brain Res 86:155-166.

Cuenca N, Haverkamp S, Kolb H (2000): Choline acetyltransferase is found in terminals of horizontal cells that label with GABA, nitric oxide synthase and calcium binding proteins in the turtle retina. Brain Res 878:228-239.

Cury Y, Picolo G, Gutierrez VP, Ferreira SH (2011): Pain and analgesia: the dual effect of nitric oxide in the nociceptive system. Nitric Oxide 25:243-254.

Czarnecka A, Lenda T, Domin H, Konieczny J, Smialowska M, Lorenc-Koci E (2013): Alterations in the expression of nNOS in the substantia nigra and subthalamic nucleus of 6-OHDA-lesioned rats: the effects of chronic treatment with L-DOPA and the nitric oxide donor, molsidomine. Brain Res 1541: 92-105.

Chaparro-Huerta V, Beas-Zarate C, Guerrero MU, Feria-Velasco A (1997): Nitric oxide involvement in regulating the dopamine transport in the striatal region of rat brain. Neurochem Int 31:607-616.

Chertok VM, Kotsuba AE (2013): The distribution of NADPH-diaphorase and neuronal no synthase in rat medulla oblongata nuclei (in Russian). Morfologiia 144:9-14.

Chiba A (2005): Neuropeptide Y-immunoreactive (NPY-ir) structures in the brain of the gar Lepisosteus oculatus (Lepisosteiformes, Osteichthyes) with special regard to their anatomical relations to gonadotropin-releasing hormone (GnRH)-ir structures in the hypothalamus and the terminal nerve. Gen Comp Endocrinol 142:336-346.

Chiba A, Oka S (1999): Serotonin-immunoreactive structures in the central nervous system of the garfish Lepisosteus productus (Semionotiformes, Osteichthyes). Neurosci Lett 261: 73-76.
Chu SC, Hu YY, Li QJ, Li HN, Li WB (2011): Effects of nitric oxide on spontaneous pain reaction and neuronal apoptosis in the spinal cord of rats induced by formalin inflammatory pain (in Chinese). Zhongguo Ying Yong Sheng Li Xue Za Zhi 27:372-375.

Darius S, Wolf G, Huang PL, Fishman MC (1995): Localization of NADPH-diaphorase/nitric oxide synthase in the rat retina: an electron microscopic study. Brain Res 690:231-235.

Dawson TM, Sasaki M, Gonzalez-Zulueta M, Dawson VL (1998): Regulation of neuronal nitric oxide synthase and identification of novel nitric oxide signaling pathways. Prog Brain Res 118:3-11.

Demski LS, Knigge KM (1971): The telencephalon and hypothalamus of the bluegill (Lepomis macrochirus): evoked feeding, aggressive and reproductive behavior with representative frontal sections. J Comp Neurol 143:116.

Desvignes C, Robert F, Vachette C, Chouvet G, Cespuglio R, Renaud B, Lambás-Señas L (1997): Monitoring nitric oxide (NO) in rat locus coeruleus: differential effects of NO synthase inhibitors. Neuroreport 8:1321-1325.

Domínguez JM, Brann JH, Gil M, Hull EM (2006): Sexual experience increases nitric oxide synthase in the medial preoptic area of male rats. Behav Neurosci 120:1389-1394.

Domínguez L, González A, Moreno N (2015): Patterns of hypothalamic regionalization in amphibians and reptiles: common traits revealed by a genoarchitectonic approach. Front Neuroanat 9:3.

Doone GV, Pelissier N, Manchester T, Vizzard MA (1999): Distribution of NADPH-d and nNOS-IR in the thoracolumbar and sacrococcygeal spinal cord of the guinea pig. J Auton Nerv Syst 77:98-113.

Dun NJ, Dun SL, Förstermann U (1994): Nitric oxide synthase immunoreactivity in rat pontine medullary neurons. Neuroscience 59: 429-445.

Dun NJ, Dun SL, Förstermann U, Tseng LF (1992): Nitric oxide synthase immunoreactivity in rat spinal cord. Neurosci Lett 147:217220.

Dun NJ, Dun SL, Wu SY, Förstermann U, Schmidt HH, Tseng LF (1993): Nitric oxide synthase immunoreactivity in the rat, mouse, cat and squirrel monkey spinal cord. Neuroscience 54:845-857.

Dzoljic E, Grbatinic I, Kostic V (2015): Why is nitric oxide important for our brain? Funct Neurol 30:159-163.

Egberongbe YI, Gentleman SM, Falkai P, Bogerts B, Polak JM, Roberts GW (1994): The distribution of nitric oxide synthase immunoreactivity in the human brain. Neuroscience 59: 561-578.

Fabris G, Steiner AA, Anselmo-Franci JA, Branco LG (2000): Role of nitric oxide in rat locus coeruleus in hypoxia-induced hyperventilation and hypothermia. Neuroreport 11:29912995.
Ferrando S, Gallus L, Gambardella C, Amaroli A, Cutolo A, Masini MA, Vallarino M, Vacchi M (2012): Neuronal nitric oxide synthase (nNOS) immunoreactivity in the olfactory system of a cartilaginous fish. J Chem Neuroanat 43:133-140.

Finger TE, Kanwal JS (1992): Ascending general visceral pathways within the brainstems of two teleost fishes: Ictalurus punctatus and Carassius auratus. J Comp Neurol 320:509520.

Fischer AJ, Stell WK (1999): Nitric oxide synthase-containing cells in the retina, pigmented epithelium, choroid, and sclera of the chick eye. J Comp Neurol 405:1-14.

Folgueira M, Anadón R, Yáñez J (2003): Experimental study of the connections of the gustatory system in the rainbow trout, Oncorhynchus mykiss. J Comp Neurol 465:604-619.

Fuentes-Santamaría V, McHaffie JG, Stein BE (2008): Maturation of multisensory integration in the superior colliculus: expression of nitric oxide synthase and neurofilament SMI32. Brain Res 1242:45-53.

Funakoshi K, Kadota T, Atobe Y, Goris RC, Kishida R (1997): NADPH-diaphorase activity in the vagal afferent pathway of the dogfish, Triakis scyllia. Neurosci Lett 237:129-132.

Funakoshi K, Kadota T, Atobe Y, Nakano M, Goris RC, Koshida R (1999): Nitric oxide synthase in the glossopharyngeal and vagal afferent pathway of a teleost, Takifugu niphobles. The branchial vascular innervation. Cell Tissue Res 298:45-54.

Gaikwad A, Biju KC, Barsagade V, Bhute Y, Subhedar N (2009): Neuronal nitric oxide synthase in the olfactory system, forebrain, pituitary and retina of the adult teleost Clarias batrachus. J Chem Neuroanat 37:170-181.

Ganz J, Kaslin J, Freudenreich D, Machate A, Geffarth M, Brand M (2012): Subdivisions of the adult zebrafish subpallium by molecular marker analysis. J Comp Neurol 520:633-655.

Garthwaite J (1991): Glutamate, nitric oxide and cell-cell signalling in the nervous system. Trends Neurosci 14:60-67.

Gasulla J, Calvo DJ (2015): Enhancement of tonic and phasic GABAergic currents following nitric oxide synthase inhibition in hippocampal CA1 pyramidal neurons. Neurosci Lett 590: 29-34.

Gayoso JA, Castro A, Anadon R, Manso MJ (2011): Differential bulbar and extrabulbar projections of diverse olfactory receptor neuron populations in the adult zebrafish (Danio rerio). J Comp Neurol 519:247-276.

Giráldez-Pérez RM, Gaytan SP, Pasaro R (2013): Cholinergic and nitrergic neuronal networks in the goldfish telencephalon. Acta Neurobiol Exp (Warsaw) 73:338-353.

Giráldez-Pérez RM, Gaytan SP, Ruano D, Torres B, Pasaro R (2008): Distribution of NADPHdiaphorase and nitric oxide synthase reactivity in the central nervous system of the goldfish (Carassius auratus). J Chem Neuroanat $35: 12-32$. 
Giráldez-Pérez RM, Gaytan SP, Torres B, Pasaro $R$ (2009): Co-localization of nitric oxide synthase and choline acetyltransferase in the brain of the goldfish (Carassius auratus). J Chem Neuroanat 37:1-17.

Golombek DA, Agostino PV, Plano SA, Ferreyra GA (2004): Signaling in the mammalian circadian clock: the NO/cGMP pathway. Neurochem Int 45:929-936.

González A, López JM, Sánchez-Camacho C, Marín O (2002a): Localization of choline acetyltransferase (ChAT) immunoreactivity in the brain of a caecilian amphibian, Dermophis mexicanus (Amphibia: Gymnophiona). J Comp Neurol 448:249-267.

González A, Moreno N, López JM (2002b): Distribution of NADPH-diaphorase/nitric oxide synthase in the brain of the caecilian Dermophis mexicanus (amphibia: gymnophiona): comparative aspects in amphibians. Brain Behav Evol 60:80-100.

González A, Morona R, Moreno N, Bandín S, López JM (2014): Identification of striatal and pallidal regions in the subpallium of anamniotes. Brain Behav Evol 83:93-103.

González A, Muñoz A, Muñoz M, Marín O, Arévalo R, Porteros A, Alonso JR (1996): Nitric oxide synthase in the brain of a urodele amphibian (Pleurodeles waltl) and its relation to catecholaminergic neuronal structures. Brain Res 727:49-64

González A, Northcutt RG (2009): An immunohistochemical approach to lungfish telencephalic organization. Brain Behav Evol 74: 43-55.

González A, ten Donkelaar HJ (2007): Comparative analysis of descending supraspinal projections in amphibians; in Becker CG, Becker $\mathrm{T}$ (eds): Model Organisms in Spinal Cord Regeneration. Weinheim, Wiley-VCH.

González-Domenech CM, Muñoz-Chapuli R (2010): Molecular evolution of nitric oxide synthases in metazoans. Comp Biochem Physiol Part D Genomics Proteomics 5:295301.

Gotti S, Sica M, Viglietti-Panzica C, Panzica G (2005): Distribution of nitric oxide synthase immunoreactivity in the mouse brain. Microsc Res Tech 68:13-35.

Granjeiro EM, Machado BH (2009): NO in the caudal NTS modulates the increase in respiratory frequency in response to chemoreflex activation in awake rats. Respir Physiol Neurobiol 166:32-40.

Grassi C, Santarelli R, Nisticò S, Bagetta G, Azzena GB (1995): Possible modulation of auditory middle latency responses by nitric oxide in the inferior colliculus of anaesthetized rats. Neurosci Lett 196:213-217.

Guglielmotti V, Fiorino L (1999): Nitric oxide synthase activity reveals an asymmetrical organization of the frog habenulae during development: a histochemical and cytoarchitectonic study from tadpoles to the mature Rana esculenta, with notes on the pineal complex. J Comp Neurol 411:441-454.
Gulati K, Ray A (2014): Differential neuromodulatory role of $\mathrm{NO}$ in anxiety and seizures: an experimental study. Nitric Oxide 43:55-61.

Haamedi SN, Djamgoz MB (2002): Dopamine and nitric oxide control both flickering and steady-light-induced cone contraction and horizontal cell spinule formation in the teleost (carp) retina: serial interaction of dopamine and nitric oxide. J Comp Neurol 449: 120-128.

Hadeishi Y, Wood RI (1996): Nitric oxide synthase in mating behavior circuitry of male Syrian hamster brain. J Neurobiol 30:480-492.

Haley JE, Wilcox GL, Chapman PF (1992): The role of nitric oxide in hippocampal long-term potentiation. Neuron 8:211-216.

Hardingham N, Dachtler J, Fox K (2013): The role of nitric oxide in pre-synaptic plasticity and homeostasis. Front Cell Neurosci 7:190.

Harper A, Blythe WR, Zdanski CJ, Prazma J, Pillsbury HC, III (1994): Nitric oxide in the rat vestibular system. Otolaryngol Head Neck Surg 111:430-438.

Hars B (1999): Endogenous nitric oxide in the rat pons promotes sleep. Brain Res 816:209-219.

Haverkamp S, Eldred WD (1998): Localization of nNOS in photoreceptor, bipolar and horizontal cells in turtle and rat retinas. Neuroreport 9:2231-2235.

Haverkamp S, Kolb H, Cuenca N (2000): Morphological and neurochemical diversity of neuronal nitric oxide synthase-positive amacrine cells in the turtle retina. Cell Tissue Res 302:11-19.

Herbison AE, Simonian SX, Norris PJ, Emson PC (1996): Relationship of neuronal nitric oxide synthase immunoreactivity to GnRH neurons in the ovariectomized and intact female rat. J Neuroendocrinol 8:73-82.

Hervera A, Negrete R, Leánez S, Martín-Campos JM, Pol O (2010): The spinal cord expression of neuronal and inducible nitric oxide synthases and their contribution in the maintenance of neuropathic pain in mice. PLoS One 5:e14321.

Hoegg S, Brinkmann H, Taylor JS, Meyer A (2004): Phylogenetic timing of the fish-specific genome duplication correlates with the diversification of teleost fish. J Mol Evol 59:190203.

Hoffpauir B, McMains E, Gleason E (2006): Nitric oxide transiently converts synaptic inhibition to excitation in retinal amacrine cells. J Neurophysiol 95:2866-2877.

Holmqvist B, Ellingsen B, Alm P, Forsell J, Oyan AM, Goksoyr A, Fjose A, Seo HC (2000): Identification and distribution of nitric oxide synthase in the brain of adult zebrafish. Neurosci Lett 292:119-122.

Holmqvist BI, Ostholm T, Alm P, Ekstrom P (1994): Nitric oxide synthase in the brain of a teleost. Neurosci Lett 171:205-208.

Hope BT, Michael GJ, Knigge KM, Vincent SR (1991): Neuronal NADPH diaphorase is a nitric oxide synthase. Proc Natl Acad Sci USA 88:2811-2814.
Hopkins DA, Steinbusch HW, Markerink-van Ittersum M, De Vente J (1996): Nitric oxide synthase, cGMP, and NO-mediated cGMP production in the olfactory bulb of the rat. J Comp Neurol 375:641-658.

Huang PL, Dawson TM, Bredt DS, Snyder SH, Fishman MC (1993): Targeted disruption of the neuronal nitric oxide synthase gene. Cell 75:1273-1286.

Huynh P, Boyd SK (2007): Nitric oxide synthase and NADPH diaphorase distribution in the bullfrog (Rana catesbeiana) CNS: pathways and functional implications. Brain Behav Evol 70:145-163.

Iwase K, Iyama K, Akagi K, Yano S, Fukunaga K, Miyamoto E, Mori M, Takiguchi M (1998): Precise distribution of neuronal nitric oxide synthase mRNA in the rat brain revealed by non-radioisotopic in situ hybridization. Brain Res Mol Brain Res 53:1-12.

Jadhao AG, Malz CR (2004): Nicotinamide adenine dinucleotide phosphate (NADPH)-diaphorase activity in the brain of a cichlid fish, with remarkable findings in the entopeduncular nucleus: a histochemical study. J Chem Neuroanat 27:75-86

Jesuthasan S (2012): Fear, anxiety, and control in the zebrafish. Dev Neurobiol 72:395-403.

Jiang PJ, Terashima S (1996): Distribution of NADPH-diaphorase in the central nervous system of an infrared-sensitive snake, Trimeresurus flavoviridis. Brain Res 713:168-177.

Jin HB, Yang YL, Song YL, Yang YB, Li YR (2012): Nitric oxide modulated the expression of DREAM/calsenilin/KChIP3 in inflammatory pain of rats. Inflammation 35:1867-1871.

Jin XG, Chen SR, Cao XH, Li L, Pan HL (2011): Nitric oxide inhibits nociceptive transmission by differentially regulating glutamate and glycine release to spinal dorsal horn neurons. J Biol Chem 286:33190-33202.

Johnson MD, Ma PM (1993): Localization of NADPH diaphorase activity in monoaminergic neurons of the rat brain. J Comp Neurol 332:391-406.

Kato T, Yamada Y, Yamamoto N (2011): General visceral and gustatory connections of the posterior thalamic nucleus of goldfish. J Comp Neurol 519:3102-3123.

Kendrick KM, Guevara-Guzman R, Zorrilla J, Hinton MR, Broad KD, Mimmack M, Ohkura S (1997): Formation of olfactory memories mediated by nitric oxide. Nature 388:670674

Kharazia VN, Schmidt HH, Weinberg RJ (1994): Type I nitric oxide synthase fully accounts for NADPH-diaphorase in rat striatum, but not cortex. Neuroscience 62:983-987.

Kikugawa K, Katoh K, Kuraku S, Sakurai H, Ishida O, Iwabe N, Miyata T (2004): Basal jawed vertebrate phylogeny inferred from multiple nuclear DNA-coded genes. BMC Biol 2:3.

Kinoshita M, Ito E, Urano A, Ito H, Yamamoto N (2006): Periventricular efferent neurons in the optic tectum of rainbow trout. J Comp Neurol 499:546-564. 
Kishimoto J, Keverne EB, Hardwick J, Emson PC (1993): Localization of nitric oxide synthase in the mouse olfactory and vomeronasal system: a histochemical, immunological and in situ hybridization study. Eur J Neurosci 5: 1684-1694.

Kiss JP, Hennings EC, Zsilla G, Vizi ES (1999): A possible role of nitric oxide in the regulation of dopamine transporter function in the striatum. Neurochem Int 34:345-350.

Kiss JP, Zsilla G, Vizi ES (2004): Inhibitory effect of nitric oxide on dopamine transporters: interneuronal communication without receptors. Neurochem Int 45:485-489.

Kluchová D, Klimcík R, Kloc P (2002): Neuronal nitric oxide synthase in the rabbit spinal cord visualised by histochemical NADPH-diaphorase and immunohistochemical NOS methods. Gen Physiol Biophys 21:163-174.

Kong SZ, Fan MX, Zhang BH, Wang ZY, Wang Y (2009): Nitric oxide inhibits excitatory vagal afferent input to nucleus tractus solitarius neurons in anaesthetized rats. Neurosci Bull 25:325-334.

Kurenni DE, Thurlow GA, Turner RW, Moroz LL, Sharkey KA, Barnes S (1995): Nitric oxide synthase in tiger salamander retina. J Comp Neurol 361:525-536.

Kyriakatos A, Molinari M, Mahmood R, Grillner S, Sillar KT, El Manira A (2009): Nitric oxide potentiation of locomotor activity in the spinal cord of the lamprey. J Neurosci 29:1328313291.

Lamb CF, Caprio J (1993): Diencephalic gustatory connections in the channel catfish. J Comp Neurol 337:400-418.

Lawrence AJ, Castillo-Melendez M, McLean KJ, Jarrott B (1998): The distribution of nitric oxide synthase-, adenosine deaminase- and neuropeptide Y-immunoreactivity through the entire rat nucleus tractus solitarius: effect of unilateral nodose ganglionectomy. J Chem Neuroanat 15:27-40.

Lawrence AJ, Jarrott B (1993): Nitric oxide increases interstitial excitatory amino acid release in the rat dorsomedial medulla oblongata. Neurosci Lett 151:126-129.

Lázár G, Losonczy A (1999): NADPH-diaphorase-positive neurons and pathways in the brain of the frog Rana esculenta. Anat Embryol (Berlin) 199:185-198.

Léger L, Charnay Y, Burlet S, Gay N, Schaad N, Bouras C, Cespuglio R (1998): Comparative distribution of nitric oxide synthase- and serotonin-containing neurons in the raphe nuclei of four mammalian species. Histochem Cell Biol 110:517-525.

Leonard CS, Kerman I, Blaha G, Taveras E, Taylor B (1995): Interdigitation of nitric oxide synthase-, tyrosine hydroxylase-, and serotonincontaining neurons in and around the laterodorsal and pedunculopontine tegmental nuclei of the guinea pig. J Comp Neurol 362: 411-432.

Lloyd RV, Jin L, Qian X, Zhang S, Scheithauer BW (1995): Nitric oxide synthase in the human pituitary gland. Am J Pathol 146:86-94.
López JM, González A (2002): Ontogeny of $\mathrm{NADPH}$ diaphorase/nitric oxide synthase reactivity in the brain of Xenopus laevis. J Comp Neurol 445:59-77.

López JM, Lozano D, Morona R, González A (2016): Organization of the nitrergic neuronal system in the primitive bony fishes Polypterus senegalus and Erpetoichthys calabaricus (Actinopterygii: Cladistia). J Comp Neurol 524:1770-1804

López JM, Moreno N, Morona R, Muñoz M, González A (2005): Colocalization of nitric oxide synthase and monoamines in neurons of the amphibian brain. Brain Res Bull 66: 555-559.

Lorenc-Koci E, Czarnecka A (2013): Role of nitric oxide in the regulation of motor function: an overview of behavioral, biochemical and histological studies in animal models. Pharmacol Rep 65:1043-1055.

Lu Y, Simpson KL, Weaver KJ, Lin RC (2010): Coexpression of serotonin and nitric oxide in the raphe complex: cortical versus subcortical circuit. Anat Rec (Hoboken) 293:1954-1965.

Luebke JI, Weider JM, McCarley RW, Greene RW (1992): Distribution of NADPH-diaphorase positive somata in the brainstem of the monitor lizard Varanus exanthematicus. Neurosci Lett 148:129-132.

Lukácová $\mathrm{N}$, Cízková $\mathrm{D}$, Marsala $\mathrm{M}$, Lukác I, Marsala J (2002): The regional distribution of nitric oxide synthase activity in the spinal cord of the dog. Brain Res Bull 58:173-178.

Maggesissi RS, Gardino PF, Guimaraes-Souza EM, Paes-de-Carvalho R, Silva RB, Calaza KC (2009): Modulation of GABA release by nitric oxide in the chick retina: different effects of nitric oxide depending on the cell population. Vision Res 49:2494-2502.

Malz CR, Jahn H, Meyer DL (1999): Centrifugal Phe-Met-Arg-Phe-NH2-like immunoreactive innervation of the retina in a non-teleost bony fish, Lepisosteus osseus. Neurosci Lett 264:33-36.

Mancuso C, Scapagini G, Curro D, Giuffrida Stella AM, De Marco C, Butterfield DA, Calabrese V (2007): Mitochondrial dysfunction, free radical generation and cellular stress response in neurodegenerative disorders. Front Biosci 12:1107-1123.

Marín O, Smeets WJ, González A (1997): Distribution of choline acetyltransferase immunoreactivity in the brain of anuran (Rana perezi, Xenopus laevis) and urodele (Pleurodeles waltl) amphibians. J Comp Neurol 382:499534.

Marín O, Smeets WJ, González A (1998a): Basal ganglia organization in amphibians: evidence for a common pattern in tetrapods. Prog Neurobiol 55:363-397.

Marín O, Smeets WJ, González A (1998b): Evolution of the basal ganglia in tetrapods: a new perspective based on recent studies in amphibians. Trends Neurosci 21:487-494.

McCann SM (1997): The nitric oxide hypothesis of brain aging. Exp Gerontol 32:431-440.
McLean DL, Sillar KT (2000): The distribution of NADPH-diaphorase-labelled interneurons and the role of nitric oxide in the swimming system of Xenopus laevis larvae. J Exp Biol 203:705-713.

Medina L, Abellán A, Vicario A, Desfilis E (2014): Evolutionary and developmental contributions for understanding the organization of the basal ganglia. Brain Behav Evol 83:112125

Meek J, Nieuwenhuys R (1998): Holosteans and teleosts; in Nieuwenhuys R, ten Donkelaar HJ, Nicholson C (eds): The Central Nervous System of Vertebrates. Berlin, Springer, vol 2, pp 759-937.

Miyagawa A, Okamura H, Ibata Y (1994): Coexistence of oxytocin and NADPH-diaphorase in magnocellular neurons of the paraventricular and the supraoptic nuclei of the rat hypothalamus. Neurosci Lett 171:13-16.

Mizukawa K, Vincent SR, McGeer PL, McGeer EG (1989): Distribution of reduced-nicotinamide-adenine-dinucleotide-phosphate diaphorase-positive cells and fibers in the cat central nervous system. J Comp Neurol 279: 281-311.

Mizutani A, Saito H, Abe K (1993): Involvement of nitric oxide in long-term potentiation in the dentate gyrus in vivo. Brain Res 605:309311.

Moreno N, González A (2003): Hodological characterization of the medial amygdala in anuran amphibians. J Comp Neurol 466:389-408.

Moreno N, González A (2004): Localization and connectivity of the lateral amygdala in anuran amphibians. J Comp Neurol 479:130148.

Moreno N, González A (2005a): Forebrain projections to the hypothalamus are topographically organized in anurans: conservative traits as compared with amniotes. Eur J Neurosci 21:1895-1910.

Moreno N, González A (2005b): Central amygdala in anuran amphibians: neurochemical organization and connectivity. J Comp Neurol 489:69-91.

Moreno N, González A (2006): The common organization of the amygdaloid complex in tetrapods: new concepts based on developmental, hodological and neurochemical data in anuran amphibians. Prog Neurobiol 78:6190.

Moreno N, González A (2007a): Regionalization of the telencephalon in urodele amphibians and its bearing on the identification of the amygdaloid complex. Front Neuroanat 1:1.

Moreno N, González A (2007b): Evolution of the amygdaloid complex in vertebrates, with special reference to the anamnio-amniotic transition. J Anat 211:151-163.

Moreno N, González A (2011): The non-evaginated secondary prosencephalon of vertebrates. Front Neuroanat 5:12.

Moreno N, González A, Rétaux S (2009): Development and evolution of the subpallium. Semin Cell Dev Biol 20:735-743. 
Moreno N, López JM, Sánchez-Camacho C, González A (2002): Development of NADPHdiaphorase/nitric oxide synthase in the brain of the urodele amphibian Pleurodeles waltl. J Chem Neuroanat 23:105-121.

Morona R, López JM, Domínguez L, González A (2007): Immunohistochemical and hodological characterization of calbindin-D28k-containing neurons in the spinal cord of the turtle, Pseudemys scripta elegans. Microsc Res Tech 70:101-118.

Morona R, López JM, González A (2006): Calbindin-D28k and calretinin immunoreactivity in the spinal cord of the lizard Gekko gecko: colocalization with choline acetyltransferase and nitric oxide synthase. Brain Res Bull 69: 519-534.

Morona R, López JM, Northcutt RG, González A (2013): Comparative analysis of the organization of the cholinergic system in the brains of two holostean fishes, the Florida gar Lepisosteus platyrhincus and the bowfin Amia calva. Brain Behav Evol 81:109-142.

Muñoz M, Marín O, González A (2000): Localization of NADPH diaphorase/nitric oxide synthase and choline acetyltransferase in the spinal cord of the frog, Rana perezi. J Comp Neurol 419:451-470.

Muñoz M, Muñoz A, Marín O, Alonso JR, Arévalo R, Porteros A, González A (1996): Topographical distribution of NADPH-diaphorase activity in the central nervous system of the frog, Rana perezi. J Comp Neurol 367:54-69.

Nakamura T, Tu S, Akhtar MW, Sunico CR, Okamoto S, Lipton SA (2013): Aberrant protein S-nitrosylation in neurodegenerative diseases. Neuron 78:596-614.

Necker R (2004): Distribution of choline acetyltransferase and NADPH diaphorase in the spinal cord of the pigeon. Anat Embryol (Berlin) $208: 169-181$.

Necker R (2005): Embryonic development of choline acetyltransferase and nitric oxide synthase in the spinal cord of pigeons and chickens with special reference to the superficial dorsal horn. Anat Embryol (Berlin) 210:145154.

Neitz A, Mergia E, Eysel UT, Koesling D, Mittmann T (2011): Presynaptic nitric oxide/ cGMP facilitates glutamate release via hyperpolarization-activated cyclic nucleotide-gated channels in the hippocampus. Eur J Neurosci 33:1611-1621.

Nelson JS, Grande TC, Wilson MVH (2016): Fishes of the World, ed 5. New York, John Wiley \& Sons.

Ng YK, Xue YD, Wong PT (1999): Different distributions of nitric oxide synthase-containing neurons in the mouse and rat hypothalamus. Nitric Oxide 3:383-392.

Nie G, Wang J (2002): Localization of nitric oxide synthase in the chicken vestibular system. Lin Chuang Er Bi Yan Hou Ke Za Zhi 16:426-427.

Nieuwenhuys R (1967): Comparative anatomy of the cerebellum. Prog Brain Res 25:1-93.
Nieuwenhuys R (2011): The development and general morphology of the telencephalon of actinopterygian fishes: synopsis, documentation and commentary. Brain Struct Funct 215: 141-157.

Nieuwenhuys R, Meek J (1990): The telencephalon of sarcopterygian fishes; in Jones EG, Peters A (eds): Cerebral Cortex, vol 8A: Comparative Structure and Evolution of Cerebral Cortex, Part I. New York, Plenum, pp 75-106.

Nöll GN, Billek M, Pietruck C, Schmidt KF (1994): Inhibition of nitric oxide synthase alters light responses and dark voltage of amphibian photoreceptors. Neuropharmacology 33:1407-1412.

Northcutt RG (1982): Localization of neurons afferent to the optic tectum in longnose gars. J Comp Neurol 204:325-335.

Northcutt RG (2009a): Telencephalic organization in the spotted African lungfish, Protopterus dolloi: a new cytological model. Brain Behav Evol 73:59-80.

Northcutt RG (2009b): Phylogeny of nucleus medianus of the posterior tubercle in rayfinned fishes. Integr Zool 4:134-152.

Northcutt RG, Braford MJ (1980): New observations in the organization and evolution of the telencephalon of actinopterygian fishes; in Ebbensson SOE (ed): Comparative Neurology of the Telencephalon. New York, Plenum, pp 41-98.

Northcutt RG, Butler AB (1976): Retinofugal pathways in the lingnose gar Lepisosteus osseus (Linnaeus). J Comp Neurol 166:1-15.

Northcutt RG, Butler AB (1980): Projections of the optic tectum in the longnose gar, Lepisosteus osseus. Brain Res 190:333-346.

Northcutt RG, Butler AB (1993): The diencephalon and optic tectum of the longnose gar, Lepisosteus osseus (L.): cytoarchitectonics and distribution of acetylcholinesterase. Brain Behav Evol 41:57-81.

Nutsch VL, Will RG, Hattori T, Tobiansky DJ, Domínguez JM (2014): Sexual experience influences mating-induced activity in nitric oxide synthase-containing neurons in the medial preoptic area. Neurosci Lett 579:92-96.

Ostholm T, Holmqvist BI, Alm P, Ekstrom P (1994): Nitric oxide synthase in the CNS of the Atlantic salmon. Neurosci Lett 168:233237.

Ota D, Downing JE, Cook JE (1999): Neuronal and glial cell types revealed by NADPHdiaphorase histochemistry in the retina of a teleost fish, the grass goby (Zosterisessor ophiocephalus, Perciformes, Gobiidae). Anat Embryol (Berlin) 200:487-494.

Oyan AM, Nilsen F, Goksøyr A, Holmqvist B (2000): Partial cloning of constitutive and inducible nitric oxide synthases and detailed neuronal expression of NOS mRNA in the cerebellum and optic tectum of adult Atlantic salmon (Salmo salar). Brain Res Mol Brain Res 78:38-49.
Panzica GC, Arévalo R, Sánchez F, Alonso JR, Aste N, Viglietti-Panzica C, Aijón J, Vázquez R (1994): Topographical distribution of reduced nicotinamide adenine dinucleotide phosphate-diaphorase in the brain of the Japanese quail. J Comp Neurol 342:97-114.

Panzica GC, Garzino A, García Ojeda E (1996): Coexistence of NADPH-diaphorase and tyrosine hydroxylase in the mesencephalic catecholaminergic system of the Japanese quail. J Chem Neuroanat 11:37-47.

Papantchev V, Paloff A, Christova T, HinovaPalova D, Ovtscharoff W (2005): Light microscopical study of nitric oxide synthase I-positive neurons, including fibres in the vestibular nuclear complex of the cat. Acta Histochem 107:113-120.

Parent A, Northcutt RG (1982): The monoaminecontaining neurons in the brain of the garfish, Lepisosteus osseus. Brain Res Bull 9:189-204.

Pasquier J, Cabau C, Nguyen T, Jouanno E, Severac D, Braasch I, Journot L, Pontarotti P, Klopp C, Postlethwait JH, Guiguen Y, Bobe J (2016): Gene evolution and gene expression after whole genome duplication in fish: the PhyloFish database. BMC Genomics 17:368.

Pérez SE, Adrio F, Rodríguez MA, Anadón R, Rodríguez-Moldes I (1995): The nitric oxide synthase (NOS)-like immunoreactive extrahypophysial projections of the neurosecretory preoptic nucleus of the electric ray (elasmobranchs) suggest a neuroregulatory role for this nucleus. Neurosci Lett 195:85-88.

Pérez SE, Adrio F, Rodríguez MA, RodríguezMoldes I, Anadón R (1996): NADPH-diaphorase histochemistry reveals oligodendrocytes in the rainbow trout (teleosts). Neurosci Lett 205:83-86.

Pinelli C, D'Aniello B, Polese G, Rastogi RK (2004): Extrabulbar olfactory system and nervus terminalis FMRFamide immunoreactive components in Xenopus laevis ontogenesis. J Chem Neuroanat 228:37-46.

Pinelli C, Rastogi RK, Scandurra A, Jadhao AG, Aria M, D'Aniello B (2014): A comparative cluster analysis of nicotinamide adenine dinucleotide phosphate (NADPH)-diaphorase histochemistry in the brains of amphibians. J Comp Neurol 522:2980-3003.

Pisu MB, Conforti E, Botta L, Valli P, Bernocchi G (2002): Nitric oxide synthase in the frog cerebellum: response of Purkinje neurons to unilateral eighth nerve transection. Anat Rec 268:73-83.

Porteros A, Arévalo R, Crespo C, Briñón JG, Weruaga E, Aijón J, Alonso JR (1996): Nitric oxide synthase activity in the olfactory bulb of anuran and urodele amphibians. Brain Res 724:67-72.

Pose-Méndez S, Candal E, Adrio F, RodríguezMoldes I (2014): Development of the cerebellar afferent system in the shark Scyliorhinus canicula: insights into the basal organization of precerebellar nuclei in gnathostomes. J Comp Neurol 522:131-168. 
Pottek M, Schultz K, Weiler R (1997): Effects of nitric oxide on the horizontal cell network and dopamine release in the carp retina. Vision Res 37:1091-1102.

Prasada Rao PD, Sato T, Ueck M (1997): Distribution of NADPH-diaphorase activity in the hypothalamo-hypophysial system of the frog, Rana esculenta. Neurosci Lett 235:61-64.

Puelles L (1995): A segmental morphological paradigm for understanding vertebrate forebrains. Brain Behav Evol 46:319-337.

Puelles L, Rubenstein JL (2003): Forebrain gene expression domains and the evolving prosomeric model. Trends Neurosci 26:469-476.

Puelles L, Rubenstein JL (2015): A new scenario of hypothalamic organization: rationale of new hypotheses introduced in the updated prosomeric model. Front Neuroanat 9:27.

Pushchina EV (2007): Nitric oxide-ergic organization of medullar cranial nuclei in teleost fishes (in Russian). Tsitologiia 49:471-483.

Pushchina EV, Diuîzen IV (2004): Structure and neurochemistry of the raphe nuclei in teleosts (in Russian). Morfologiia 125:32-37.

Pushchina EV, Obukhov DK (2010): NADPHdiaphorase, nitric oxide synthase, and tyrosine hydroxylase in the diencephalon of the Rhodeus sericeus (Cyprynidae: Teleostei) (in Russian). Tsitologiia 52:739-748.

Pushchina EV, Obukhov DK (2012): Nitric oxide-factor, which regulates proliferation and apoptosis in the adult brain of amur sturgeon Acipenser schrenckii. Adv Biosci Biotechnol 3: 788-804.

Pushchina EV, Varaksin AA, Kalinina GG (2007): Cytoarchitectonic and neurochemical properties of spinal cord in teleost fishes (in Russian). Tsitologiia 49:460-470.

Radmilovich M, Fernández A, Trujillo-Cenóz O (1997): Localization of NADPH-diaphorase containing neurons in the spinal dorsal horn and spinal sensory ganglia of the turtle Chrysemys d'orbigny. Exp Brain Res 113:455-464.

Rafalovich IV, Melendez AE, Plotkin JL, Tanimura A, Zhai S, Surmeier DJ (2015): Interneuronal nitric oxide signaling mediates post-synaptic long-term depression of striatal glutamatergic synapses. Cell Rep 13:1336-1342.

Raju K, Doulias PT, Evans P, Krizman EN, Jackson JG, Horyn O, Daikhin Y, Nissim I, Yudkoff M, Nissim I, Sharp KA, Robinson MB, Ischiropoulos H (2015): Regulation of brain glutamate metabolism by nitric oxide and Snitrosylation. Sci Signal 8:ra68.

Rink E, Wullimann MF (2001): The teleostean (zebrafish) dopaminergic system ascending to the subpallium (striatum) is located in the basal diencephalon (posterior tuberculum). Brain Res 889:316-330.

Rink E, Wullimann MF (2002): Connections of the ventral telencephalon and tyrosine hydroxylase distribution in the zebrafish brain (Danio rerio) lead to identification of an ascending dopaminergic system in a teleost. Brain Res Bull 57:385-387.
Rodrigo J, Springall DR, Uttenthal O, Bentura ML, Abadía-Molina F, Riveros-Moreno V, Martínez-Murillo R, Polak JM, Moncada S (1994): Localization of nitric oxide synthase in the adult rat brain. Philos Trans R Soc Lond B 345:175-221.

Rudkouskaya A, Sim V, Shah AA, Feustel PJ, Jourd'heuil D, Mongin AA (2010): Long-lasting inhibition of presynaptic metabolism and neurotransmitter release by protein S-nitrosylation. Free Radic Biol Med 49:757-769.

Sánchez F, Alonso JR, Arévalo R, Blanco E, Aijón J, Vázquez R (1994): Coexistence of NADPH-diaphorase with vasopressin and oxytocin in the hypothalamic magnocellular neurosecretory nuclei of the rat. Cell Tissue Res 276:31-34.

Sánchez F, Alonso JR, Arévalo R, Bruning G, Panzica GC (1996): Absence of coexistence between NADPH-diaphorase and antidiuretic hormone in the hypothalamus of two galliforms: Japanese quail (Coturnix japonica) and chicken (Gallus domesticus). Neurosci Lett 216:155-158

Sánchez-Camacho C, Marín O, ten Donkelaar HJ, González A (2001): Descending supraspinal pathways in amphibians. I. A dextran amine tracing study of their cells of origin. J Comp Neurol 434:186-208.

Santos-Lobato BL, Del-Bel E, Pittella JE, Tumas V (2016) Cytoarchitecture of nitrergic neurons in the human striatum and subthalamic nucleus. Brain Res Bull 124:129-35.

Satoh K, Arai R, Ikemoto K, Narita M, Nagai T, Ohshima H, Kitahama K (1995): Distribution of nitric oxide synthase in the central nervous system of Macaca fuscata: subcortical regions. Neuroscience 66:685-696.

Saxon DW, Beitz AJ (2000): The normal distribution and projections of constitutive NADPH$\mathrm{d} / \mathrm{NOS}$ neurons in the brainstem vestibular complex of the rat. J Comp Neurol 425:97120.

Schober A, Malz CR, Schober W, Meyer DL (1994a): NADPH-diaphorase in the central nervous system of the larval lamprey (Lampetra planeri). J Comp Neurol 345:94-104.

Schober A, Meyer DL, Von Bartheld CS (1994b): Central projections of the nervus terminalis and the nervus praeopticus in the lungfish brain revealed by the nitric oxide synthase. J Comp Neurol 349:1-19.

Scicolone G, Ortalli AL, Álvarez G, López-Costa JJ, Rapacioli M, Ferrán JL, Sánchez V, Flores V (2006): Developmental pattern of NADPHdiaphorase positive neurons in chick optic tectum is sensitive to changes in visual stimulation. J Comp Neurol 494:1007-1030.

Sergeeva OA, Doreulee N, Chepkova AN, Kazmierczak T, Haas HL (2007): Long-term depression of cortico-striatal synaptic transmission by DHPG depends on endocannabinoid release and nitric oxide synthesis. Eur J Neurosci 26:1889-1894.
Shibuki K, Okada D (1991): Endogenous nitric oxide release required for long-term synaptic depression in the cerebellum. Nature 349: 326-328.

Shiells R, Falk G (1992): Retinal on-bipolar cells contain a nitric oxide-sensitive guanylate cyclase. Neuroreport 3:845-848.

Shlosberg D, Buskila Y, Abu-Ghanem Y, Amitai Y (2012): Spatiotemporal alterations of cortical network activity by selective loss of NOSexpressing interneurons. Front Neural Circuits 6:3.

Simonian SX, Herbison AE (1996): Localization of neuronal nitric oxide synthase-immunoreactivity within sub-populations of noradrenergic $\mathrm{A} 1$ and $\mathrm{A} 2$ neurons in the rat. Brain Res 732:247-252.

Simpson KL, Waterhouse BD, Lin RC (2003): Differential expression of nitric oxide in serotonergic projection neurons: neurochemical identification of dorsal raphe inputs to rodent trigeminal somatosensory targets. J Comp Neurol 466:495-512.

Singru PS, Sakharkar AJ, Subhedar N (2003): Neuronal nitric oxide synthase in the olfactory system of an adult teleost fish Oreochromis mossambicus. Brain Res 977:157168

Skinner RD, Conrad C, Henderson V, Gilmore SA, García-Rill E (1989): Development of NADPH-diaphorase-positive pedunculopontine nucleus neurons. Exp Neurol 104: 15-21.

Smeets WJAJ, Alonso JR, González A (1997): Distribution of NADPH-diaphorase and nitric oxide synthase in relation to catecholaminergic neuronal structures in the brain of the lizard Gekko gecko. J Comp Neurol 377:121141

Smeets WJAJ, González A (2000): Catecholamine systems in the brain of vertebrates: new perspectives through a comparative approach. Brain Res Brain Res Rev 33:308-379.

Sobreviela T, Mufson EJ (1995): Reduced nicotinamide adenine dinucleotide phosphate-diaphorase/nitric oxide synthase profiles in the human hippocampal formation and perirhinal cortex. J Comp Neurol 358:440-464.

Song JK, Northcutt RG (1991): The primary projections of the lateral-line nerves of the Florida gar, Lepisosteus platyrhincus. Brain Behav Evol 37:38-63.

Stanton PK, Winterer J, Bailey CP, Kyrozis A, Raginov I, Laube G, Veh RW, Nguyen CQ, Muller W (2003): Long-term depression of presynaptic release from the readily releasable vesicle pool induced by NMDA receptor-dependent retrograde nitric oxide. J Neurosci 23:5936-5944.

Steinert JR, Chernova T, Forsythe ID (2010): Nitric oxide signaling in brain function, dysfunction, and dementia. Neuroscientist 16: $435-452$

Sternberger LA (1979): Immunocytochemistry, ed 2. New York, Wiley, p 354. 
Stiassny MLJ, Wiley EO, Johnson GD, de Carvalho MR (2004): Assembling the Tree of Life. New York, Oxford University Press, pp 410429.

Sultana R, Poon HF, Cai J, Pierce WM, Merchant M, Klein JB, Markesbery WR, Butterfield DA (2006): Identification of nitrated proteins in Alzheimer's disease brain using a redox proteomics approach. Neurobiol Dis 22:76-87.

Takumida M, Anniko M (2000a): Direct evidence of nitric oxide production in guinea pig vestibular sensory cells. Acta Otolaryngol 120:34-38.

Takumida M, Anniko M (2000b): Glutamate-induced production of nitric oxide in guinea pig vestibular sensory cells. Acta Otolaryngol 120: 466-472.

Tarasenko A, Krupko O, Himmelreich N (2014): New insights into molecular mechanism(s) underlying the presynaptic action of nitric oxide on GABA release. Biochim Biophys Acta 1840:1923-1932.

Tekmen-Clark M, Gleason E (2013): Nitric oxide production and the expression of two nitric oxide synthases in the avian retina. Vis Neurosci 30:91-103.

Terenghi G, Riveros-Moreno V, Hudson LD, Ibrahim NB, Polak JM (1993): Immunohistochemistry of nitric oxide synthase demonstrates immunoreactive neurons in spinal cord and dorsal root ganglia of man and rat. J Neurol Sci 118:34-37.

Vanhatalo S, Soinila S (1995): Nitric oxide synthase in the hypothalamo-pituitary pathways. J Chem Neuroanat 8:165-173.

Varathan V, Shigenaga Y, Takemura M (2001): Nitric oxide synthase/nicotinamide adenine dinucleotide phosphate-diaphorase in the brainstem trigeminal nuclei after transection of the masseteric nerve in rats. J Neurosci Res 66:428-438.

Veleanu M, Axen TE, Kristensen MP, Kohlmeier KA (2016): Comparison of bNOS and chat immunohistochemistry in the laterodorsal tegmentum (LDT) and the pedunculopontine tegmentum (PPT) of the mouse from brain slices prepared for electrophysiology. J Neurosci Methods 263:23-35.

Vielma AH, Retamal MA, Schmachtenberg O (2012): Nitric oxide signaling in the retina: what have we learned in two decades? Brain Res 1430:112-125.

Villani L, Guarnieri T (1995): Localization of NADPH-diaphorase in the goldfish brain. Brain Res 679:261-266.

Vincent SR, Kimura H (1992): Histochemical mapping of nitric oxide synthase in the rat brain. Neuroscience 46:755-784.
Virgili M, Poli A, Beraudi A, Giuliani A, Villani L (2001): Regional distribution of nitric oxide synthase and NADPH-diaphorase activities in the central nervous system of teleosts. Brain Res 901:202-207.

Vizzard MA, Erdman SL, Roppolo JR, Förstermann U, de Groat WC (1994): Differential localization of neuronal nitric oxide synthase immunoreactivity and NADPH-diaphorase activity in the cat spinal cord. Cell Tissue Res 278:299-309.

Vizzard MA, Erickson K, de Groat WC (1997): Localization of NADPH diaphorase in the thoracolumbar and sacrococcygeal spinal cord of the dog. J Auton Nerv Syst 64:128142.

Wang H, Morris JF (1996): Presence of neuronal nitric oxide synthase in the suprachiasmatic nuclei of mouse and rat. Neuroscience 74 : 1059-1068.

Wang HG, Lu FM, Jin I, Udo H, Kandel ER, de Vente J, Walter U, Lohmann SM, Hawkins RD, Antonova I (2005): Presynaptic and postsynaptic roles of NO, cGK, and RhoA in longlasting potentiation and aggregation of synaptic proteins. Neuron 45:389-403.

Wang HL, Morales M (2009): Pedunculopontine and laterodorsal tegmental nuclei contain distinct populations of cholinergic, glutamatergic and GABAergic neurons in the rat. Eur J Neurosci 29:340-358.

Wang QP, Guan JL, Nakai Y (1995): Distribution and synaptic relations of NOS neurons in the dorsal raphe nucleus: a comparison to 5-HT neurons. Brain Res Bull 37:177-187.

West AR, Grace AA (2000): Striatal nitric oxide signaling regulates the neuronal activity of midbrain dopamine neurons in vivo. J Neurophysiol 83:1796-1808.

Wetts R, Vaughn JE (1994): Choline acetyltransferase and NADPH diaphorase are co-expressed in rat spinal cord neurons. Neuroscience 63:1117-1124.

Wilson M, Nacsa N, Hart NS, Weller C, Vaney DI (2011): Regional distribution of nitrergic neurons in the inner retina of the chicken. Vis Neurosci 28:205-220.

Wolff DJ, Datto GA (1992): Identification and characterization of a calmodulin-dependent nitric oxide synthase from GH3 pituitary cells. Biochem J 285:201-206.

Wotherspoon G, Albert M, Rattray M, Priestley JV (1994): Serotonin and NADPH-diaphorase in the dorsal raphe nucleus of the adult rat. Neurosci Lett 173:31-36.

Wu MD, Kimura M, Hiromichi I, Helfert RH (2008): A classification of NOergic neurons in the inferior colliculus of rat according to coexistence with classical amino acid transmitters. Okajimas Folia Anat Jpn 85:17-27.
Wu WC, Wang Y, Kao LS, Tang FI, Chai CY (2002): Nitric oxide reduces blood pressure in the nucleus tractus solitarius: a real time electrochemical study. Brain Res Bull 57:171-177.

Wullimann MF, Meyer DL (1990): Phylogeny of putative cholinergic visual pathways through the pretectum to the hypothalamus in teleost fish. Brain Behav Evol 36:14-29.

Wullimann MF, Meyer DL, Northcutt RG (1991): The visually related posterior pretectal nucleus in the non-percomorph teleost Osteoglossum bicirrhosum projects to the hypothalamus: a DiI study. J Comp Neurol 312:415435

Yamakawa Y, Shiraishi H, Yamakawa M (1997): Characterization of nitric oxide synthase in the cerebellum of the chicken. Comp Biochem Physiol B Biochem Mol Biol 118:457461.

Yamamoto K, Ruuskanen JO, Wullimann MF, Vernier P (2011): Differential expression of dopaminergic cell markers in the adult zebrafish forebrain. J Comp Neurol 519:576598

Yamamoto K, Takei H, Koyanagi Y, Koshikawa N, Kobayashi M (2015): Presynaptic cell typedependent regulation of GABAergic synaptic transmission by nitric oxide in rat insular cortex. Neuroscience 284:65-77.

Yáñez J, Souto Y, Pineiro L, Folgueira M, Anadón R (2017): Gustatory and general visceral centers and their connections in the brain of adult zebrafish: a carbocyanine dye tract-tracing study. J Comp Neurol 525:333-362.

Yang Q, Chen SR, Li DP, Pan HL (2007): Kv1.1/1.2 channels are downstream effectors of nitric oxide on synaptic GABA release to preautonomic neurons in the paraventricular nucleus. Neuroscience 149:315-327.

Yassin L, Radtke-Schuller S, Asraf H, Grothe B, Hershfinkel M, Forsythe ID, Kopp-Scheinpflug C (2014): Nitric oxide signaling modulates synaptic inhibition in the superior paraolivary nucleus (SPN) via cGMP-dependent suppression of KCC2. Front Neural Circuits 8:65.

Yoshimoto M, Yamamoto N (2010): Ascending general visceral sensory pathways from the brainstem to the forebrain in a cichlid fish, Oreochromis (Tilapia) niloticus. J Comp Neurol 518:3570-3603.

Zhu XZ, Luo LG (1992): Effect of nitroprusside (nitric oxide) on endogenous dopamine release from rat striatal slices. J Neurochem 59: 932-935. 